\title{
EVALUATION OF JUVENILE SALMONID BYPASS FACILITIES AND PASSAGE AT WATER DIVERSIONS ON THE LOWER UMATILLA RIVER
}

\author{
Prepared by: \\ W illiam A. Cameron \\ Suzanne M. Knapp \\ R ichard w. Carmichael \\ O regon Department of Fish and W ildlife
}

\section{Prepared for:}

u. s. Department of Energy

B onneville Power Administration

Environment, fish and W ildlife

P.O. B ox 3621

Portland. OR 97208-3621

Project $N$ umber $89-24-01$

Contract N umber DE-B I 79-89B P 01385 


\section{CONIENIS}

Page

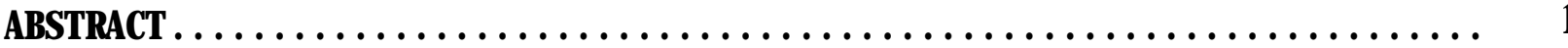

INTRODDCTION ...................................... 2

SIUDYSITES $\ldots \ldots \ldots \ldots \ldots \ldots \ldots \ldots \ldots \ldots \ldots \ldots \ldots \ldots \ldots \ldots \ldots \ldots \ldots \ldots$

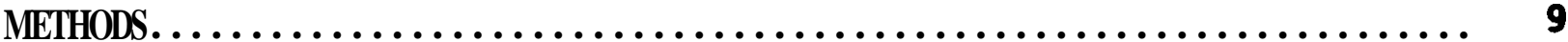

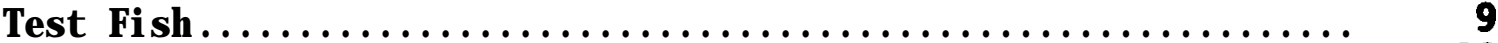

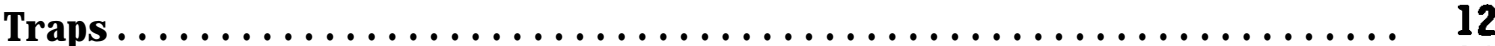

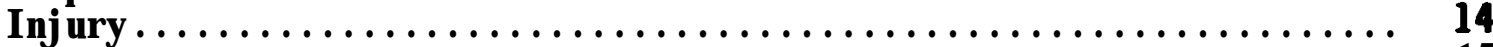

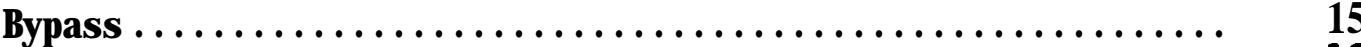

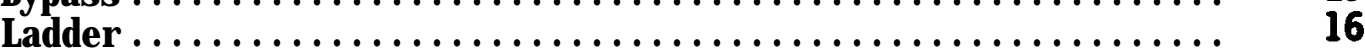

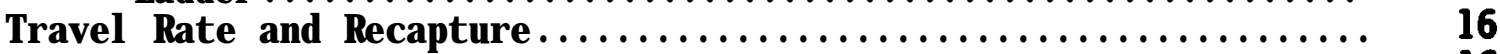

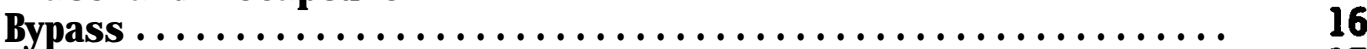

Ladder . ............................................ 17

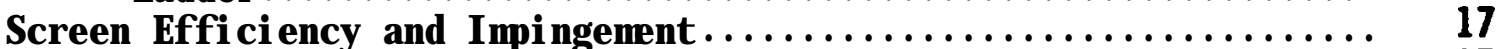

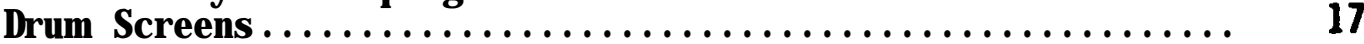

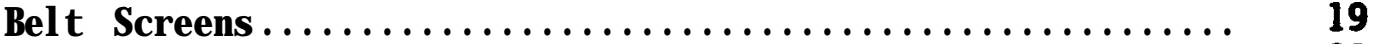

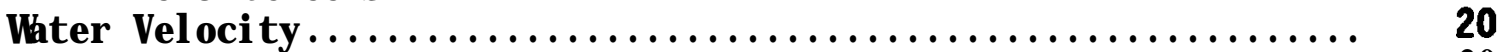

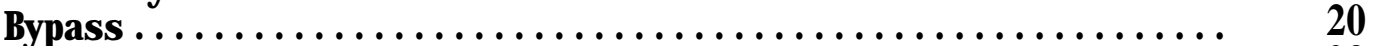

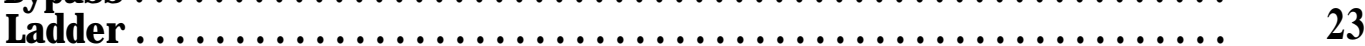

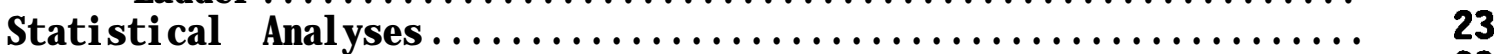

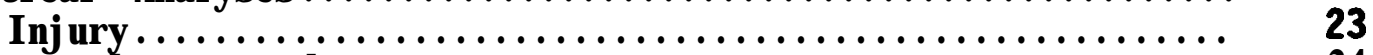

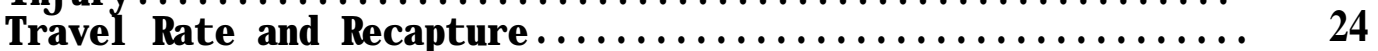

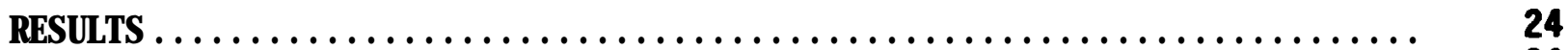

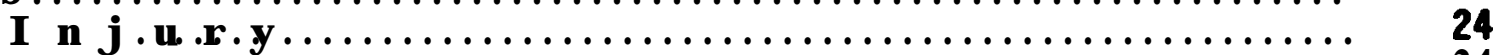

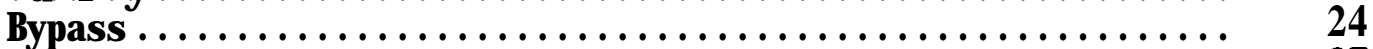

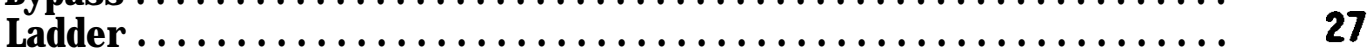

Travel Rate and Recapture........................... 29

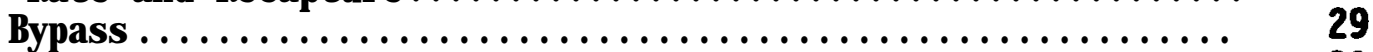

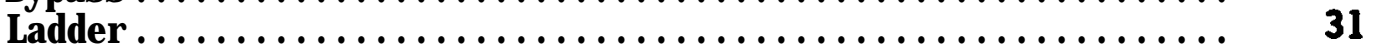

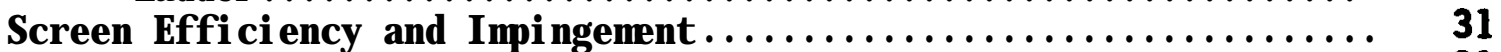

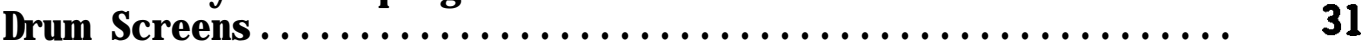

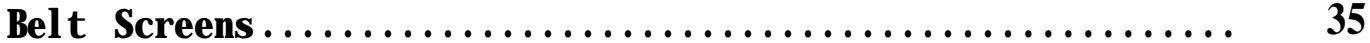

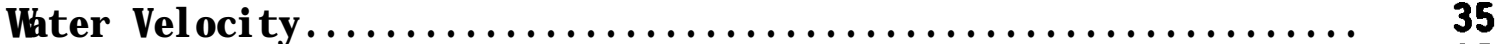

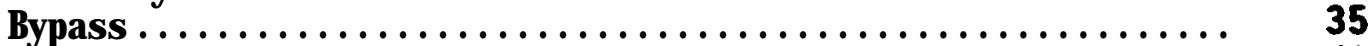

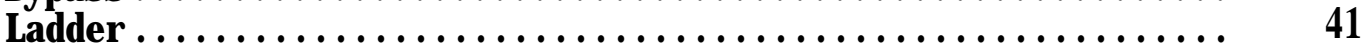

DISCUSSION..................................... 44

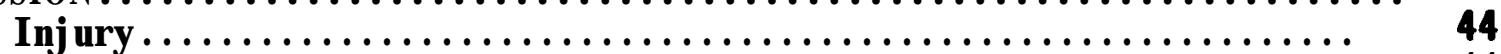

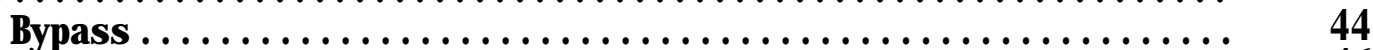

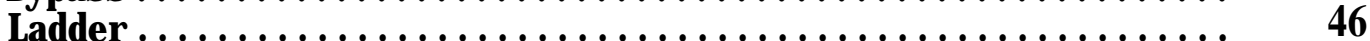

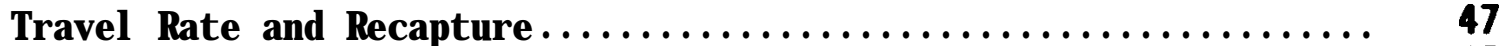

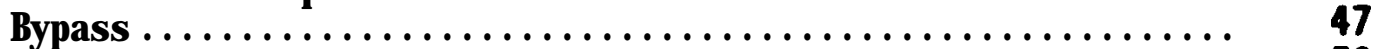

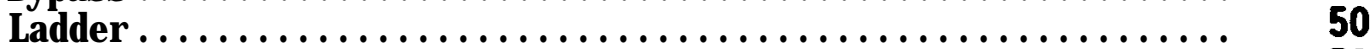

Screen Effi ci ency and I mpi ngenent ..................... 50

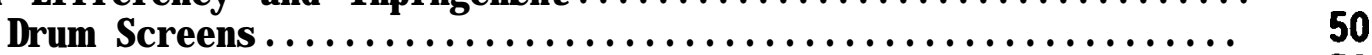

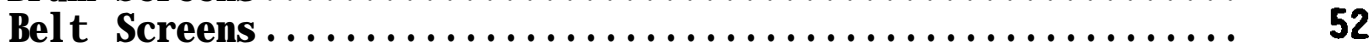




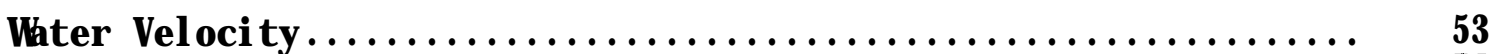

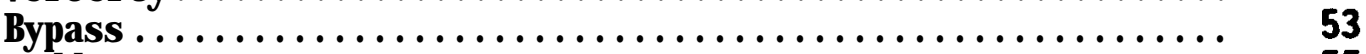

Ladder $, \ldots, \ldots, \ldots, \ldots, \ldots, \ldots, \ldots, \ldots, \ldots, \ldots, \ldots, \ldots, \ldots, \ldots, \quad 55$

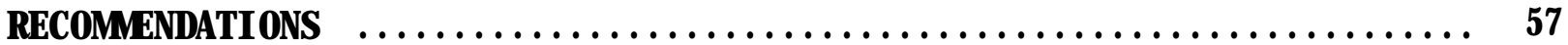

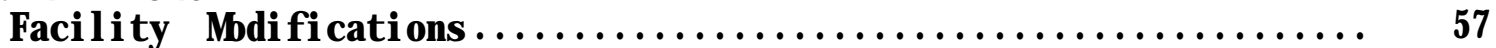

Facility Operations $\ldots \ldots \ldots \ldots, \ldots, \ldots, \ldots, \ldots, \ldots, \ldots, \ldots, \ldots \ldots \ldots, \quad 57$

Desi gn Consi derati ons $\ldots \ldots \ldots \ldots \ldots \ldots \ldots \ldots, \ldots, \ldots, \ldots, \ldots, \ldots, \quad 58$

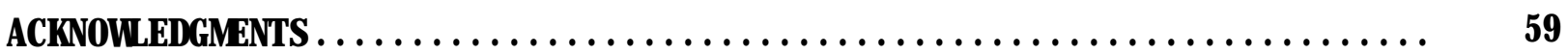

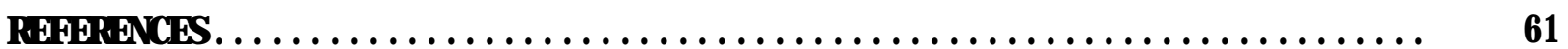

\section{LIST OF TABLES}

Table 1. Speci fications of $f i$ sh bypass facil $i$ ti es at i rrigation canal s on the I ower Unatilla Ri ver, Oregon.

Table 2. Speci fi cati ons of $\mathrm{f} i \mathrm{sh}$ I adders at i rri gati on dans on the I ouer Unati I I . Ri ver, Oregon.

Tabl e 3. Schedul e of study acti vi ti es conducted at $\mathrm{fi}$ sh bypasses and I adders associ ated wi th i rrigati on dans on the I ower Unati Il a

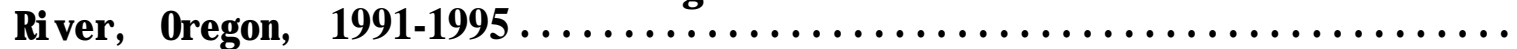

Table 4. Travel ti ne and percent of fi sh recaptured by the end of testing at the five maj or $i$ rrigati on canal s on the I over Umatilla Ri ver, Oregon.

Table 5. Test fi sh rel ease and recapt ure data, fi sh leakage through drum screens, and screeni ng ef $i$ ci ency of drum screens at four i rrigati on canal s on the lower Untill a Ri ver, Oregon............

Table 6. Percent of maxi mum canal fl ow expected in March- Hay, canal fl ow when water vel ocity measurenents were col lected, canal fl ow esti mated from vel oci ty measurements, and percent of vel ocity measurements meeting approach vel ocity and sweep to approach vel oci ty criteri a at maxi mum canal fl ow expected in March-May at i rrigati on canals on the lower Unatilla Ri ver, Oregon........

Tabl e 7. Wher vel oci ty measured at bypass channel entrances during hi gh-f I ow bypass operati ons at i rri gati on canal s on the I over

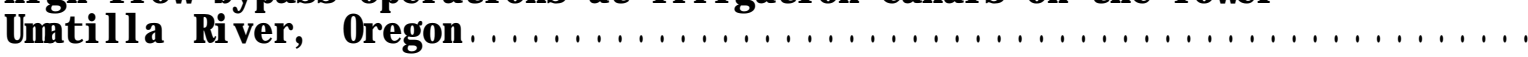

Table 8. Whter vel ocity and fl ow at the bel $t$ screen and bypass channel entrance of Weşt Extensi on Canal during pumpback operati ons with one or tuo $0.28-\mathrm{m}^{2} / \mathrm{s}$ pumps on and when the pumpback bay drai $\mathrm{n}$ pi pe was $20 \% 30 \%$ or $40 \%$ open. 
Fi gure 1. Locati on of i rri gati on dans and canal s on the I over

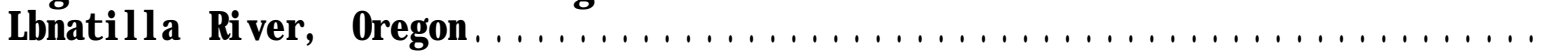

Figure 2. General ized schenatic of fish bypass facilities at i rrigati on canals on the I over Dntilla River, Oregon.................

Fi gure 3. General i zed schenatic of a drumscreen used in fi sh bypass facilities at irrigati on canal $s$ on the l ower Lhnatilla Ri ver, Oregon......

Fi gure 4. Schematic of fi sh I adders at i rrigation dans on the l ower Dnatilla Ri ver, Oregon $\ldots \ldots \ldots \ldots \ldots \ldots \ldots \ldots \ldots \ldots \ldots \ldots \ldots \ldots \ldots$

Fi gure 5. Fl oating trap net and incli ned plane trap used for fish collection at bypass facilities and fish ladders on the I ower Lhnatilla Ri ver, Oregon.

Fi gure 6. Devi ce used with an el ectronagnetic uater vel ocity neter to neasure the angl e of the naxi mum vel ocity vector in front of screens and diffusers at fish passage facilities on the lower Dnatilla River,

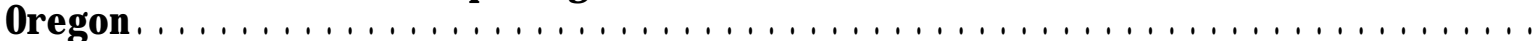

Fi gure 7. Mean net-wei ght ed i nj ury i ncurred by treatnent and control fi sh in varying segments of the bypass facility at West . Ext ensi on Canal, I hnati I l a Ri ver, Oregon.

Fi gure 8. Mean net- wei ghted i nj ury i ncurred by treat nent and control fish in varying segnents of bypass facilities at Maxuel I, Uest I and, Feed, and Furni sh canal s, Lhnati I l a Ri ver, Oregon.

Fi gure 9. Mean net- wei ghted inj ury i ncurred by treatment and control fi sh i $n$ varyi ng segnents of adul $t$ fi sh ladders at Three M le Fal I s, Uestl and, Feed Canal, and Stanf $i$ el d dans, Lhnati Il a

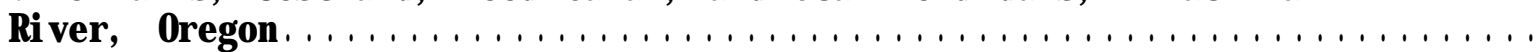

Fi gure 10. Cumul ati ve percent recapture of treat nent $\mathrm{fi}$ sh rel eased during i nj ury tests conducted in the lover porti on of $\mathrm{fi}$ sh bypass faci I i ti es at Furni sh, West I and, and West Extensi on canal s, Unati I la

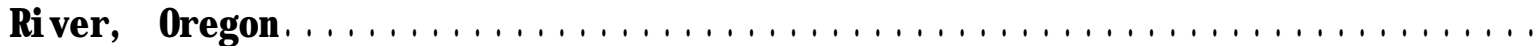

Fi gure 11. Cumul ati ve percent recapture of treatnent $\mathrm{fi}$ sh rel eased during inj ury tests conducted in the passage and auxil $i$ ary water secti ons of fi sh I adders at Stanfi el d, Feed Canal, Utstl and, and Three Mle Falls dans, Dnatilla River, Oregon.

Fi gure 12. Rati o of sueep to approach water vel oci ty and approach water vel oci ty neasured in front of drum screens at West Extensi on and Mexuel I canal s, Unatill a Ri ver, Oregon $\ldots \ldots \ldots \ldots \ldots \ldots \ldots \ldots \ldots \ldots$

Fi gure 13. Rati o of sueep to approach water vel ocity and approach vater vel oci ty measured in front of drum screens at Westl and Canal, Unati II a Ri ver, Oregon. 
Fi gure 14. Rati o of sueep to approach water vel oci ty and approach uater vel oci ty measured in front of drumscreens at Feed Canal,

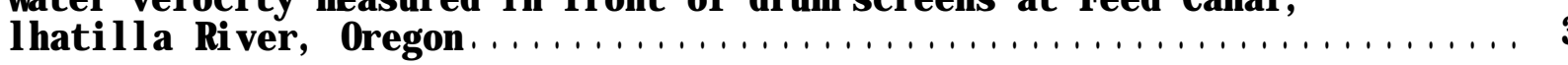

Fi gure 15. Rati o of sueep to approach uater vel oci ty and approach water vel oci ty measured in front of drum screens at Furni sh Canal, Unati I I a Ri ver, Oregon.

Fi gure 16. Approach and sueep water vel oci ty measured i $n$ front of Di f user 1 l ocated in the passage secti on of the $\mathrm{fi}$ sh I adder at Three MI e Fal Is Dam Unatil I a River, Oregon .......................

Fi gure 17. Approach and sweep water vel oci ty measured i $n$ front of Di ff user 2 l ocated bet ween the auxi I $i$ ary' water system and ent rance pool of the fish Iadder at Three Hile Fal Is Dam Unatilla River, 
Out dated $\mathrm{j}$ uveni l e and adul $t$ fi sh passage facil i ti es were recent l y reconstructed at the fi ve maj or i rri gati on dans on the I over Umat i I la Ri ver, Oregon to meet Nati onal Mari ne Fi sheri es Servi ce (NMF) desi gn standards. Changes in desi gn at $j$ uveni l e fi sh bypass faci l iti es i ncl uded reduced nesh si ze on the rotating drum screens, I arger screeni ng area, a nore obl i que ori ent ati on of the drum screens to canal fl ow i mproved screen seal s, repl acenent of bypass portal s with verti cal sl ot bypass channel s, and i ncreased bypass pi pe di aneters. Wei $r$-and-pool adul $t$ fi sh ladders and j ump pool s nere repl aced wi th verti cal - sl ot I adders. From 1991-1995, we i nvesti gated i nj ury and travel rate of j uveni l e fi sh noving through the facilities, and efficiency of screens in preventing fish entry into the canal s. Uater vel ociti es i $n$ front of canal screens, at bypass channel entrances, and at I adder diffusers were measured to assess adherence to NFS criteria and i dentify hydraul i c patterns. Bi ol ogi cal eval uati ons uere conducted by rel easi ng and recapt uring marked yearli ing summer steel head (Oncorhynchus myki ss), yearl i ng spri ng chi nook sal mon ( 0 . tshawytscha), and subyearl ing fal I chi nook sal non (0. t shawytscha) i n varyi ng l ocati ons wi thi n the fish passage facilities. Nost test fish passing through bypass facilities and fi sh I adders i ncurred i nsi gni fi cant or negl i gi bl e i nj ury ( $P>0.10)$. Si gni fi cant i nj ury at West Extensi on Canal ( $P=0.006$ ) and Feed Canal ( $P$ 0.01) bypasses uas probabl y a resul $t$ of sampli ng error and handl ing i nj ury, respecti vel y. Subyearling fal l chi nook sal mon were i nj ured i $n$ the passage secti on of the east-bank fi sh I adder at Three H I e Fal Is Dam ( $P=0.04)$ and i $n$ the auxi I $i$ ary water system of the $f i$ sh I adder at Uest I and $\operatorname{Dam}(P=0.05)$. Respecti ve descal ing and nortal ity rates for subyearl ing fall chi nook sal non uere $19.2 \%$ and $3.2 \%$ at the Three MIe Fal I s Daml adder, and $1.4 \%$ and $0 \%$ at the Uest I and Dam I adder. H dchannel di ffusers probabl y caused nost of the descal ing at both si tes; the sl ot-and-pool segnent of the passage secti on caused nost of the nortality at Three Mle Fal Is Dam Mbvenent of subyearling fal I chi nook sal mon was sl ower near drum screens ( $62 \mathrm{mdh}$ ) than in the headuorks canal ( $485 \mathrm{~m} / \mathrm{h}$ ) at Furni sh Canal. Short del ays uere associ ated with the headgates and outfal I at West Extensi on Canal and the bypass pi pe at Uestl and Canal. Extensi ve del ay uas associ ated wi th the uppernost midchannel diffuser in the passage secti on of the east-bank $f i$ sh I adder at Three M I e Fal I s Dam Screeni ng effi ci enci es of drum and vertical bel $t$ screens were greater than $99.7 \%$ and $99.4 \%$ respecti vel y. I mi ngenent of test $\mathrm{fi}$ sh on the verti cal bel $t$ screen at West Extensi on Canal was less than 0.7\% Approach vel ocities in front of drumscreens are expected to neet criteria for smol $t$ protection ( $10.24 \mathrm{~m} / \mathrm{s}$ ) and exceed criteria for fry protection ( $10.12 \mathrm{~m} / \mathrm{s}$ ) at maxi mum canal fl ow expected from March through May. Hi ghest approach vel ociti es were usual ly neasured at screens near the bypass channel. Sueep to approach vel ocity criteria (> 2:I) was net at al I si tes except Haxuel I Canal, where sueep vel oci ti es were I ow $(0.08-0.16 \mathrm{~m} / \mathrm{s})$ at the screen f urthest from the bypass channel. Whter vel oci ti es at bypass channel entrances rangi ng from 0.58-0.82 mis met criteria. Whter vel ocity in front of the vertical bel $t$ screen at West Extensi on Canal net criteri a when both $0.28 \mathrm{~m} / \mathrm{s}$-pumps were on or the pumpback bay drai $n$ pi pe was $20 \%$ open. Di recti on and magni tude of fl ow approachi ng I adder diff user panel s was vari able. In general, current desi gns of bypass and I adder faci I i ti es on the I ower Unat i I l a Ri ver saf el y and qui ckl y pass j uveni le sal moni ds. However, sone faci l ity components pose passage probl ens for j uvenile fish. Regul ar mai nt enance and proper operati on of facilities, and mor modification of facility struct ures are recommded. 
Desi gns for adul $t$ fi sh I adders shoul d i ncl ude consi derati on of $j$ uveni l e fi sh passage.

\section{INTRODUCTION}

Large runs of sal mon (Oncorhyncus spp.) and steel head ( 0 . myki ss) once supported producti ve fi sheries in the Umatill a Ri ver, Oregon. By the 1920s, dans with inadequate adul t fish passage facilities, unscreened canal s, di versi on of ri ver fl ow f or i rri gati on, and habi tat degradati on had exti rpated the sal non runs and drastical ly reduced the steel head run (COFW and CTU R 1989). However, a comprehensi ve fi sheri es rehabi I $i$ tati on program was i niti ated in the nid-19803 under the Northwest Power Pl anni ng Council' s Col unbi a Ri ver Basi n Fi sh and Vill dl i fe Program(1987). The rehabil i tati on pl an i ncl uded i mproved fi sh passage facili ities, enhanced ri ver fl ow, rehabil i tati on of fish habi tat, and increased hatchery producti on (Boyce 1986). Sal non runs in the Unatill a Ri ver are presentl y suffici ent to provi de a fi shery in nost years, but they are sti ll bel ow l ong-range producti on goal s (ODFW and CTU R 1990).

Fi ve maj or i rri gati on dans in the l over ri ver had out dat ed fi sh passage facilities. Rotating drum screens at the fi sh bypass facilities had a high potential for fish leakage and i mpi ngenent due to thei $r$ smal I si ze, perpendi cul ar ori entati on to canal fl owy and I arge mesh openi ngs. Al so, smal I bypass portal s ( $0.15 \mathrm{mdi}$ aneter) and verti cal sl ots $(0.15-0.20 \mathrm{mw}$ de) were conduci ve to passage del ay and fi sh i nj ury when occl uded-with debris. Adul t passage facilities at the dans were al so i neffective. The tal lest and l owernost dam (Three Mle Fal Is) was the nost si gnificant barri er to adult migrati ons. Poor attracti on to an overfl ow wei $r$ I adder on the east bank and a vertical -sl ot I adder on the west bank presented passage problens at al I ri ver fl ous (Boyce 1986). Si It and debri s accumul ati on and lack of sel f-regul ating fl ow vere addi ti onal probl ens for the overfl ow wei $r$ I adder. Snal ler dans upri ver were barriers to adul $t$ fi sh migrati on at I ow and noderate ri ver fl ons due to shal l ow pool depths bel ow the dans.

$J$ uveni $l e$ and adul $t$ fish passage facil $i$ ti es were reconstructed at the five i rri gati on dans bet ueen 1988 and 1994. The state- of-the-art faciliti es vere i intended to correct potenti al fi sh I eakage, i mpi ngenent, del ay, and i nj ury problens. Rotating drum screens were enl arged and re-ori entated at an obl i que angl e to canal fl ow and screen mesh openi ngs were reduced. Bypass systens vere repl aced wi th I arger, verti cal sl ot channel s coupl ed with a wei $r$ for fl ow regul ation and I arger di aneter pi pes for returning fish to the river. Verti cal - sl ot adul $t$ fi sh I adders were constructed at nost dans to i mprove adul $t$ fi sh passage.

Bypass faci lity desi gns have i mproved i ncrenental l y over the years in response to inf or nati on gai ned from facil i ty eval uati ons, operati onal experi ence, hydraul i c nodel i ng, and I aborat ory experi ments (Easterbrooks 1984, Rai ney 1985, Taft 1986, Bates 1988, Pearce and Lee 1991). Eval uati ons of rotating drum screen systens are largel y reported in technical li terature. Taft (1986) sumari zed operati onal experi ences and unpubl $i$ shed eval uat $i$ ons of twenty-two facilities that utilize rotating drum screens. Mre recently, eval uati ons have been conducted at rotati ng drum screen systens at i rri gati on di versi ons on the Yaki ma Ri ver, Whishi ngt on ( Nei tzel et al. 1985, 1987, 1988, 
1990a, 1990b, 1991; and Hosey and Associates 1988a, 1988b, 1989, 1990;

Abernet hy et al. 1989a, 1989b) and Sacranent o Ri ver, Cal i forni a (Craner 1992). These st udi es found that rotati ng drum screen systens desi gned accordi ng to current criteria are usual ly hi ghl y effecti ve at qui ckly ret urning migrating j uveni le sal moni ds to the ri ver unharned. However, i ntermittent nat ural events such as floods or freezes can reduce facility effecti veness. Mai ntenance of key facility components was al so essential for proper operati on. This i nf ormati on has al l oued the Nati onal Mri ne Fi sheri es Servi ce (NMFS) i n conj uncti on with state fi sheri es agenci es to update and $f i$ ne- $t$ une criteria for the design and operation of fish bypass facilities (NMFS 1989, 1990).

Desi gn criteri a for fi sh I adders has al nost excl usi vel y been based on requi renents for upstream passage of adul $t$ fi sh ( $\mathrm{d}$ ay 1961, 1995; Bel I 1986; Orsborn 1985). However, fi sh I adders al so provi de j uveni le sal noni ds an al ternate downstream passage route at dans. Neverthel ess, few st udi es have been conducted on downst ream passage of $j$ uveni l e sal noni ds through adul $t$ fi sh I adders. Studi es were conducted at dans on the North Fork $\mathbf{Q}$ ackamas Ri ver, Oregon (Gunsol us and Ei ther 1970). and South Cow Creek, . Cal i forni a (Mock and Steitz 1985) where fish I adders are used as the primary bypass system These st udi es document ed percent recapt ure of j uveni l e sal noni ds passi ng through the fi sh I adders but di d not determine whether fi sh vere inj ured.

from 1991 to 1995, we conducted st udi es to eval uate whether j uveni I e sal moni ds are abl e to saf el y and quickly pass through reconstructed $j$ uveni I e fi sh bypass and adut fi sh ladder faci I i ti es associ ated wi th mj or i rri gation dans on the I over Uhati I la Ri ver, Oregon. Usi ng nark-recapt ure nethodol ogi es, we assessed I) facility-caused i nj ury, 2) rate of travel and recapt ure, and 3) screen ef fi ci ency (I eakage) and i mpi ngenent ( rol l over). We al so measured water vel ocities at key facility l ocations to determine whether vel ocities were withi n NMS criteria. Our studies were nodel ed after eval uations conducted in the Yaki ma $\mathrm{Ri}$ ver basi $n$ to provi de a comparable data base.

\section{STUDY SI TES}

St udi es were conducted at $\mathbf{j}$ uveni l e fi sh bypass faci l i ti es and adul $t$ fi sh I adders associ ated wi th the fi ve mi or i rri gati on canal s and dans on the I ower Unatilla Ri ver (Fi gure 1). Fi sh bypass facilities are constructed wi thi $n$ West Extensi on Canal at Three MIe Fal Is Dam Haxuel I Canal at Haxuel I Dam Uestl and Canal at Uest I and Dam Feed Canal at Feed Canal Dam and Furni sh Canal at Stanfi el d Dam Al dans are approxi matel y $1 \mathrm{~m}$ i $\mathrm{n}$ hei ght, except Three Hile_Fal Is Dam whi ch is 7.3- $\mathrm{m}$ hi gh. Maxi mum canal wi thdraual s range from 2-9 $\mathrm{m}^{3} / \mathrm{s}$ at the study si tes (Table 1). Mst canal s del i ver wat er to i rri gators from mid-March to earl y October, with peak demand in May, J une, and July. Feed Canal is operated near naxi mum capacity from Novenber to My to fill a storage reservoi $r$.

Fi sh bypass facilities are built into i rrigation canal s to qui ckl y return fish to the river unharned. They are usual Iy l ocated near the poi nt of uat er di versi on to mini me the ti ne fi sh spend in the canal. However, topographic constrai nts at Mxuel I and Furni sh canal s resul ted in construction of bypass facilities 2, $425 \mathrm{~m}$ and $985 \mathrm{mfrom}$ the poi nt of di versi on, respectivel y (Tabl e 1). The basi c components of fi sh bypass systens i ncl ude 1) screens to excl ude 


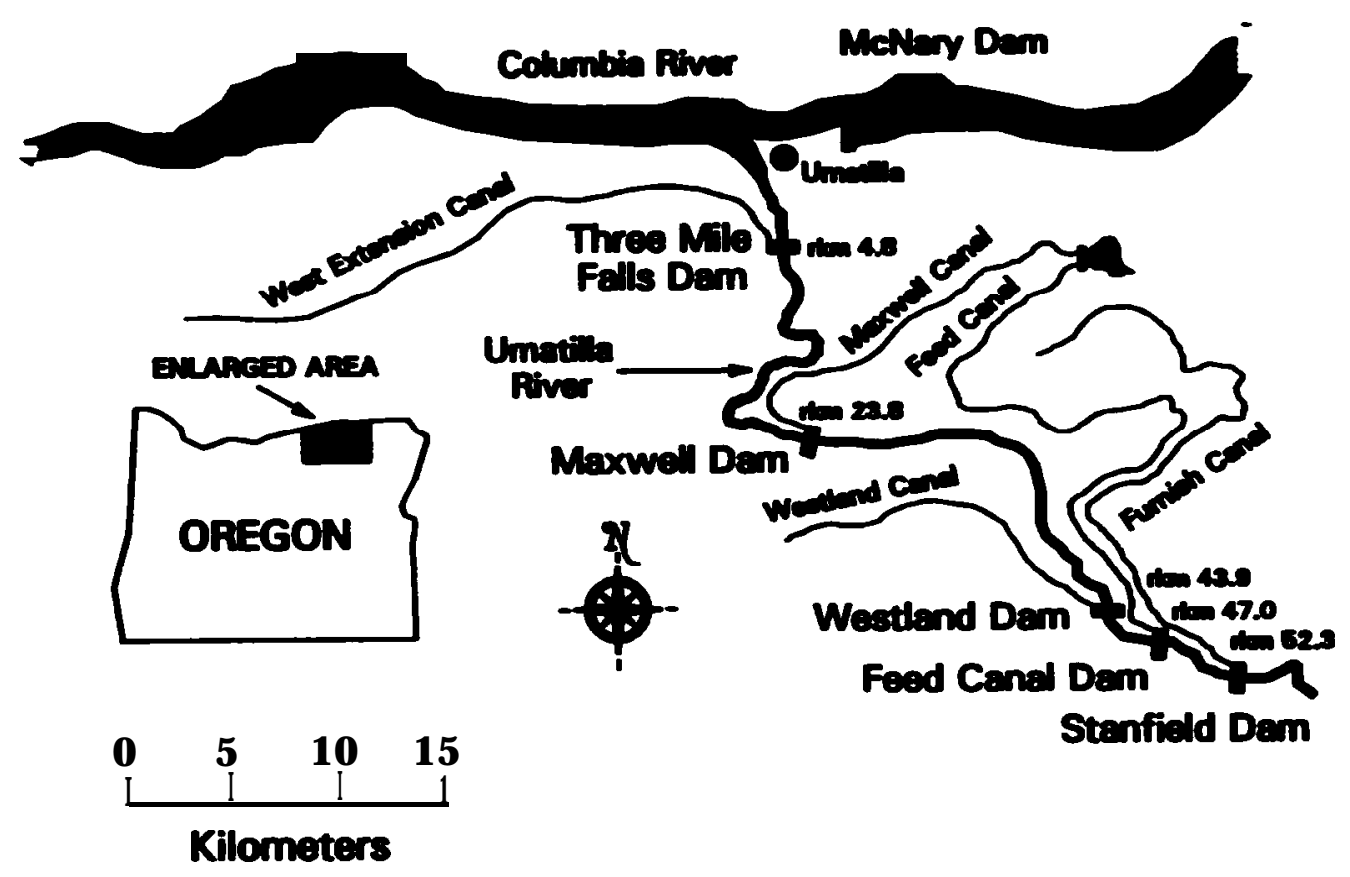

Figure 1. Locati on of i rri gati on dans and canal s on the I ower Unati I la Ri ver, Oregon.

fi sh from the canal, 2) a bypass channel at the dounstreamend of the screens that provides fish an exit mite from the screen forebay, 3) a wei $r$ and stilling chanber (downuel I) in the bypass channel to regul ate bypass fl ow 4) a bypass pi pe at the downuel I for returning fish to the river, and 5) an outfal I or submerged outl et structure at the terminus of the bypass pi pe ( Figure 2).

Rotating drum screens are utilized at fi sh bypass facilities on the lower I hati I la Ri ver because they performuel I in waters with hi gh debri s I oads and temperatures above freezing. The bypass faciliti eswere designed with varying numbers and si zes of screens to provi de enough surface area when screens are $80 \%$ submerged to prevent approach vel oci ti es from exceeding $0.15 \mathrm{nds}$ at maxi mumcanal wi thgrawal. The screens are const ructed of-stai $\mathrm{nl}$ ess steel wi re cl oth, with 3. 2- $a^{2}$ openi ngs, ri veted to a spoke-and- wheel frame (Fi gure 3). They are mount ed on netal frames and depl oyed i nto gui des i $n$ concrete support structures. Gaps between the screen and frame are seal ed wi th 6.4- nmthi ck strips of rubber (89-102 A wi de) extending from the si des and bott om of the frane ( $\mathrm{fl}$ at seal). At West Extensi on Canal, sol i d-bul b seal s ( $9.5 \mathrm{~mm}$ thi ck) are used to seal the si des of I arge di aneter screens. Gaps between the bottom of the screen frane and canal bott om are seal ed with a hol $I$ ow bul b or $f I$ at seal. At Furni sh Canal, pl astic vedges were instal l ed in the frane gui des to facilitate gap cl osure between the frane and guide. 
Table 1. Specifi cations of $f i$ sh bypass facilities at i rrigation canal s on the lower Unatilla Ri ver. Oreaon.

\begin{tabular}{|c|c|c|c|c|c|c|c|c|c|c|}
\hline \multirow{2}{*}{ M } & \multirow{2}{*}{$\begin{array}{c}\text { Maximuma } \\
\text { canal } \\
f_{3} \text { ow } \\
\left(\mathrm{m}^{2} / \mathrm{s}\right)\end{array}$} & \multirow{2}{*}{$\begin{array}{c}\text { Di st ance } \\
\text { from } \\
\text { head- } \\
\text { gates } \\
\text { to } \\
\text { bypass } \\
\text { (n) }\end{array}$} & \multicolumn{4}{|c|}{ Drum screens } & \multicolumn{4}{|c|}{ Bvoass fl ow Bypass pi pe } \\
\hline & & & $\begin{array}{c}\text { Num } \\
\text { ber }\end{array}$ & $\begin{array}{l}\text { Length } \\
\text { (n) }\end{array}$ & $\begin{array}{c}\text { Di a- } \\
\text { met er } \\
\text { (m) }\end{array}$ & $\begin{array}{c}\text { Angle } \\
\text { to } \\
\text { flow } \\
\left({ }^{\circ}\right)\end{array}$ & $\begin{array}{l}\text { Normal } \\
\left(m^{3} / s\right)\end{array}$ & $\left(\mathrm{m}^{\mathrm{L}} \mathrm{w} / \mathrm{s}\right)$ & $\begin{array}{c}\text { Length } \\
\text { (m) }\end{array}$ & $\begin{array}{c}\text { Ter- } \\
\text { minus }\end{array}$ \\
\hline $\begin{array}{l}\text { West } \\
\text { Ext ensi on }\end{array}$ & n 5.1 & 39 & 4 & 3. 7 & 2.4 & 15 & 0.71 & 0.14 & $73 c$ & outf al I \\
\hline Haxuel I & 1. 7 & 2,425 & 3 & 3.7 & 1.2 & 25 & 0.25 & 0.06 & 69 & outf al I \\
\hline Uest I and & d 9.3 & 100 & 10 & 3.8 & 1.8 & 16 & 0.74 & $\mathbf{0}$ & 213 & out l et \\
\hline Feed & 6.9 & 212 & 10 & 3.7 & 1.7 & 16 & 0.51 & 0.16 & a9 & out l et \\
\hline Furni sh & 4.3 & 985 & 7 & 3.8 & 1.5 & 24 & 0.57 & 0.42 & 140 & out l et \\
\hline
\end{tabular}

a Mainomanal flows reported in fish passage facility predesign memor andums.

Drum screens are ori ent ated at a $15-25^{\circ}$ angl e to canal fl ow to gui de fi sh toward the entrance of the bypass channel (Tabl e 1). Bypass channel s at the si tes are 0.61 mwde, vary from 0.9-1.8 min depth, and are open at top to provide natural I ighting. Bypass fl ow is regul ated by a wei $r$ at the terminus of the bypass channel. Bypass fl ous are reduced at nost si tes when ri ver fl ow is l ow (Table 1). Spi II over the bypass vei $r$ pl unges i nto a 0.61. 2-m deep pool of water in the downuel I (Fi gure 2). Downuel Is are rectangul ar in shape at al I si tes except Feed Canal, whi ch has an L-shaped downuell to di rect the bypass pi pe tonard the river. Bypass pi pes are $0.61 \mathrm{~m}$ in di aneter at al I si tes except Feed Canal ( $0.76 \mathrm{mdi}$ aneter). Bypass pi pe sl opes are fai rl y uni form( $0.6-0.8 x)$. At Uest l and Canal, a 0.69-m di aneter drai $n$ pi pe from the pumpback bay and juveni le fish trap ti es into the bypass pi pe $\mathbf{4 4} \mathbf{m}$ from the downuel I. Host si tes have subnerged outl ets with si mple concrete structures that anchor the terminus of the bypass pi pe. The outfal I at West Extensi on Canal has a 7.6 - ml ong sl oped channel at the terminus of the bypass pi pe to sl ow water vel oci ty, fol l oved by a ramp that di rects fi sh through a notched wei $r$. Fi sh passing over the vei $r$ drop approxi matel y $3.2 \mathrm{~m}$ into a river pl unge pool.

Fi sh trapping faciliti es were incorporated into the fi sh bypass facilities at Uestl and and West Extensi on canal s (Fi gure 2). The trap at Uest I and Canal is used to col l ect $j$ uveni $l e$ and adul $t$ fi sh migrati ng downstream during periods of I ow river fl ow Fi sh are subsequently transported to the river nouth. The trap at West Extensi on Canal is used to sample nigrating j uveni le fi sh (Knapp and Whrd 1990). During trapping operati ons at both 


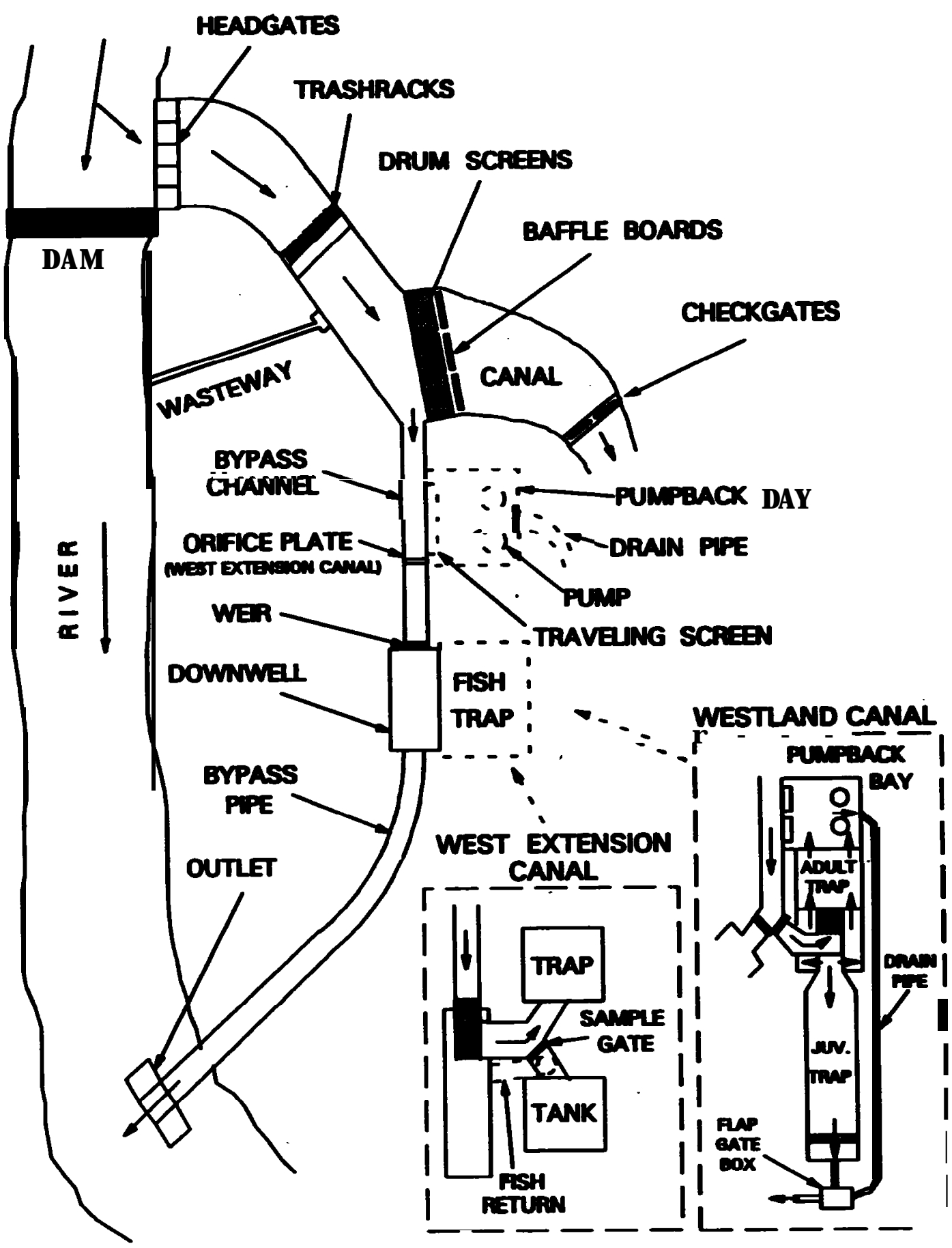

Fi gure 2. General i zed schematic of fi sh bypass facilities at i rrigation canal s on the I over Umatilla Ri ver, Oregon. 


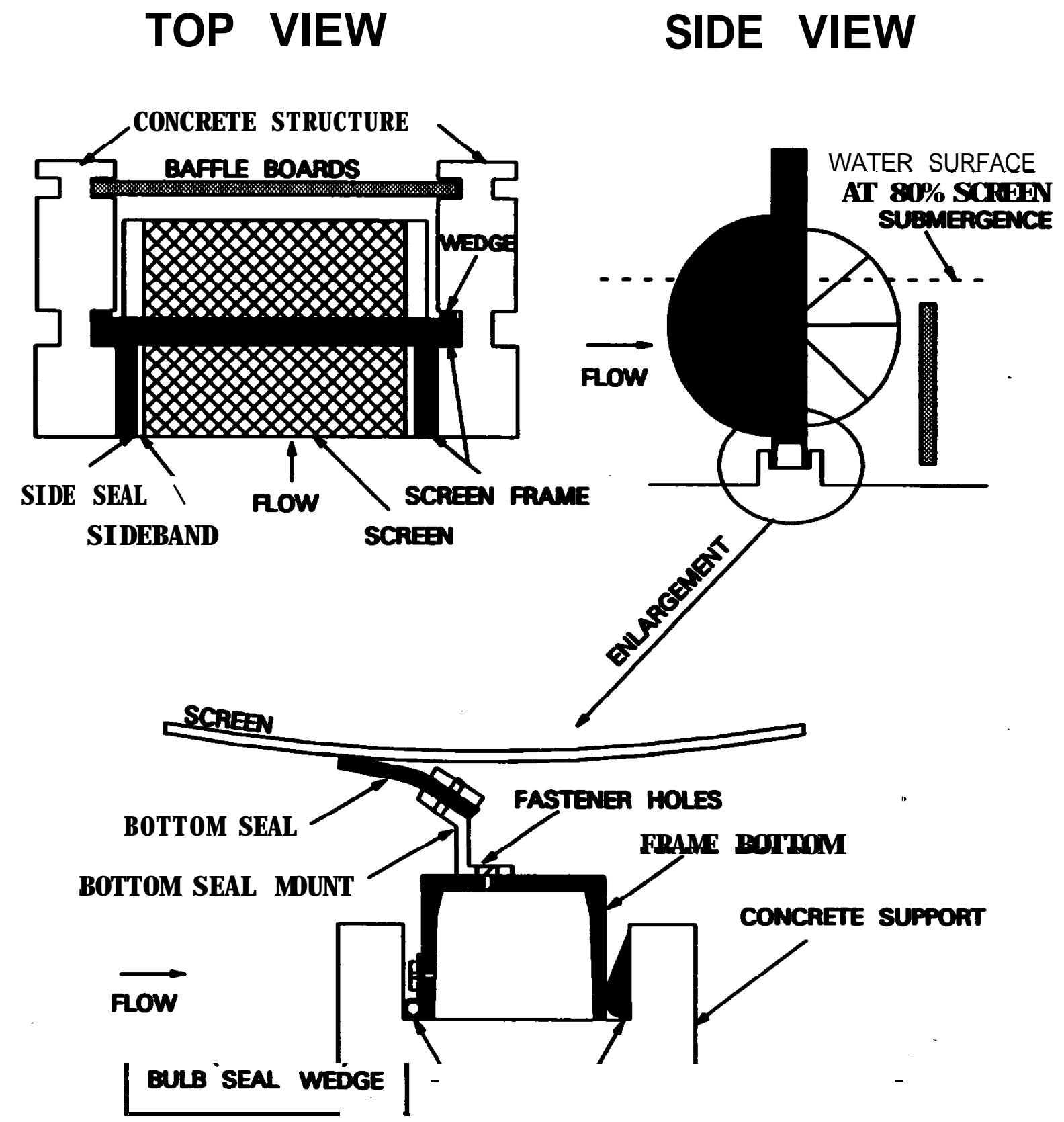

Fi gure 3. General i zed schenati c of a drum screen used i $\mathbf{n}$ fi sh bypass facilities at i rrigati on canal s on the l ower Unatilla Ri ver, Oregon. 
si tes, bypass fl ous are reduced by $80 \%$ to achi eve proper water bal ance i $n$ the traps. Reducti on of bypass fl ow decreases uater vel oci ty at the bypass channel entrance. Pumpback systens draw water through verti cal bel $t$ screens during trapping operati ons to reestablish the 0.6- mis water vel ocity at the bypass channel entrance that oscurs during nornal bypass operati ons ( Fi gure 2). At Westl and Canal, $0.09 \mathrm{~m} / \mathrm{s}$ of fl ow i s drawn passi vel y through 75- $\mathrm{mx}$ 762-nmorifice sl ots behind each of the two bel $t$ screens. The subnerged porti on of the bel $t$ screens are 1.2 m wi de $x 1.4 \sim \mathrm{mhi}$ gh. Vertical bel $t$ screens are seal ed wi th 6.4- $\mathrm{mm}$ thi ck rubber stri ps al ong the si des and bottom Excess water entering the pumpback bay is renoved by a drai $n$ pi pe or two variable fl ow pumps. At West Extensi on Canal, fl ow through the 2.3 $\mathrm{m}$ wi de $x$ 1. 9 $\mathrm{mhi}$ gh verti cal bel $t$ screen i s adj ust ed by varyi ng pumpback operati ons. Nornal pumpback operati ons i ncl ude tuo $0.28 \mathrm{~m} / \mathrm{s}$-pumps operated si ngul arly or intandem or opeirizng the 0.5 m di ane ter pumpback bay drai $n$ pi pe $20 \%$ (0.4 $\left.\mathrm{m}^{3} / \mathrm{s}\right), 30 \%\left(0.5 \mathrm{~m}^{3} / \mathrm{s}\right)$, or $40 \%(0.8 \mathrm{~m} / \mathrm{s})$.

Several key structures are pri marily associ ated with canal operations. Canal fl ow and el evati on is regul ated by adj usting the openi ngs of canal headgates and checkgates (Fi gure 2). Large debri s i s i ntercepted by rounded trashrack bars, wi th 140-11 openi ngs, I ocated upstream of the drum screens or headgates. Si lt accumul ation at the base of drumscreens is mi ni zed by baffle boards set $152 \mathrm{~mm}$ downstream of the drum screens that i ncrease wat er vel ocity near the bott om of the screens. Baffle boards usual ly bl ock about $80 \%$ of the water col um.

Verti cal sl ot fi sh I adders were constructed at the di versi on dans on the I over Unati II a Ri ver because they mai ntai $n$ uni form fl ow through the fi shuay over a wide range of river fl ous. The I arger $f i$ sh I adders at West I and and Three M I e Fal I s dans i ncorporate both passage and auxi I i ary water components to the total I adder desi gn (Table 2; Fi gure 4). The passage secti on provi des a route for fish migration; the auxili ary water secti on i ncreases fl ow through the fish entrances for fish attraction. The ori gi nal design for the fish I adder at Stanf $i$ el d Dam i ncl uded an auxi I $i$ ary water system but was subsequent l y changed to a doubl e fi shway to si mpl i fy operation.

Fi sh I adders on the Unati I a Ri ver have standard desi gns for thei $r$ pri mary fl ow stabilizing structures. They are 2.4- $\mathrm{m}$ wide $\times 3.0-\mathrm{ml}$ ong pool s w th 38- cm wi de verti cal sl ots and a maxi mum hydraul i c drop of $0.3 \mathrm{~m}$ per sl ot. Wter depth is approxi matel y $1.5 \mathrm{~m}$ i $\mathrm{n}$ the sl ot and pool secti on. The standard 36 ori entation of the sl ot jet centerline uas used at all si tes except-Three MIe Fal Is Dam where the sl ot j et is orientated at a- 46 angl e. Fl ow through the fi sh I adders is pri marily determined by whether thei $r$ hi gh or I ow fl ow fi sh entrance gate (outfl ow) is open. Al the fi sh I adders have hi gh and I ow fl ow entrance gates for fl ow regul ati on, except the fi sh I adder at Feed Canal Dam where orifice $\mathrm{pl}$ ates are inserted at the vertical sl ots to reduce fl ow Fl ow through the auxi I i ary water systens at Three MIe Fal Is and West I and dans is regul ated with a nei $r$.

Fi sh I adders at Three MIe Fal I s and West I and dans use di ffuser panel s and $f($ ow baffles to reduce fi sh attraction to the auxi I i ary water system (D. 2 at Three MIe Fal Is Dam Fi gure 4). Diffusers at the upper end of the passage secti on of the Three M le Fal Is Damfi sh I adder gui de adul $t$ fi sh past a vi ew ng wi ndow (D 3) and i nto a steeppass (D-I) that leads to a fi sh trap. Trashracks at the i nf I ow of the auxi I ary water system at both dans have the 
Tabl e 2. Speci fi cati ons of fi sh I adders at i rrigation dans on the I ower Unatilla Ri ver. Oregon

\begin{tabular}{|c|c|c|c|c|c|c|}
\hline $\operatorname{Dam}^{a}$ & $\begin{array}{c}\frac{\text { Lac }}{\text { Length }} \\
\text { (n) }\end{array}$ & 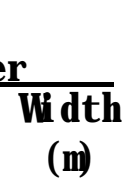 & $\begin{array}{l}\text { Pool to tail - } \\
\text { race head } \\
\text { di fferenti al } \\
\text { (n) }\end{array}$ & $\frac{\text { Passar }}{L^{\mathbf{L}^{W}}}$ & 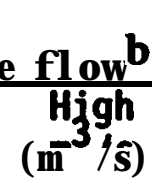 & $\begin{array}{c}\text { Auxi I i ary } \\
\text { water } \\
\text { ow } \\
(3 / 5)\end{array}$ \\
\hline $\begin{array}{l}\text { Three Mle } \\
\text { Fal I s }\end{array}$ & 41. 1 & 9.4 & 3.0 . & 1.1 & I. 4 & $0.0-4.0$ \\
\hline Uest I and & 32.8 & 5.2 & 1.2 & 1.1 & 1.4 & $0.0-4.0$ \\
\hline Feed & 9.1 & 2.4 & 0.8 & $\mathrm{NA}$ & 1.0 & -- \\
\hline Stanf $i$ el d & 29.3 & 4.9 & 1.1 . & 2.3 & 3.1 & -- \\
\hline
\end{tabular}

g No fish ladder s are present at Mexwell Dam.

Meximemdesign flow.

sane desi gn as diffusers. Trashracks at the fi shway i nf I ow consi st of $76-\mathrm{mm}$ di aneter bars spaced wi th 203-nmopeni ngs.

\section{METHODS}

Our i nvesti gati ons began at Three M I e Fal I s Dam and proceeded upri ver as reconstructi on of fish passage facilities was compl eted (Table 3). Ye conducted tests to eval uate i nj ury, rate of travel and recapture, and screen effici ency, and neasured screen and bypass channel vel ociti es. Screen effici ency tests were not perforned at Maxuel I Canal. An additi onal test was conducted at Uest Extensi on Canal to ascertai $\mathrm{n}$ fi sh i mpi ngement on the bel $t$ screen at varyi ng pumpback bay operati ons. I nj ury to $j$ uveni l e sal noni ds passing through fi sh ladders was al so eval uat ed at Three M le Fal Is, Uest I and, Feed Canal, and Stanfi el d dans. I mprovenents in test nethodol ogy vere progressi vel y adopted throughout the fi ve-year study.

\section{Test Fi sh}

Yearl ing spri ng chi nook sal non, yearl ing sumer steel head, and subyearl ing fal I chi nook sal mon were sel ected for inj ury tests because they are present in the Lhnatilla Ri ver. Mean fork lengths of fi sh used in inj ury tests ranged from 144-195 MMfor sumer steel head, 124-168 $\mathrm{mm}$ or spring chi nook sal non, and $79-91 \mathrm{~mm}$ for fall chi nook sal non. Subyearl ing fal I chi nook sal non were used for screen effi ci ency and i mpi ngenent tests i nuedi atel $y$ after hatchery marking. Mean fork lengths of $f$ al I chi nook sal mon ranged from 57-67 mm or drum screen effici ency tests, 63-64 $\mathrm{mmf}$ or bel $\mathrm{t}$ screen effici ency tests, and 61-71 $\mathrm{mm}$ for bel $t$ screen i mpi ngenent tests. 


\section{THREE MILE FALS DAM}

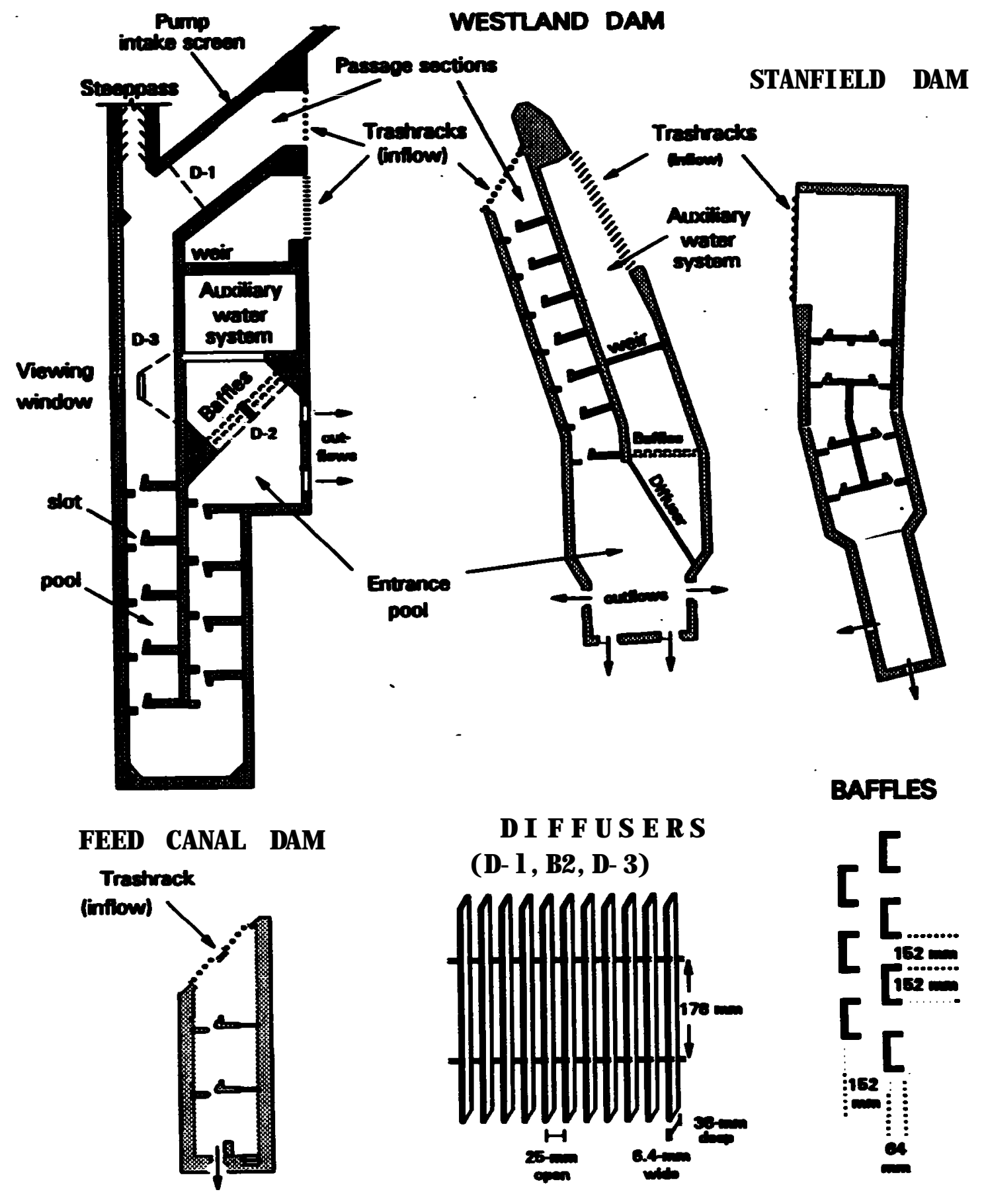

Fi gure 4. Schematic of fi sh I adders at i rrigation dans on the I ower Unatilla Ri ver, Oregon. 
Table 3. Schedul e of st udy acti vi ti es conducted' at fi sh bypasses and I adders associ ated wi th irrigati on dans on the I oner Unatilla Ri ver, Oregon, 19911995.

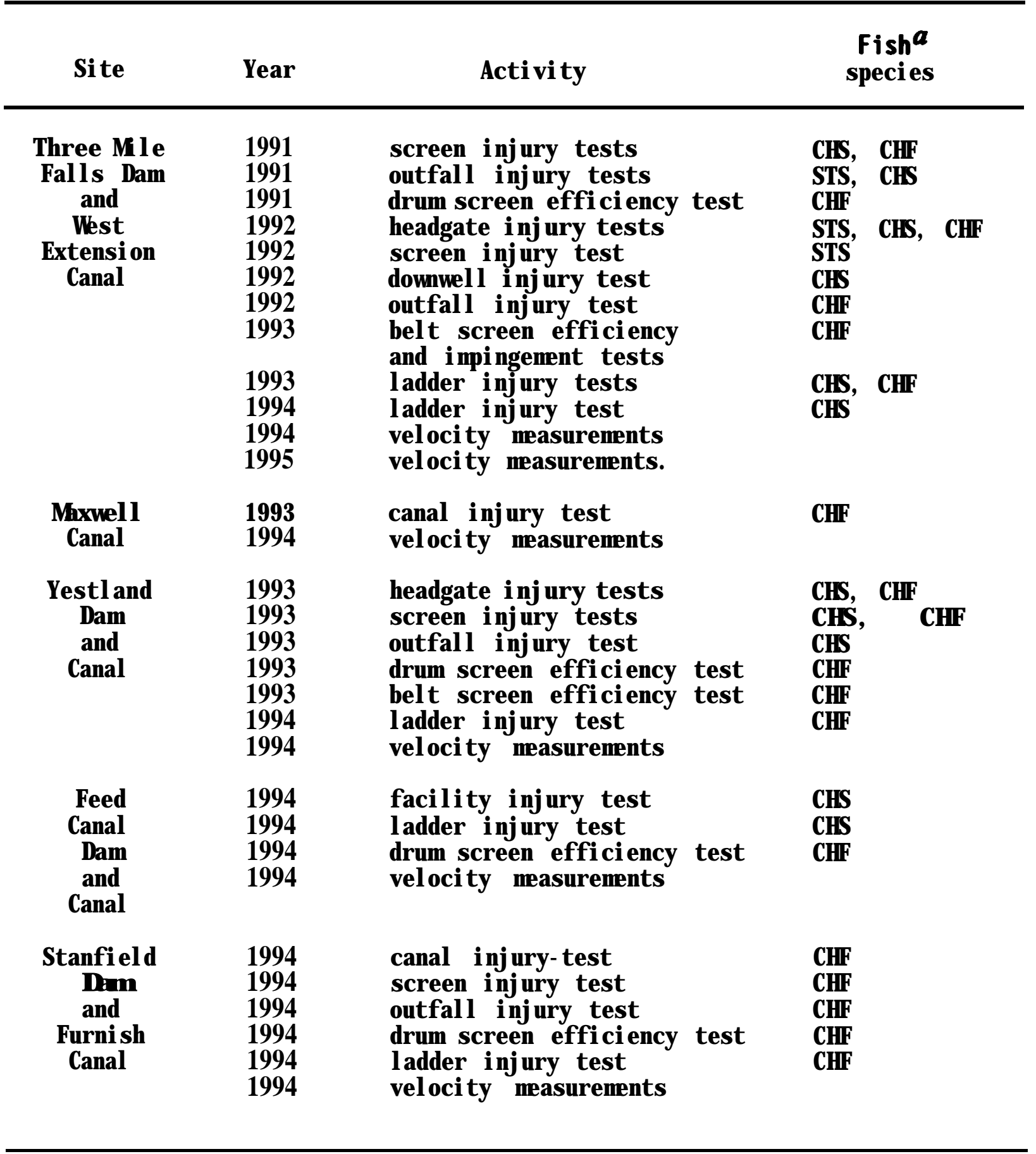

a STS =surer steel head, CHS - spring chinook salmon, CFF=subyearling fall chinook sanon 
Fi sh were transported from hatcheri es to study si tes in a 1.0- $m^{3}$ or 1.5$\mathbf{m}^{3}$ oxygenated transport tank. Transport ti mes ranged from 0.5-3.0 hours. I nj ury test fi sh were hel d in tuo to si $x, 2.3-\mathrm{m}$ ci rcul ar tanks suppl i ed with $0.2-0.3 \mathrm{~m} / \mathrm{s}$ of canal water i nfl ow or in 1.2- $\mathrm{m} \times 2.4-\mathrm{m} \times 1.2-\mathrm{m}$ net Jens subnerged in the canal. Hol di ng densi ti es were kept bel ow $32 \mathrm{~kg} / \mathrm{m}^{3}$. Fi sh were hel d on si te from l-24 days pri or to thei $r$ rel ease in tests.

\section{Traps}

Ye installed traps in the bypass facilities to collect fish at the bypass nei $r$ and bypass out let/outfal I structures. At nost si tes, we i nstalled i ncl i ned pl ane traps at the bypass wei $r$ (Knapp 1992; Fi gure 5) to recapt ure test fi sh rel eased in the upper bypass duri ng i nj ury, screen ef $\mathrm{f} i \mathrm{ci}$ ency, and i mpi ngenent tests. I ncl i ned pl ane traps were constructed of al umi num and i ncl uded a hi nged mouth, perforated pl ate fl oor (40\% open) wi th 3.2-w di aneter hol es, and a terminal I i ve box. Traps were si zed to maxi mum bypass . fl ow provi di ng $4.9 \mathrm{~m}^{2}$ of perforated floor per $1 \mathrm{~m} / \mathrm{s}$ of bypass fl ow Li ve box capaci ti es ranged from 0. 08-0.12 $\mathrm{m}^{3}$.

A permanent sampl i ng faci I i ty uas used at West Extensi on Canal to col I ect fi sh rel eased in the upper bypass (Knapp and Whrd 1990; Fi gure 2). An i ncl ined screen in the bypass channel gui ded fish over the bypass wei $r$ where a separator passed fi sh ( $<400 \mathrm{~mm})$ i nto a Y-shaped transf er fl une. A sampl e gate at the fl une fork di verted fi sh to ei ther a trap or a 0.15-m di aneter pi pe that term nated in the downuel I. Fi sh vere renoved from the trap usi ng an i nternal crouder and I ift basket.

A fl oating net pen was used to col l ect $f i$ sh beneath the bypass out $f$ al $I$ at Vest Extensi on Canal (Knapp and VArd 1990). The net nouth was attached to a $1.8 \mathrm{mfl}$ oating frane; net depth was $3.4 \mathrm{mflaring}$ to a wi dth of $3.1 \mathrm{~m}$ at the l ead- uei ght ed bott om Trap netti ng consi sted of an i nner 4. 8- $\mathrm{mm}$ nesh rei nf orced by an outer 7.9-m nesh of knotl ess nyl on. At ot her bypass outl ets, ue used a fl oating trap net to capture test fish, (Cameron et al. 1994; Fi gure 5). The 6. 1- $\mathrm{m}$ l ong net tapered froma 1.5-Th mouth to a ci rcul ar 0.4- $\mathrm{m}$ di anet er end. A 0.9-m I i ve box was attached to the terminal end of the net. The net was attached to a uooden frane made buoyant wi th Styrof oam bl ocks.

Fi sh I eaki ng through or rol ling over drum screens were capt ured using fyke nets depl oyed behi nd each screen i $n$ gui des normal I y used for baffl e boards (Knapp 1992; Caneron and Knapp 1993; Cameron et al. 1994, 1995). Normal canal operati ons were si mul ated by fixing baffle boards to the net frames. Fyke nets were si zed to screen di nensi ons and canal fl ow Nets made of 4.8- $\mathrm{mm}$ knotl ess nyl on netti ng ranged i $\mathrm{n}$ si ze from 1. 2-7. 6- $\mathrm{ml}$ ong, and tapered to a 0.3-0.6- $\mathrm{m}$ cod end. $\mathrm{Net}$ shapes were-angl ed to conf or $\mathrm{m}$ to l ocal i zed fl ow patterns behi nd each screen.

Fyke nets vere al so used to capt ure fi sh behi nd bel $t$ screens at West Extensi on and Uest l and canal s. At West Extensi on Canal, the net was attached to the outl et of the pumpback bay drai $n$ pi pe (Knapp 1992). The 3.7-neter-I ong net tapered from a $0.6-\mathrm{m} \times 0.8-\mathrm{m}$ mouth to a $0.15-\mathrm{m}$ cod end. At Uest land Canal, the openi ng in an orifice plate l ocated behi nd each screen was util i zed for net attachnent. These nets consi sted of a subnerged porti on that tapered 

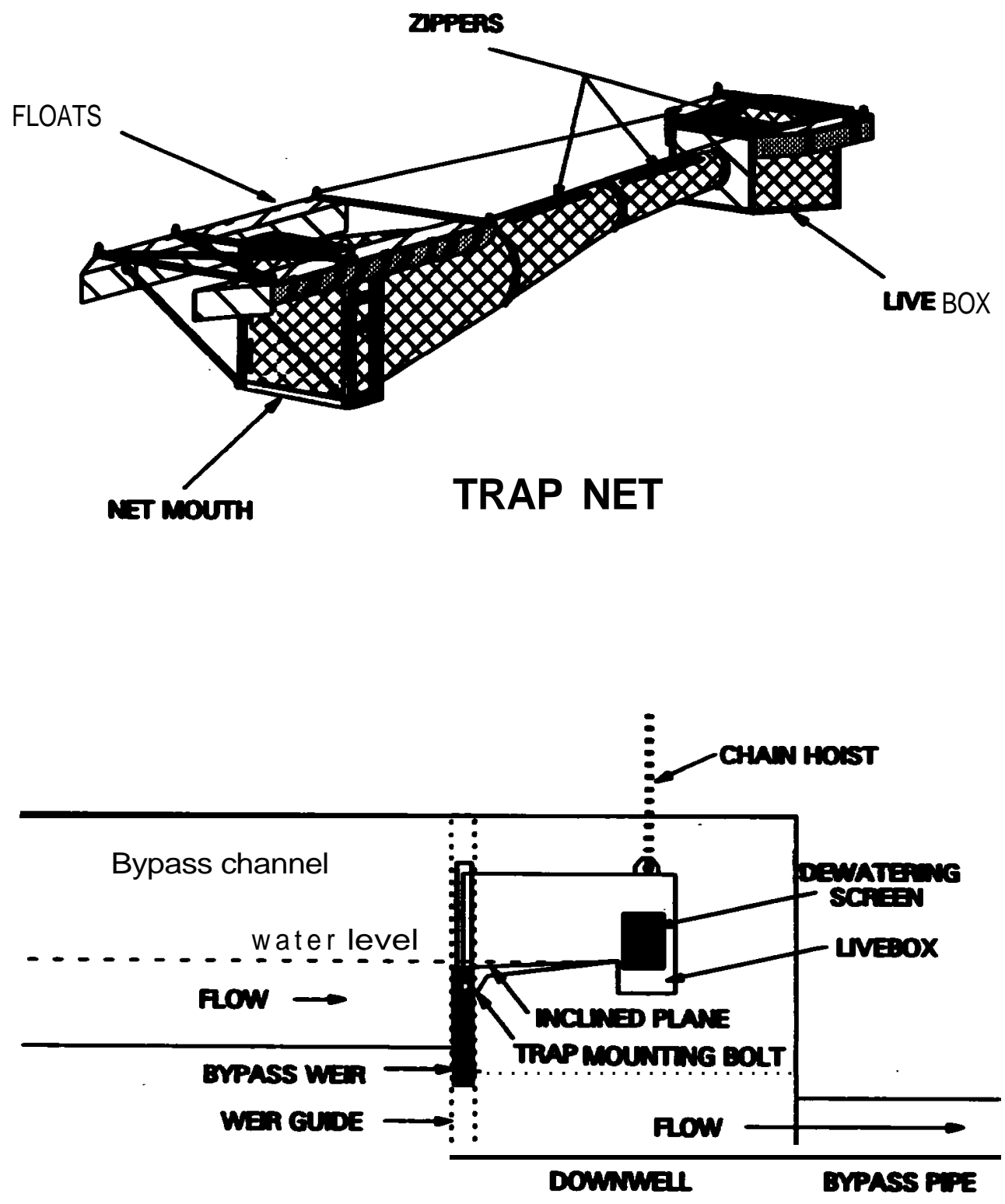

INCLINED PLANE TRAP

Fi gure 5. Fl oati ng trap net and i ncl i ned plane trap used for fi sh coll ection at bypass facilities and fi sh I adders on the l ower Unatilla River, Oregon. 
froma di aneter of $0.6 \mathrm{mto} 0.3 \mathrm{~m}$ and a neck porti on that bri dged the gap between the nouth and submerged portions of the net (Cameron and Knapp 1993).

Ye collected test fish at fi ish I adders using the fl oating net trap at Three Mle Fal Is, Feed Canal, and Stanfiel d dans. We nodifi ed a drum screen fyke net used at Feed Canal to col lect test fish at the Uestl and Damfi sh I adder.

\section{Inj ury}

Inj ury tests consi sted of rel eases of one to three groups of uni quel y marked treat ment and control fi sh on two to three consecuti ve dates (Table 3). Treat ment fi sh were rel eased upstream of the facility struct ure bei ng eval uat ed; control fi sh were rel eased ei ther i mmedi at el y downst ream from the structure or in a recovery trap to assess trap and handling-caused inj ury. I nj ury was eval uated on al I or a subsample of $\mathrm{fi}$ sh fromeach repl $\mathrm{i}$ cate group pri or to rel ease to establ ish pre-rel ease condi ti on. If subsampl ed, exami ned fi sh were not returned to the rel ease group. Inj ury rates of recaptured treat ment and control fi sh were compared to determine facility-caused i nj ury.

In 1991 and 1992, we determined fi sh condi ti on (i nj ury) usi ng descal i ng criteri a devel oped by the Army Corps of Engi neers (Basham 1982). Fi sh conditi on was based on the percentage of scal e l oss in each of fi ve desi gnated secti ons per fi sh si de. Fi sh were cl assi fi ed as "heal thy" ( scal e loss $\leq 3 \%$ in each section), "partl y descal ed" ( scal e loss > 3\% but < the equi val ent of $40 \%$ of two secti ons), or ' descal ed" ( scal e I oss $\geq$ the equi val ent of $40 \%$ of t no secti ons). Other types of i nj uri es recorded i ncl uded body and head i nj uri es, torn opercul uns, bi rd marks, mammal i an predat or marks, parasi tes, and fungal i nf ecti ons. In 1993 and 1994, ve nodi fied the criteri a by subdi vi di ng the partl y descal ed category i nto l ow parti al l y descal ed (> $3 \%$ scal e loss and $\leq$ the equi val ent of $20 \%$ of t no secti ons) and noderate parti al Iy descal ed ( $>20 \%$ and < the equi val ent of $40 \%$ of t no secti ons).

Facility-caused inj ury was di termined for each test by comparing the anount and severity of inj ury incurred by treat nent and control fi sh after rel ease. Net- wei ghted i nj ury uni ts were used as a quanti tat i ve measure. They were computed by fi rst cal cul ati ng the percentage of uni nj ured, I ow parti al I y descal ed, noderate parti al l y descal ed, ot herwi se i nj ured, descal ed, and dead fi sh for each pre- and post-rel ease repli cate. These percentages vere mul ti pl i ed by wei ghti ng fact ors that refl ected the severity of each cat egory uni nj ured ( 0.0$)$, I ow parti al ly descal ed (0.167), noderate parti al ly descal ed (0.33), ot herwi se i nj ured (0.33), descal ed (0.67), and dead (1.0). (A wei ghting factor of 0.33 was used for the si ngl e partl y descal ed cat egory used in tests at West Extensi on Canal in 1991 and 1992). Wei ght ed percent ages of each i nj ury category were summed for each repl i cate. These suns vere averaged for each pre- and post-test treat ment and control group to cal cul ate wei ghted i nj ury. Net- wei ghted i nj ury was cal cul at ed for treat nents and control s by subtracting wei ghted pre-test inj ury from wei ghted post-test i nj ury. Facil ity-caused i nj ury was cal cul ated as the mean difference bet ween treatment and control net- wei ghted inj ury rates.

Some changes in nethodol ogy were adopted over the course of the study to i mprove the accuracy of inj ury tests. These changes i ncl uded i ncreased sample 
si zes, i ncreased subsampl i ng rates for pre-test i nj ury, expanded descal i ng criteria, and i mproved marking and hol di ng logi sti cs. In 1992, sample si zes of treatment and control groups vere i ncreased from $100 \mathrm{fi}$ sh to $150 \mathrm{fi}$ sh and subsampling rates were i ncreased from $10 \%$ to $30 \%$ In 1993, we subdi vi ded the partially descal ed category to i mprove detection of I ow I evel s of descal ing. In 1994, new marki ng techni ques al l owed $100 \%$ of the test fi sh to be eval uated for pre-test inj ury and rel eased a couple hours after marking.

Several techni ques were used to mark and hol d i ndi vi dual rel ease groups. Bet ween 1991 and 1993, freeze brandi ng was used to mark treatment and control fish. In 1991 and 1992, marked fi sh were segregated by brand i nto net pens or perforated pl asti c contai ners subnerged i $n$ ci rcul ar tanks and hel d 48- 72 hours to al I ow brands to darken. In 1993, we attempted to reduce the variability in pre-test i nj ury anong segregated groups of test fi sh by hol di ng groups with common rel ease dates and l ocati ons i n a si ngl e net pen. Four hours pri or to rel ease, fi sh were sorted i nto separate rel ease cont ai ners and a $30 \%$ subsample of fish was eval uated for pre-test condition. Brand retenti on and readability was checked during pre-test subsampling. I n 1994, test fi sh were marked by i njecti ng approxi natel y $0.1 \mathrm{~m}$ of acryl i c pai nt onto the ventral body surface usi ng ei ther-a syringe with 26-gauge i ntradernal needl e or Panj et needl el ess i nj ect or ( Hart and Pi tcher 1969; Thedi nga and J ohnson 1995). Thi s al I owed eval uation of pre-test injury on al l test fish during the marking process. After narki ng, groups of test fi sh were hel $d$ i n separate contai ners for approxi matel y two hours pri or to rel ease.

\section{Bypass}

Separate i nj ury tests were conducted in the upper and I ower segnents of nost fish bypass facilities. For our eval uations, we defined the upper bypass as that segnent upstream of the bypass wei $r$ whi ch contai ned the headgates, headuorks canal, screen for ebay, drum screens and bypass channel. Upper bypass tests i ncl uded headgate i nj ury, canal i nj ury, and screen i nj ury tests. The I over bypass was that segnent downstream of the bypass wei $r$ whi ch contai ned the bypass downuel I, pi pe, and out l et. Lower bypass tests i ncl uded downuel I i nj ury and out l et/ outfal I i nj ury tests. Duri ng upper bypass tests, traps at the bypass wei $r$ were operated on a conti nuous basi s for at l east 96 hours after test fish were rel eased. In l ower bypass tests, trapping at bypass out l ets was conducted during dayl i ght for approxi matel y t wo to si $x$ hours after test fish rel eases.

Mst i nj ury tests were conducted under normal operati ng condi ti ons. - At West Extensi on Canal, downuel I and outfal I j nj ury tests were conducted at desi gn bypass flous of $0.14 \mathrm{~m} / \mathrm{s}$ and $0.71 \mathrm{~m} / \mathrm{s}$. We al so tested a non-standard operating procedure by increasing pool depth in the downuel I to $3.1 \mathrm{M}$ to test whether turbul ence and (potenti al ) fi sh i nj ury could be reduced. Nor mal downuel I pool depths were $0.6 \mathrm{~m}$ and $1.2 \mathrm{~m}$ at $0.14-\mathrm{m}^{3} / \mathrm{s}$ and $0.71-\mathrm{m}^{3} / \mathrm{s}$ bypass fl ous, respecti vel y. Downuel I pool depth was i ncreased for the $0.71-\mathrm{m}^{3} / \mathrm{s}$ hi gh- pool tests by reducing the gate openi ng at the bypass pi pe term nus. During the 0.14- $\mathrm{m}^{3} / \mathrm{s}$ hi gh-pool test, we cl osed the bypass pi pe gate compl etel y to back up uater in the downwel I. When pool depth reached $3.1 \mathrm{~m}$ we si mul taneousl y rel eased test $\mathrm{fi}$ sh and rai sed the gate at the bypass pi pe terminus. Approxi matel y 40 seconds el apsed unti I the downuel I pool ret urned to a depth of $0.6 \mathrm{~m}$ 
Test fi sh were transported to rel ease si tes in 20-gal I on or 5-gal I on contai ners. Fi sh were rel eased by ei ther caref ul l y pouring out the contai ner contents or netting smal I groups of fi sh from the contai ners. Ye rel eased fi sh i $n$ the upper bypass approxi matel y one neter upstream of the headgat es for headgate i nj ury treatments, 20 m downst ream of the headgat es for canal i nj ury treat ments, 32-78 mupstream of the drum screens for screen i nj ury treat nents, and at the mouth of the trap for screen inj ury controls. At Maxuel I Canal, canal inj ury controls were rel eased at the trap nouth. Screen inj ury treatment groups were rel eased from the bank on the screened si de of the canal at nost si tes. At West Extensi on Canal, one repl i cate group of screen i nj ury treat nents was rel eased i nto each of three fl ow control fl unes upstream of the screens.

Ye rel eased fi sh at the bypass nei $r$ for downuel I and outl et/out fal I i nj ury treatments, at the start of the bypass pi pe for downuel I i nj ury control s, and i nto the trap nouth for outl et/outfal I controls. Downuel I i nj ury control fi sh were rel eased i nto the bypass pi pe entrance usi ng a hopper wi th a 51-m di anet er hose. Rel eases of treatment and control groups were pai red i $n$ downuel I and outl et/outfal I i nj ury tests at 0.5 hour to 1 hour i nterval s.

After capt ure, test fi sh were separated from col l ected ri ver-run fi sh and ei ther processed i medi atel y or hel d nomentarily i n net pens. Col l ected fi sh were anest heti zed usi ng a $50-\mathrm{ppm}$ to $100 \mathrm{ppm}$ sol uti on of tri cai ne methanosul fonate. Exam nations were completed wi thi $n$ one hour of sorting. Collecti on ti me, scal e. I oss, i njuries, and test marks vere recorded on al I recaptured test fish.

\section{Ladder}

Ladder i nj ury tests fol I owed the same sampl ing protocol descri bed above for bypass i nj ury tests. We rel eased fi sh i $\mathrm{n}$ fi sh l adders $0.5 \mathrm{~m}$ upstream of the vertical sl ot cl osest to the fish exit for passage treatnents, at the crest of the auxili ary water wei $r$ for auxili ary water treatments, and approxi matel y one neter in front of the trap- nouth for control s. At the St anf $i$ el d Dam fi sh I adder, approxi mat el y equal nunbers of fi sh uere rel eased in each hal $f$ of the dual-passage I adder. Tho treat nent groups were rel eased in the passage secti on of the fish I adder at Three Mle Fal Is Dam to assess i nj ury associ ated with midchannel di ff user panel s. Rel ease l ocati ons for the treat nents were 7 m upst ream of Di ff user 1 ('Treat ment UD) and 5 m downst ream of Diff user 3 (Treat nent DD).

\section{Travel Rate and Recapt ure}

Bypass

Ye recorded rel ease and recapt ure ti mes of fish duri ng i nj ury tests conducted in fish bypass facilities to determine the ti me for the fish to travel froma rel ease l ocati on to recapt ure si te. For tests conducted in the upper bypasses, - rate of $\mathrm{fi}$ sh movenent was quantifi ed by cal cul ating the average ti me to recapt ure $50 \%$ (nedi an travel ti me) and $95 \%$ of the test fi sh rel eased. For tests conducted in the l ower bypasses, fi sh novenents were 
quant $i$ fi ed by pl otting average cumul ati ve percent recapt ure of test fish agai nst average ti ne after rel ease. Cumul ati ve percent recapt ure was corrected for trap effici ency. We al so used nedi an travel speed to quantify fi sh novement in the upper and l ower bypass. Medi an travel speed ( $\mathrm{m} / \mathrm{s}$ ) was based on medi an travel ti ne. It was cal cul ated by di vi di ng di stance travel ed by medi an travel ti me. Percent recapt ure was cal cul ated for tests conducted in the upper bypass as the percentage of $\mathrm{fi}$ sh recapt ured at the end of the test, and uas not corrected for trap effici ency.

\section{Ladder}

We recorded rel ease and recapture ti mes of fi sh during i nj ury tests at fi sh I adders to determine the average ti me for fi sh to pass through the I adder. Fi sh novenents vere quant i i i ed by pl otting average cumul at i ve percent recapt ure of test $f i s h$ agai nst average ti me after rel ease. Cumul ati ve percent recapt ure was corrected for trap effi ci ency.

\section{Screen Ef fi ci ency and I mpi ngement}

\section{Dru Screens}

Screen ef fi ci ency of (I eakage) and i mpi ngenent at ( rol l-over) drum screens was eval uated by rel easi ng unmarked subyearl i ng fal I chi nook sal mon upstream of the screens and recapt uring them in fyke nets depl oyed behi nd the screens and at the bypass downuel I trap. Harked fi sh were rel eased in the nouth of fyke nets and at the bypass channel entrance to determ ne trap capt ure effici encies. Trap effi ci ency fi sh were marked by i mmersi on i n a 24$\mathrm{ng} / \mathrm{I}$ sol uti on of Bi smark brown dye. The dye i mparted an or ange stai $n$ on the body surface and gills of test fi sh that was detectable for at l east 48 hours after rel ease.

Drum screen effici ency tests were repl i cated three ti nes at each si te: Test i nterval s of 48 hours were sel ected to al l ow adequate ti me for test fi sh to cl ear the system bef ore rel easi ng the next group of fish. At Uest Extensi on Canal, each test consi sted of midnorni ng rel eases of 300 unmarked fi sh upstream of the screens, 300 marked fish at the bypass channel entrance, ' and a total of 300 marked $\mathrm{fish} i \mathrm{n}$ the fyke nets. At Uestl and, Feed, and Furni sh canal s, sample si zes of-test fi sh rel eased upstream of - the screens and at the bypass channel entrance were proportional to the total number of $f i s h$ rel eased in the fyke nets (100 fi sh per screen); fi sh rel eased upstream of the screens were equal to the total number of fi sh rel eased in the fyke nets and hal f as many fish uere rel eased at the bypass channel entrance. Test fish rel eased upstream of the screens and at the bypass channel entrance were spl it equal Iy anong a midmorning and I ate afternoon rel ease. Trap effici ency fish uere onl y rel eased into the fyke nets in midmorni ng. We checked traps at the downuel I at least once per hour and fyke nets 2-4 ti nes per day. At al I si tes, we peri odi call y moni tored the drum screens for fi sh i mpi ngenent af ter each rel ease and recorded number, date, ti me, and l ocati on of i mpi nged fi sh.

Screen effici enci es were esti mated as the percentage of $f i$ sh gui ded saf el y past drum screens. Esti mates uere based on the nunber of fi sh capt ured behi nd the screens in fyke nets and the number of fi sh capt ured in the bypass- 
trap. Number of fi sh captured in the fyke nets and bypass trap were corrected for trap capture effi ci ency. We cal cul ated effi ci encies for i ndi vi dual screens and an overall screen effici ency for each test peri od. Overal I effici enci es for the three tests were then averaged to cal cul ate a nean screen effici ency for the fish bypass facility. We assuned fish caught in the fyke nets were retai ned. The for mul a for cal cul ating fyke net capture effi ci ency (EFFf $n$ ) behi nd each screen was

$$
\text { EFFf } n=\frac{n f n}{N F n}
$$

where nf $n$ was the nunber of control fish rel eased at the fyke net nouth and captured i $n$ the fyke net, and $\mathrm{N} n$ was the number of control fi sh rel eased at the fyke net nouth.

The formul a for cal cul ati ng bypass col l ecti on effi ci ency (EFF

$$
\mathrm{EFF}_{\mathrm{bc}}=\frac{\mathrm{nbc}}{\mathrm{Nbc}}
$$

where nbc was the number of control fish rel eased at the bypass channel entrance and captured in the bypass trap, and $\mathrm{Noc}$ was the nunber of control fi sh rel eased in the bypass channel entrance.

The formul a for cal cul ating both effi ci ency of i ndi vi dual screens and an overal I screen effici ency $\left(\mathrm{EFF}_{\mathrm{SC}}\right.$ ) for al I screens conbi ned was

$$
E F_{d s}=\left[1-\frac{(X f n)}{\left(E F F f_{f n}\right)(N)}\right]
$$

where $\mathrm{Xf} n$ was the nunber of treat ment fi sh rel eased upstream of the screens and recaptured behi nd the screens, and $N$ uas an esti nate of the total number of fish encountering the screens.

$$
N=\frac{X_{f n}}{E F F n}+\frac{{ }^{\prime} X_{b c}}{E F F_{b c}}
$$

where $\mathrm{Xb}_{c}$ was the number of treat ment fi sh rel eased upstream of the screens and caught in the bypass trap.

The formul a for cal cul ating overal I screen effici encies at Uestl and Canal was nodified because we were unable to collect fish in the downuel I trap and, thus, could not esti nate the number of fish encountering the screens. Screen effi ci ency esti nates (EFF ${ }_{S C}$ ) were nodified by assuming the number of fi sh encountering the screens (N) was equal to the number of $f i$ sh rel eased upstream of the screens withi $n$ each test period. 


\section{Bolt Screens}

Bel $t$ screen effi ci ency tests at Uest I and Canal requi red non-standard facility operations. Nornally, the bel t screens are onl y in use when the fi sh bypass facil ity is operated in a trapping node. However, fi sh bypassing was a pri ority when bel $t$ screen effici ency tests vere conducted. We si mul ated fi sh trapping operations by $f$ ul I y opening the ori fice sl ots behi nd each screen and throttling back one pumpback pump to maintain a constant water l evel in the pumpback bay. A bypass fl ow of $0.57 \mathrm{~m} / \mathrm{s}$ vas used i nstead of the $0.11-\mathrm{m}^{3} / \mathrm{s}$ fl ow that normally enters the trap.

At Uestl and Canal, treat nent rel eases consi sted of 600-800 subyearli ng fal I chi nook sal non, rel eased hourly in groups of 200 at the bypass channel entrance. Fyke nets attached to each orifi ce sl ot uere used to col l ect fi sh that l eaked through the bel t screen (Caneron and Knapp 1993). Trap effi ci ency fi sh were marked with Bi snark brown dye. We rel eased one group of 150 marked fish at the mouth of each fyke net to esti mate capt ure effici enci es of the nets at the start of the test. We rel eased groups of 100 marked fi sh downstream of the bel $t$ screen after each rel ease of treat ment $f i$ sh to esti mate capt ure efficiency of the bypass trap. We checked the bypass trap and fyke nets at least once per hour. We peri odi cally nonit ored the bel $t$ screens for fi sh i mi ngenent after each rel ease. Number, date, ti me, and I ocati on of i mpi nged fi sh were recorded.

At West Extensi on Canal, we conducted separate bel $t$ screen effi ci ency tests when the pumpback bay drai n pi pe was $20 \% 30 \%$ and $40 \%$ open. Bel $t$ screen effici ency during pump operations was not determined because of the i nability to capt ure fish at the pump outfl ow We rel eased a total of 400 unnarked subyearli ing fal I chi nook sal non hourl y in groups of 100 upstream of the screens at the bypass channel entrance. A fyke net attached to the terminus of the pumpback bay drai $n$ pi pe col lected fi sh that passed through the bel $t$ screen (Knapp 1992). Capt ure effici ency of the fyke net uas determined by rel easi ng 100 Bi smark brown- dyed fi sh int 0 the pumpback bay at the start of each test. We did not determine col lection ef ficiency of the bypass trap. Ye checked the bypass trap and fyke net at least once per hour.

We cal cul ated belt screen effi ci ency fol l owing the same formul a used for drum screen effi ci ency with the fol l owing excepti on. At West Extensi on Canal, we assuned the bypass trap was $100 \%$ ef $\mathrm{fi}$ ci ent, theref ore $\mathrm{EFF}_{\mathrm{bc}}=1$.

Bel t screen i mpi ngement tests were conducted at West Extensi on Canal when the pumpback bay drai $\mathrm{n}$ pi pe was 20\% 30\% and $40 \%$ open and bot $\mathrm{h} 0.28-\mathrm{m}^{3} / \mathrm{s}$ canal pumps were of $f$, and when the canal pumps were operated si ngul arl $y$ and i $n$ tandem with the drai $n$ pi pe cl osed. A total of 400 unnarked subyearling fal $I$ chi nook sal mon were rel eased hourly in groups of 100 at the bypass channel entrance. We rel eased $100 \mathrm{Bi}$ smark-brown dyed $\mathrm{f} i \mathrm{sh}$ downst ream of the bel $t$ screen at the start of each test to deternine capt ure effi ci ency of the bypass trap. We cont i nual I y noni tored the screen until nost of the unmarked fi sh were recapt ured. Fi sh vere counted as i mpinged if they were I ifted out of the water while pressed agai nst the screen. The screen spray wash was turned of to provide an unobstructed vi ew of the above- water porti on of the screen. 
Cal cul ati on of bel $t$ screen i mpi ngenent fol I oned a formul a anal ogous to the one used for drum screen efficiency. The formul a for percent bel $t$ screen i mpi ngenent (IMP $\mathbf{s c}$ ) was

$$
\text { I MP, , }=\frac{\left(X_{\text {imp }}\right)(100)}{N}
$$

where $X_{i m p}$ was the number of $f i s h$ i mpi nged on the bel $t$ screen, and $N$ was an esti mate of the total number of $f i s h$ encountering the screen.

$$
N=\frac{\left(X_{b t}\right)\left(N_{b t}\right)}{(n b t)}
$$

where $X_{b t}$ was the number of treat ment $f i$ sh rel eased upstream of the bel $t$ screen and caught in the bypass trap, $\mathrm{Nb}_{t}$ was the number of control fish rel eased upstream of the bypass trap, and nbt was the number of control fish rel eased upstream of the bypass trap and capt ured in the bypass trap.

\section{Whter Vel ocity}

Bypass

We measured water vel ocity i $\mathrm{n}$ front of drum and bel $\mathrm{t}$ screens and at bypass channel entrances to assess compl $i$ ance wi th vel ocity criteri a devel oped by the Nati onal Whi ne Fi sheri es Servi ce (NMFS 1989, 1990). The criteri a specifi es the requi red vel ocity for fl ow perpendi cul ar (approach vel oci ty) and fi ow paral l el (sweep vel oci ty) to the screen face. Mxi mum al l oubble approach vel ocity is $0.12 \mathrm{~m} / \mathrm{s}$ for protection of sal moni d fry ( fi sh < $60 \mathrm{~mm}$; and 0.24 $\mathrm{m}$ is for protecti on of sal nonid snol ts ( $\mathrm{fi}$ sh $>60 \mathrm{~mm}$ ). Sueep vel oci ty shoul d be at I east $t$ ice the magni tude of approach vel ocity ( sueep : approach rati 0 $\geq 2$ ). At the bypass channel entrance, approach vel ocity must equal or exceed the maxi mum vel ocity of canal flow in front of the screens.

We used a Harsh MtBi rney (Mdel 2000) el ectronagnet i c fl ounet er to collect vel ocity neasurenents during normal facility operations. The meter di spl ayed vel ocity readings as fi xed poi nt averages or i nstantaneous readi ngs. Fi xed poi nt averagi ng provi ded a mean of 150 vel oci ty readi ngs coll ected over a peri od of fi ve seconds. We used fixed poi nt averagi ng to neasure uater vel oci ty.

At drum screens, vel oci ty measurenents were taken 76- $152 \mathrm{~cm}$ upstream of the screens at three verti cal transects I ocated at $25 \% 50 \%$ and $75 \%$ of the screen I ength. Sampling depths at each transect were $20 \% 50 \%$ and $80 \%$ of screen submergence depth. At each sampl ing l ocati on, we poi nt ed the neter's sensor probe into the vector of maxi mum water vel ocity. We used a thi $n$ rod with fl agging to determine the maxi mumvel ocity vector if water cl arity uas good. If water cl arity was poor, we set the meter to i nstantaneous readi ngs and sl ow y rotated the probe to determine the vector of maxi mum vel ocity. To neasure the angl e of the maxi mum vel oci ty vect or rel ati ve to the drumscreen, we i ncorporated a modified protractor onto the meter pole (Figure 6). 


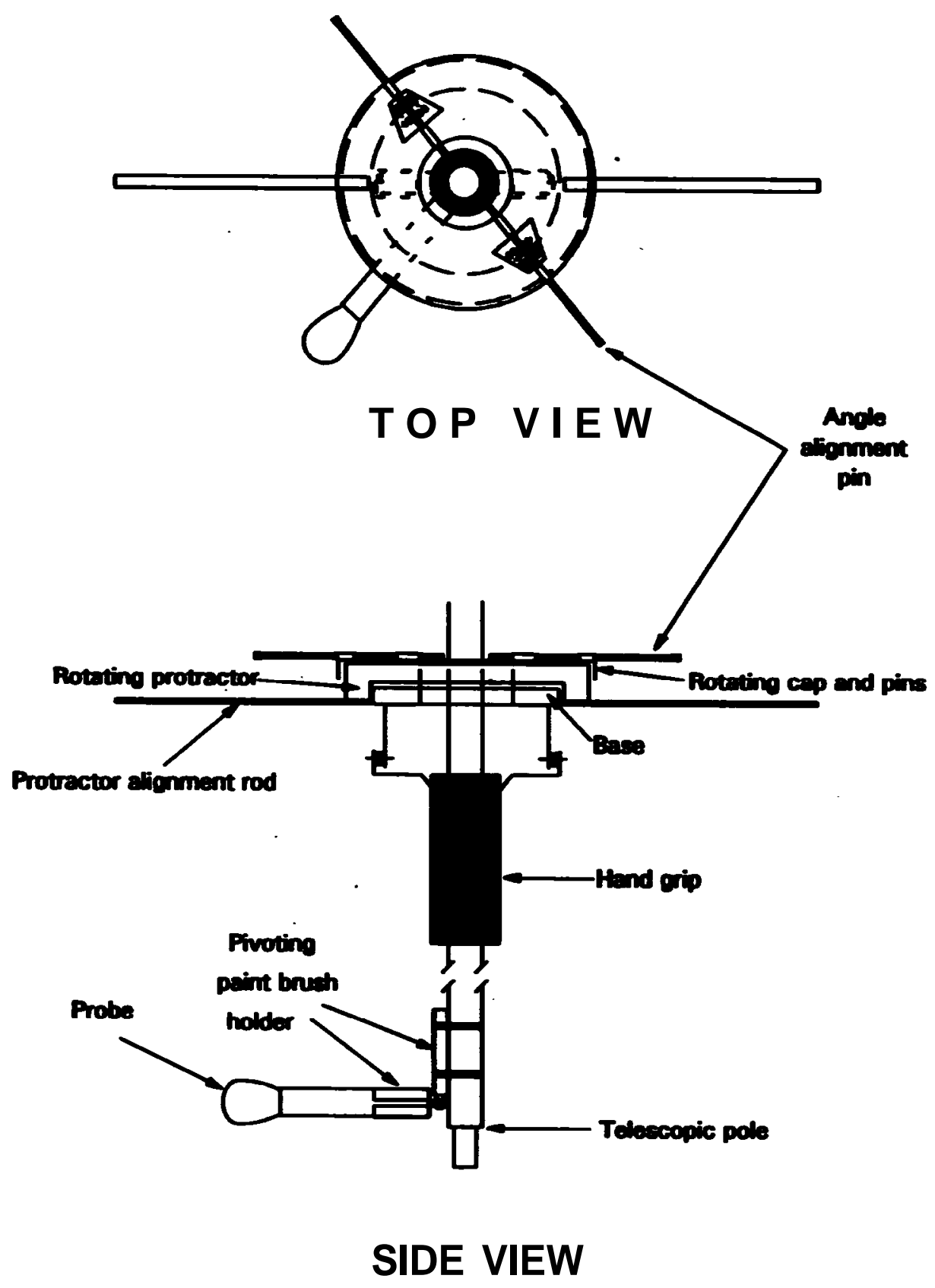

Fi gure 6. Devi ce used with an el ectromanetic uater vel oci ty meter - to measure the angle of the maxi mum vel ocity vect or in front of screens and di ffusers at fish passage facilities on the I over Unatilla River, Oregon. 
Measurements at the bypass channel entrance uere taken midchannel at $20 \%$ $50 \%$ and $80 \%$ of water depth, The probe was poi nted i nto the maxi mum vel oci ty vect or which was usual ly 90 to the bypass entrance.

We neasured water vel oci ty i $n$ front of the bel $t$ screen at West Extensi on Canal duri ng varyi ng pumpback operati ons i ncl udi ng operati on of Pump 1, Pump 2 , both pumps, and $20 \%, 30 \%$ and $40 \%$ openi ngs of the pumpback bay drai $n$ pi pe. Measurenents vere col lected at $20 \% \quad 50 \%$ and $80 \%$ of the wat er depth al ong three vertical transects. Transects were l ocated at the middle of the screen and $0.3 \mathrm{mfrom}$ the upstream and downstreamedges of the screen. We used the rod with fl agging to determine the vector of maxi mum vel ocity at $20 \%$ of water depth. Turbulence at $50 \%$ and $80 \%$ of water depth prevented us from fi ndi ng the maxi mum vel oci ty vect or usi ng i nstant aneous met er readi ngs. As an al ternative, ue rotated the-probe until the force of the water current on the probe assenbl y uas mi ni zed.

Ye used tri gononetri c functions to cal cul ate water vel oci ty perpendi cul ar (approach) and paral l el (sweep) to screens. Resul tant approach and sweep vel oci ti es were cal cul ated from the measured vel ocity and angle of maxi mum vel oci ty converted to radi ans such that

$$
\text { approach vel ocity }=\operatorname{SIN}\left[\frac{\pi}{180}(\theta)(V)\right]
$$

and,

$$
\text { sueep vel ocity }=\cos \left[\frac{\pi}{180}(\theta)(v)\right]
$$

where COS was the Cosi ne function, SI $N$ was the Si ne function, $\pi$ was the constant pi (3.14), $\theta$ was the angl e of maxi mumflow to the screen face (i degrees), and $V$ was the uater vel ocity measured.

Accuracy of drum screen vel ocity measurenents was checked by comparing canal fl ow esti nated from the vel ocity data to fl ow data recorded at Or egon Whter Resource Departnent (ORD) gaugi ng stations. Fl ow through each screen was cal cul ated as the product of mean screen approach vel ocity, ef fecti ve screen l ength, and subnerged screen depth.

Vel ocity measurenents col l ected at I ow canal f I ow di d not adequatel y assess adherence to approach vel ocity criteria. Ther ef ore, approach vel ocity neasurenents uere expanded to esti mate approach vel oci ty at the hi ghest canal fl ous expected when sal mon fry are present (March - Hay). We revi ewed fl ow data from 1992 to 1996 to esti mate the hi ghest canal floys expected in March through Hay at West Extensi on (3.4-m/s), Haxwel1 (1.1 m/s), Uest I and (7. 1 $\left.\mathrm{m}^{3} / \mathrm{s}\right)$, Feed $\left(6.9 \mathrm{~m}^{3} / \mathrm{s}\right)$ and Furni $\mathrm{sh}\left(3.4 \mathrm{~m}^{3} / \mathrm{s}\right)^{\prime}$ canal $\mathrm{s}$. The for mul a for expandi ng approach vel ocity measurenents $\left(A V_{m}\right)$ to est i mate approach vel oci ty at the hi ghest canal fl ow expected from March through My $\left(A V_{e}\right)$ was 


$$
A V_{e}=\frac{\left(A V_{m}\right)\left(F_{\text {max }}\right)(C F)}{F_{\text {act }}}
$$

where Fmax was the hi ghest expected canal fl ow from March through May, Fact was the actual canal fl ow at the ti me vel ocity neasurenents were collected (OWRD gauge reading), and CF was a correcti on fact or that compensated for i naccuracy of vel ocity measurenents.

The formul a for cal cul ating CF was

$$
\mathrm{CF}=\frac{F_{\mathrm{act}}}{F_{\mathrm{e}}}
$$

where Fe was the canal fl ow esti mated from vel oci ty data.

\section{Ladder}

We neasured water vel ocity in front of Diffusers 1 and 2 insi de the fi sh I adder at Three MI e Fal Is Dam to suppl enent i nf or mati on on fi sh i nj ury and travel rate associ ated with these structures. Col l ecti on of vel oci ty neasurements at diffusers foll owed the sampling protocol used at bypasses with the fol I owing excepti ons. At Diff user 1, measur enents were taken approxi matel y $150 \mathrm{~cm}$ in front of the diffuser al ong verti cal transects l ocated at $16.7 \% 33.3 \% \quad 50.0 \% \quad 66.7 \%$ and $83.3 \%$ of the di ff user I ength. At Di f f user 2 , neasurenents were taken downstream of the baffl es, approxi nat el y $150-230 \mathrm{~cm}$ in front of the diffuser. Vertical transects were located at $25 \% 50 \%$ and $75 \%$ of the length of the east and west panel s. Transect sampl ing dept hs at Di f f users 1 and 2 were $20 \% 50 \%$ and $80 \%$ of water depth. Locati on of the maxi mum vel ocity vect or at $D$ iff users 1 and $2 \mathrm{fol} l$ owed nethods descri bed for vel ocity measurements in front of drum and bel $t$ screens, respecti vel y. Fi sh exi $t$ gates ( $\mathrm{infl}$ ow) vere $55 \%$ open when we measured water vel ocity i $n$ front of Diffuser 1 .

We cal cul ated water vel oci ty perpendi cul ar (approach) and paral I el ( sweep) to the diffusers using the vel oci ty measurenents and angle of maxi mum vel oci ty vector. Computati on of approach and sweep water vel oci ty fol I oved the formul a used for water vel oci ty measurenents col lected in front of drum and bel $t$ screens.

\section{Injury}

\section{Stati sti cal Anal ysi s}

Parametri c pai red $t$-tests were used to test the nul I hypothesi s that nean net- wei ghted i nj ury for treat ment mi nus control uas si gni fi cantl y greater than zero. Pai ring of repl i cate treat ment and control groups was based on common rel ease ti mes. For tests wi th nore than one treatment (upper bypasses and passage secti on of Three M le Fal Is Damfi sh I adder), downstream treat ment rel eases were used as the control for upstream treatnent rel eases. We used a si gni fi cance I evel (a) of $\leq 0.10$ (one-tai led) for al I tests. 


\section{Travel Rate and Recapture}

St at i sti cal compari sons were conducted on groups of fi sh rel eases that shared common test tí nes. Paranetric i ndependent $t$-tests were used for stati sti cal anal ysi s of si ngl e compari sons of $50 \%$ travel ti me, nedi an travel speed, and percent recapt ure. We used anal ysi s of vari ance for nore than one comparison. We tested the nul I hypothesi s that differences in mean $50 \%$ travel ti me, medi an travel speed, or percent recapt ure of $f i$ sh rel eased at two or more than tuo l ocati ons were not si gni fi cantly different. Ye used a si gni ficance I evel (a) of $\leq 0.05$ (tuo-tailed) for nost tests. Ye used a one$t a i l$ ed test of si gni fi cance for compari sons of $50 \%$ travel $t i$ ne and percent recapt ure of $f i$ sh rel eased upstream and downst ream of the headgat es because ue assuned the headgates nould interrupt fish passage into the canal.

\section{RESULTS}

$$
\text { Injury }
$$

Bypass

Fi sh bypass facilities at i rrigati on canal s on the I ower Unatilla Ri ver uere hi ghl y effecti ve at ret urni ng juveni l e sal moni ds back to the ri ver unharned. The difference in i nj ury rates bet ween treatment and control fi sh uas not si gni ficantl y greater than zero in 26 of 28 i nj ury tests (Fi gures 7 and 8). Si gni fi cant i nj ury was detected i $n$ the ni ght ti ne screen i nj ury test conducted at Uest Extensi on Canal with subyearli ing fal I chi nook sal non ( $P$ = 0. 006) and the facility i nj ury test conducted at Feed Canal with yearling spring chi nook sal mon ( $P=0.01)$. Fal I chi nook sal mon that passed the screens at West Extensi on Canal at ni ght had an 8. 2\% hi gher rate of parti al descal i ng than control fish. However, $59 \%$ of the di f fer ence i $n$ i nj ury bet ween treat nent and control fish was a result of bi ased pre-test subsampling of control i nj ury. Subsampl ing bi as was evi denced by the negati ve val ue for net- uei ght ed i nj ury ( $\mathrm{NU}$ ) cal cul ated for controls. Spri ng chi nook sal non that passed by the screens and through the downuel I, bypass pi pe, and outl et at Feed Canal had a 12 . 3\% hi gher rate of I ow partial descaling and a $3 \%$ hi gher rate of ful I descal ing than control fish.

Outfal I and downuel I i nj ury tests at W'st Extensi on Canal uere I ess preci se than tests conducted in upper bypasses (Fi gures 7 and 8). The mean mi nim di fference in treat ment and control i nj ury requi red for si gni fi cance (a - 0.10) i n outfal I and downuel I i nj ury tests was 8.1 NWI uni ts compared with a mean of $3.0 \mathrm{NW}$ uni ts for tests conducted in upper bypasses. Even with thi s constrai nt, resul ts were nearl y si gni fi cant i n outfal I i nj ury tests conducted with subyearling fall chi nook sal non at a bypass fl ow of $0.14 \mathrm{~m}^{3} / \mathrm{s}$ $(P$ - 0.16$)$ and $0.71 \mathrm{~m} / \mathrm{s}(P=0.12)$, i $n$ outfal I jnjury tests conducted wi th spring chi nook sal mon at a bypass fl ow of $0.14 \mathrm{~h}^{\prime} / \mathrm{s}$ '( $\left.\mathrm{sP}=0.19\right)$, and i $\mathrm{n}$ the hi gh- pool downuel I i nj ury test conducted with spri ng chi nook sal non at a bypass fl ow of $0.14 \mathrm{~m} / \mathrm{s}(P=0.14)$. Probabilities $(P)$ were greater than 0.62 i $n$ al I ot her outfal I and downuel I inj ury tests. Inj uries were nost severe to fal I chi nook sal mon i $n$ outfal I i nj ury tests; treat ment i nj ury was greater than

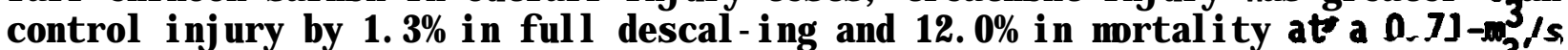
bypass fl ow and by $9.4 \%$ in ful I descal ing and $2.6 \%$ i n nortal ity at a $0.14-\mathrm{m}^{3} / \mathrm{s}$ bypass flow For spring chi nook sal non, treat nent i nj ury was greater than 


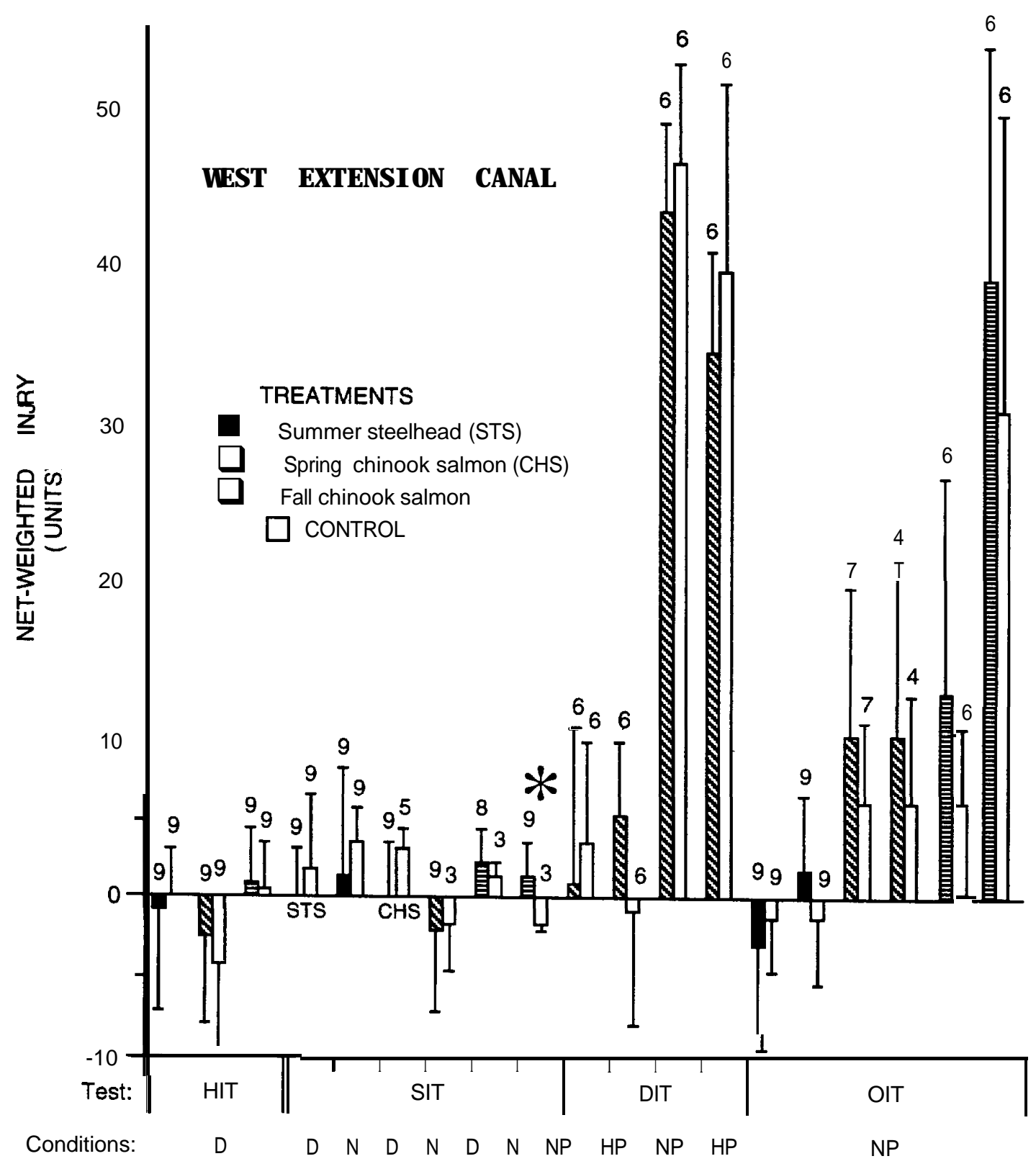

Bypass Flow $\left(\mathrm{m}^{3} / \mathrm{s}\right)$ :

$\begin{array}{llllllllll}.14 & .14 & .71 & .71 & .14 & .71 & .14 & .71 & .14 & .71\end{array}$

Fi gure 7. Mean net-wei ghted i nj ury i ncurred by treatment ( fi ll ed bars) and control (open bars) fish in varying segnents of the bypass facility at West Ext ensi on Canal, Unat i I l a Ri ver, Oregon. Sampl e si zes and si gni fi cant compari sons $(*)$ are shown above SD error bars. Tests, rel evant test conditi ons, and bypass fl ous are shown bel ow the graph ( H T = headgate i nj ury test, $S I T=$ screen i nj ury test, $D T=$ downuel I i nj ury test, $\mathbf{Q} T=$ outfal I i nj ury test, $D=$ day rel ease, $N=$ ni ght rel ease, $N P=$ nor mal downuel I pool dept $h, \mathbf{H}=$ hi gh downuel I pool depth). 


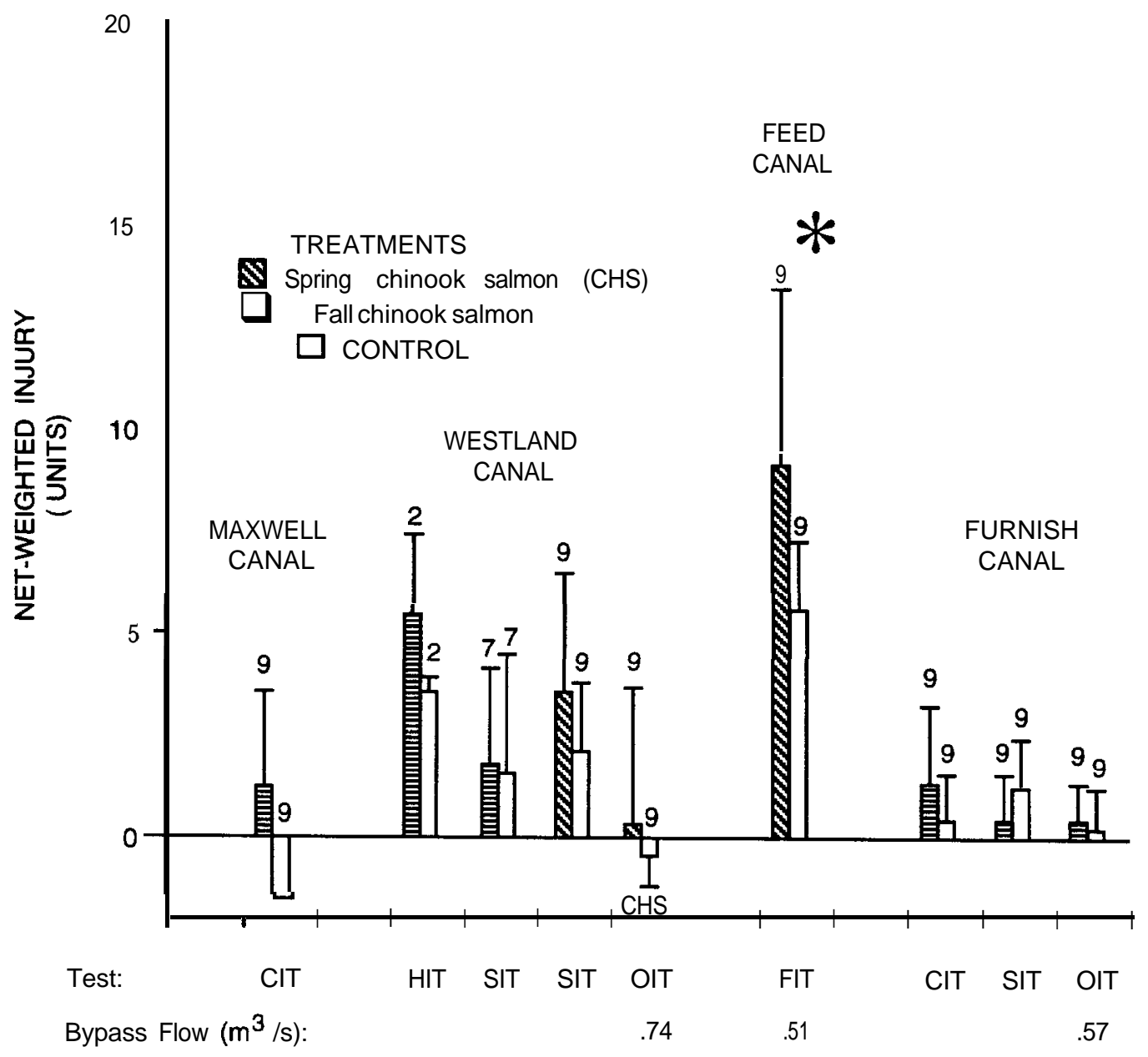

Fi gure 8. Mean net- wei ghted i nj ury i ncurred by treat ment ( fill ed bars) and control (open bars) fish in varying segnents of the bypass facilities at Maxuel I, Westl and, Feed, and Furni sh canal s, Unati I I a Ri ver, Oregon. Sampl e si zes and si gni fi cant compari sons $(*)$ are shown above SD error bars. Tests, rel evant test condi ti ons, and bypass fl ows are shown bel ow the graph $(\mathrm{Cl} T=$ canal i nj ury test, $\mathrm{HT}=$ headgate i nj ury test, $\mathrm{SI} T=$ screen i nj ury test, $\mathbf{O} \mathrm{T}=$ outfal I inj ury test, FIT = facility injury test). 
control i nj ury by $9.0 \%$ partial descaling and $0.4 \%$ ful I descal ing in the outfal I i nj ury test at a $0.14-\mathrm{m}^{3} / \mathrm{s}$ bypass fl ow and $16.3 \%$ parti al descal i ng i the hi gh-pool downuel I i nj ury test at a $0.14-\mathrm{m} / \mathrm{s}$ bypass $\mathrm{fl}$ ow

Accuracy of i nj ury tests i mproved when subsampl ing rates for pre-test condi ti on were i ncreased. Negati ve val ues for net-uei ghted inj ury occurred in $40 \%$ of the tests conducted at West Extensi on and Westl and canal s when subsampling rates were $10 \%$ and $30 \%$ When $100 \%$ of the test fi sh were eval uated for pre-test i nj ury, negative i nj ury rates decreased to $12 \%$ In I atter tests, negative i nj ury rates occurred onl y when post-test inj ury was l ow

Scal e I oss was the predomi nant i nj ury recorded duri ng bypass i nj ury tests. "Other" i nj uries recorded during tests uere attributed to preexisting inj uries. Mrtality associ ated with fi sh bypass facilities was $0.0 .4 \%$ in al I tests except the outfal I inj ury test with subyearling fall chi nook sal non at West Extensi on Canal $(0.12 \%)$.

\section{Ladder}

J uveni I e sal noni ds passed saf el y through smal l er adul t fi sh I adders on the I over Unati I I a Ri ver, but not at I arger I adders. Subyearling fal I chi nook sal non i ncurred si gnificant inj ury in the passage section of the $\mathrm{fi}$ is I adder at Three MIe Fal Is Dam during I ow fl ow operations and in the auxiliary uater secti on of the fi sh I adder at West I and Dam duri ng hi gh f I ow operati ons ( Fi gure 9) .

I nj ury to subyearling fal I chi nook sal mon was significant in the passage secti on of the fish I adder at Three MIe Fal Is Dam in segments with and wi thout diffuser panel s $(P=0.04$ and $P=0.001$, respectivel y; Fi gure 9). Total i nj ury to fall chi nook sal mon in the enti re passage section of the I adder was 2.5\% moderate parti al descal ing, 19. $2 \%$ ful I descal ing, and $3.2 \%$ mortality. The secti on with diffusers accounted for $66 \%$ of the total descal ing inj ury, whereas $78 \%$ of total nortality was attributable to the segnent of the I adder downstream of the diffusers. In contrast, yearling spring chi nook di not i ncur si gnificant inj ury in the passage section of the fi sh I adder $(P=0.32)$. Inj ury to treatment fi sh passi ng through the auxi I iary water system of the fish I adder at Three M I e Fal Is Dam was not si gni fi cant for $f$ al $I$ chi nook sal mon $(P=0.81)$ and spri ng chi nook sal mon ( $P>$ 0.50) rel ati ve to control inj ury.

Subyearling fall chi nook sal mon passing through the auxiliary water system of the fi sh I adder at West I and Dam recei ved si gni fi cant i nj ury ( $P$ = $0.05)$, whereas fi sh novi ng through the passage secti on di $d$ not $(P=0.50$; Figure 9). Treat ment $\mathrm{fi}$ sh in the auxi I i ary water system incurred greater I ow parti al descaling $(7.6 \%$, noderate partial descaling $(3.1 \%$, and ful I descal ing ( $1.4 \%$ ) than control fish.

I nj ury uas not si gnifi cant for test fi sh passing through fi sh I adders at Feed Canal $\operatorname{Dam}(P=0.13)$ or St anf i el d $\operatorname{Dam}(P=0.40$; Fi gure 9). Treat nent i nj ury was greater than control i nj ury at Feed Canal Dam by 4. $0 \%$ i n noderate parti al descal ing and $0.5 \%$ in ful $\mathbf{l}$ descal i ng. At Stanfi el d Dam treat nent i nj ury was greater than control i nj ury by $0.4 \%$ l ow parti al descal ing, $1.7 \%$ noderate partial descaling, and $0.6 \%$ ful I descaling. 


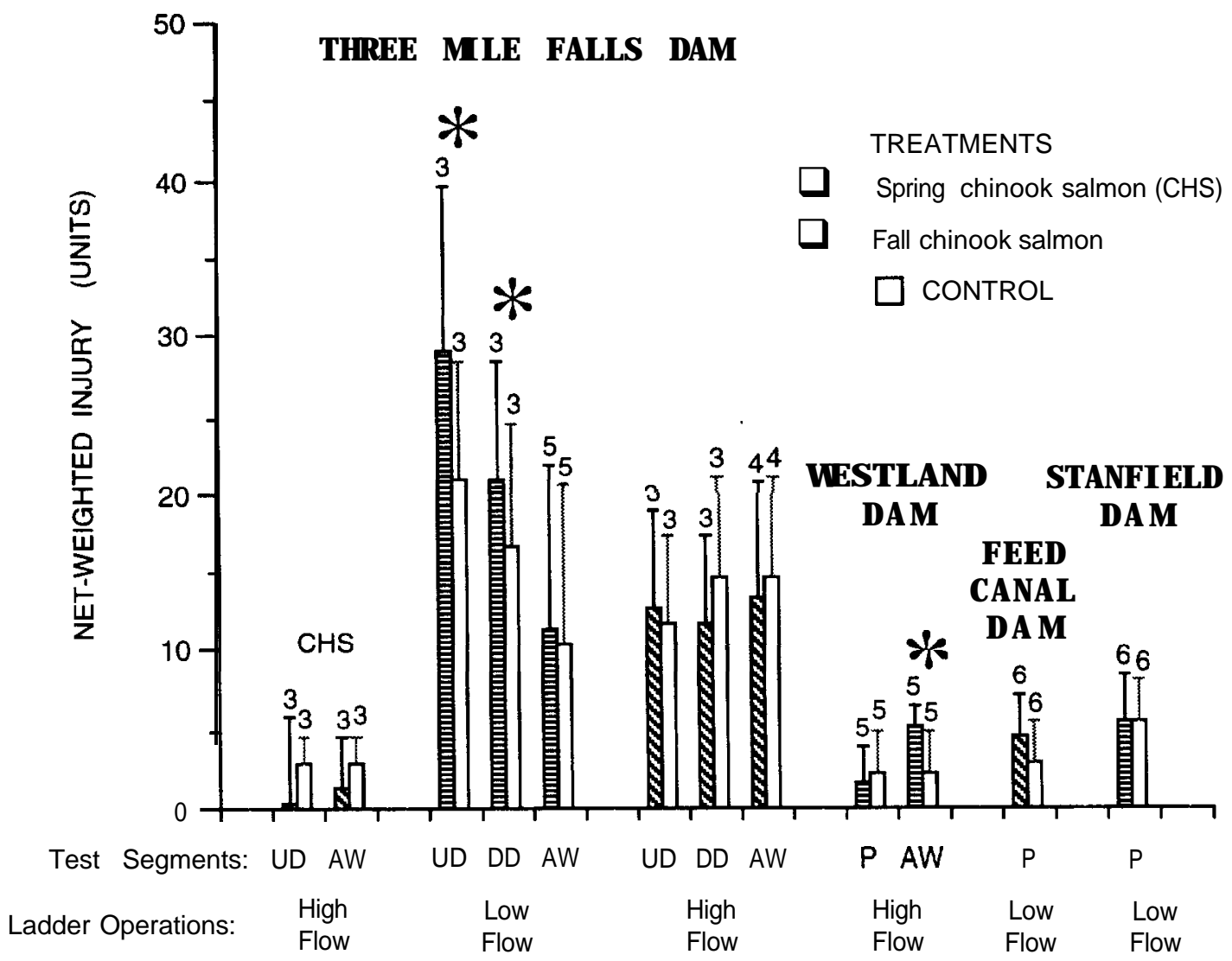

Fi gure 9. Mean net- wei ght ed i nj ury i ncurred by treat nent (filled bars) and control (open bars) fish in varying segments of fish I adders at Three MIe Fal I s, Westl and, Feed Canal, and Stanfi el d dans, Unati I la Ri ver, Oregon. Sampl e si zes and si gni fi cant compari sons $(*)$ are shown above SD error bars. Tests segnents and I adder operati ons are shown bel ow the graph (UD = upstream of diffusers, $A W=$ auxi I $i$ ary water system $D D=$ downstream of di ffusers, $P=$ passage section). 
Scal e I oss was the predom nant i nj ury recorded duri ng I adder i nj ury tests. "Other" i nj uri es were rarely observed. Onl y at Three MIe Fal Is Dam was nortal ity associ ated with passage through fi sh l adders.

\section{Travel Rate and Recapt ure}

\section{Bypass}

Test fish rel eased in the upper portion of $f i s h$ bypass facilities travel ed di stances of 32- 2, 410 m under varyi ng physi cal condi ti ons (Tabl e 4). Fi sh were rel eased in the day, eveni ng, or ni ght, and at canal wi thdrawal s of 17-94\% of maxi mum canal fl ow

Medi an travel ti me and travel speed of subyearling fal l chi nook sal mon rel eased upstream of the drumscreens at Furni sh Canal ( $0.6 \mathrm{~h}, 62 \mathrm{~m} / \mathrm{h})$ was si gni fi cantl y di fferent from those rel eased downst ream of the headgat es ( 2.0 $h$, $485 \mathrm{ndh}$; $P<0.05$ ) when canal wi thdrawal s averaged $54 \%$ of maxi mum $\mathrm{fl}$ ow At Maxuel I Canal, medi an travel speed for fal I chi nook sal mon passi ng through the headworks canal was $831 \mathrm{~m} h$ when canal fl ow was 23-48\% of maxi mum fl ow Fal I chi nook sal non rel eased short di stances upstream of screening faci $\mathrm{i}$ ti es at West Extensi on and West l and canal s travel ed onl y 5- $65 \mathrm{~m}$ h hen canal wi thdraul s averaged $68 \%$ and $71 \%$ of naxi mum $\mathrm{f} I$ ow respect $i$ vel $y$.

At West Extensi on Canal, nedi an ( $50 \%$ travel ti mes for treat nent fi sh rel eased upst ream of the headgat es were si gni fi cantl y sl over compared wi th control s rel eased upstream of the drumscreens for sumer st eel head $(P<0.01)$ and subyearling fall chi nook sal non $(P<0, \mathbf{Q})$, but not spring chi nook sal mon ( $P$ > 0. 10; Tabl e 4). Percent recapt ure of sumer steel head, spri ng chi nook, and $f$ al $I$ chi nook sal mon rel eased upstream of the headgat es was si gni $f i$ cant I $y$ I ower ( $P$ < 0.05$)$ compared with control s (Tabl e 4$)$. Mean $50 \%$ travel ti me and percent recapt ure for al I speci es of test fi sh rel eased upstream of the headgat es was 26.3 hours and $57.4 \%$ compared wi th 6.8 hours and $66.0 \%$ for $f i$ sh rel eased upstream of the drum screens, respecti vel $y$.

Travel ti ne and speed di d not appear to be associ at ed with canal fl ow when $f i s h$ were rel eased downstream of the headgates. Medi an travel speed for subyearling fal I chi nook sal mon was sl ower at Furni sh Canal ( $485 \mathrm{~m} / \mathrm{h}$ ) than Mexuel I canal ( $831 \mathrm{~m} / \mathrm{h})$, even though canal fl ow was slightly hi gher at Furni sh Canal. Medi an ( $50 \%$ travel ti mes for subyearl ing fal l chi nook and yearl i ng spri ng chi nook sal non rel eased upstream of the drumscreens at Westl and Canal were nearly equal, even though canal fl ow was more than three ti mes hi gher duri ng tests with fal I chi nook sal non (Table 4).

Medi an travel ti me for fall chi nook sal non rel eased downstream of the headgates at Maxuel I Canal was not si gnifi cantly different anong day, eveni ng, or ni ghtti me rel ease groups ( $P>0.19$ ). However, percent recapt ure of the day rel eased group uas si gni fi cant ly l ouer than the eveni ng and ni ght rel eased groups $(\mathrm{P}<0.05)$. In tests conducted at West Ext ensi on Canal i n 1991, nedi an travel ti ne of treat nent $f i$ sh rel eased upstream of the drum screens was si gnificantly faster at ni ght compared with thei $r$ dayti me novenent for fal I chi nook sal mon ( $P<0.05)$, but not for spring chi nook sal non or sumer steel head ( $P$ > 0. 05; Hyes et al. 1992). 
Table 4. Travel ti me (mean hours to recapt ure 50 percent and 95 percent of test fi sh rel eased) and percent of fish recaptured by the end of testing at the five maj or i rrigation canal s on the I ower Unatilla River,

Oregon.

\begin{tabular}{|c|c|c|c|c|c|c|c|c|c|c|}
\hline $\begin{array}{l}\text { Medi an } \\
\text { test }\end{array}$ & Release & $\begin{array}{l}\text { Travel } \\
\text { di stance }\end{array}$ & $\begin{array}{l}\text { Canal } \\
\text { flow }\end{array}$ & $\begin{array}{l}\text { Percent } \\
\text { maxi mum } \\
\text { canal }\end{array}$ & $\begin{array}{l}\text { Bypass } \\
\text { f jow }\end{array}$ & & $\begin{array}{l}50 \% \text { travel } \\
\text { ti me (hours) } \\
\text { ti (hour }\end{array}$ & $\begin{array}{r}95 \% \text { tra } \\
\text { ti me (ho }\end{array}$ & $\begin{array}{l}\text { ele } \\
\text { urs) }\end{array}$ & $\begin{array}{l}\text { Percent } \\
\text { recapture }\end{array}$ \\
\hline date Species ${ }^{\mathrm{a}}$ ti me & $b$ & (m) & $\left(m^{3} / s\right)$ & fl ow & $\left(\mathrm{m}^{3} / \mathrm{s}\right)$ & $\mathbf{N}$ & Mean SD & Mean & SD & Mean SD \\
\hline
\end{tabular}

West Extensi on Canal fi sh bypass facility

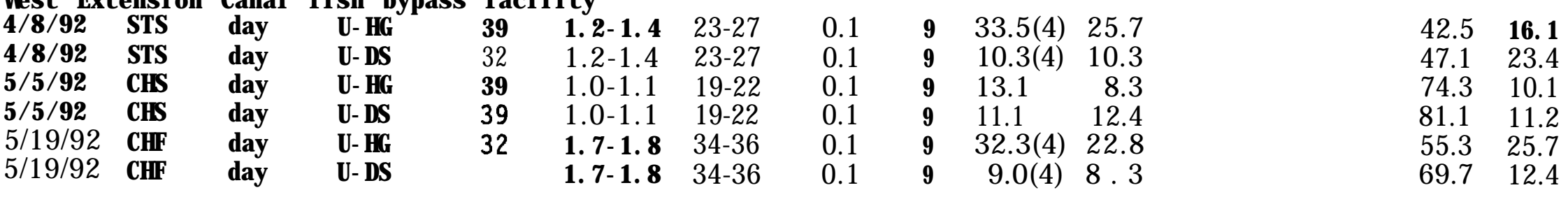

w Maxuel I Canal fish bypass facility

\begin{tabular}{|c|c|c|c|c|c|c|c|c|c|c|c|}
\hline $\begin{array}{l}5 / 13 / 93 \\
5 / 13 / 93 \\
5 / 13 / 93\end{array}$ & $\begin{array}{l}\text { CHF } \\
\text { CFF } \\
\text { CHF }\end{array}$ & $\begin{array}{l}\text { day } \\
\text { eveni ng } \\
\text { ni ght }\end{array}$ & $\begin{array}{l}\text { D. HG } \\
\text { D. HG } \\
\text { D. HG }\end{array}$ & $\begin{array}{l}2,410 \\
2,410 \\
2,410\end{array}$ & $\begin{array}{l}0.4-0.8 \\
0.4-0.8 \\
0.4-0.8\end{array}$ & $\begin{array}{l}23-48 \\
23-48 \\
23-48\end{array}$ & $\begin{array}{l}0.3 \\
0.3 \\
0.3\end{array}$ & 3 & $\begin{array}{l}3.6 \\
2.6 \\
2.6\end{array}$ & $\begin{array}{l}0.8 \\
0.6 \\
0.7\end{array}$ & $\begin{array}{l}70.3 \\
85.7 \\
80.3\end{array}$ \\
\hline
\end{tabular}

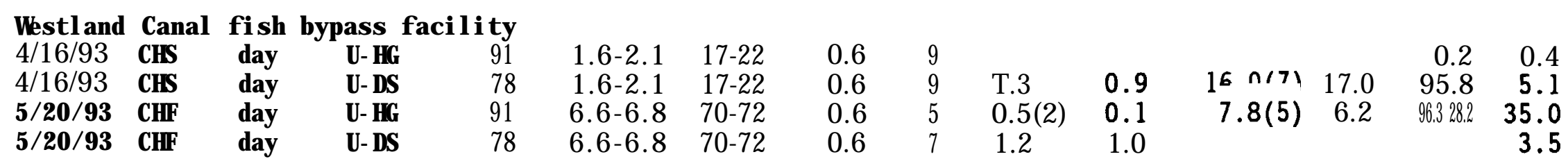

Feed Canal fish bypass facility

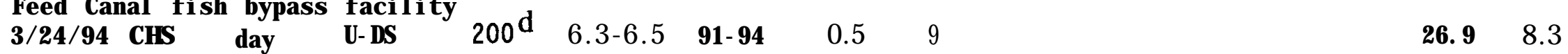

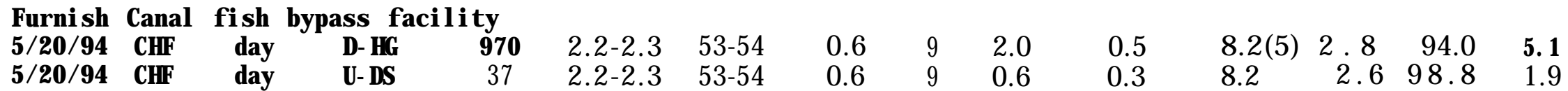

aSTS = summer stedhead CHS =spring chinook salmon, CHF = subyearling fall chinook salmon.

bU-HG = upstr eam of headgates, U-DS =upstream of drum screens, D-HG =downstr eam of headgat es.

$\mathcal{C}(N)$ given in parentheses, designates the number of test replicates that reached $50 \%$ or $95 \%$ recapture.

$\mathbf{d}$ Test fish were recapt ured at the bypass outlet instead of the cburell. 
The si ngl e bypass pi pe desi gn of the I ouer. hypass at Furni sh Canal passed subyearli ing fal I chi nook sal non qui ckl y $\left(0.57-\mathrm{m}^{3} / \mathrm{s}\right.$ bypass fl ow Fi gure 10$)$. Fi fty-t no percent of the fish rel eased at the bypass wei $r$ were recapt ured at the out l et wi thi $n$ 0. 05 hours; 97\% were recapt ured wi thi $n 1.2$ hours, af ter wards no addi ti onal fi sh were recapt ured. Medi an travel speed through the I ower bypass at Furni sh Canal $(2,800 \mathrm{~m} / \mathrm{h})$ was more than three ti mes faster than travel rates through headuorks canal s at Furni sh (485 $\mathrm{m} / \mathrm{h}$ ) and Maxuel I ( 831 mh) canal s.

The coupl ed bypass- drai $n$ pi pe desi gn of the I ower bypass at West I and Canal appeared to del ay novement of yearling spring chi nook sal mon even though bypass fl ow was $0.74 \mathrm{~m} / \mathrm{s}$. Approxi natel y hal $\mathrm{f}(47 \%)$ of the test $\mathrm{fi}$ sh travel ed through the l ower bypass at a speed of $533 \mathrm{mdh}$ and were recapt ured wi thi $\mathrm{n} 0.4$ hours (Figure 10). Further collection of $\mathrm{fish}$ uas protracted and conti nued for nore than three hours after rel ease. Onl y $76 \%$ of the test $\mathrm{fish}$ were recapt ured at the concl usi on of testing.

At West Extensi on Canal, the bypass pi pe and energy-di ssi pating desi gn of the I ower bypass channel qui ckl y passed onl y subyearling fal I chi nook sal non when bypass fl ow was $0.71 \mathrm{~m} / \mathrm{s}$ (Fi gure 10). Ni nety-t no percent were recapt ured in 0.5 hours. Thi s was si milar to the rapid travel of $f$ al I chi nook sal non through the I ower bypass at Furni sh Canal. Recapt ure decreased for I arger-sized $\mathrm{fi}$ sh and at I ower bypass fl ous. Recapt ure for fal I chi nook sal non, spri ng chi nook $s$ ąl non, and summer steel head after 0.5 hours was $92 \%$, $16 \%$ and $14 \%$ at a $0.71-\mathrm{m}^{3} / \mathrm{s}$ bypass fl ow and $17 \% \quad 13 \%$ and $0.5 \%$ at a $0.14-\mathrm{m}^{3} / \mathrm{s}$ bypass fl ow respecti vel y.

\section{Ladder}

Test fi sh travel ed qui ckly through the fi sh I adders at Stanfield and Feed Canal dans and the passage secti on of the fi sh I adder at Westl and Dam At these I ocati ons, greater than $90 \%$ recapt ure was reached in I ess than one hour; addi ti onal recapt ures mere not recorded after $\mathbf{1 . 5}$ hours (Figure 11). Travel was sl ower through the auxi I $i$ ary water secti on of the $f i$ sh I adders at Three M I e Fal I s and West l and dans. Approxi matel y 50-65\% of the fi sh rel eased i n the auxiliary water systens nere recaptured after one hour; addi ti onal recapt ure was protracted (Fi gure 11). Fi nal cumil ati ve recapt ure of treat ment fish passing through auxiliary water systens at the concl usi on of testing was $82 \%$ or subyearling fal I chi nook sal non and $54 \%$ for spri ng chi nook sal non at Three M I e Fal I s Dam and $66 \%$ for fal I chi nook sal mon at Westl and Dam Recapt ure was protracted for fi sh rel eased upstream of Diff user 1 in the passage secti on of the $f i$ sh I adder at Three MI e Fal Is Dam Recapt ure of spri ng chi nook and fal I chi nook sal mon rel eased upstream of Di ffuser 1 was $18 \%$ and $25 \%$ at the end of the testing.

Screen Effi ci ency and I mpi ngenent

\section{Drum Screens}

Mean drum screen ef $\mathrm{i}$ ci ency exceeded $99.7 \%$ at West Extensi on, West I and, Feed, and Furni sh canal s (Table 5). Canal wi thdrawal s during testing were approachi ng maxi mum desi gn fl ow at Feed and Furni sh canal $s$ and were I ess than 


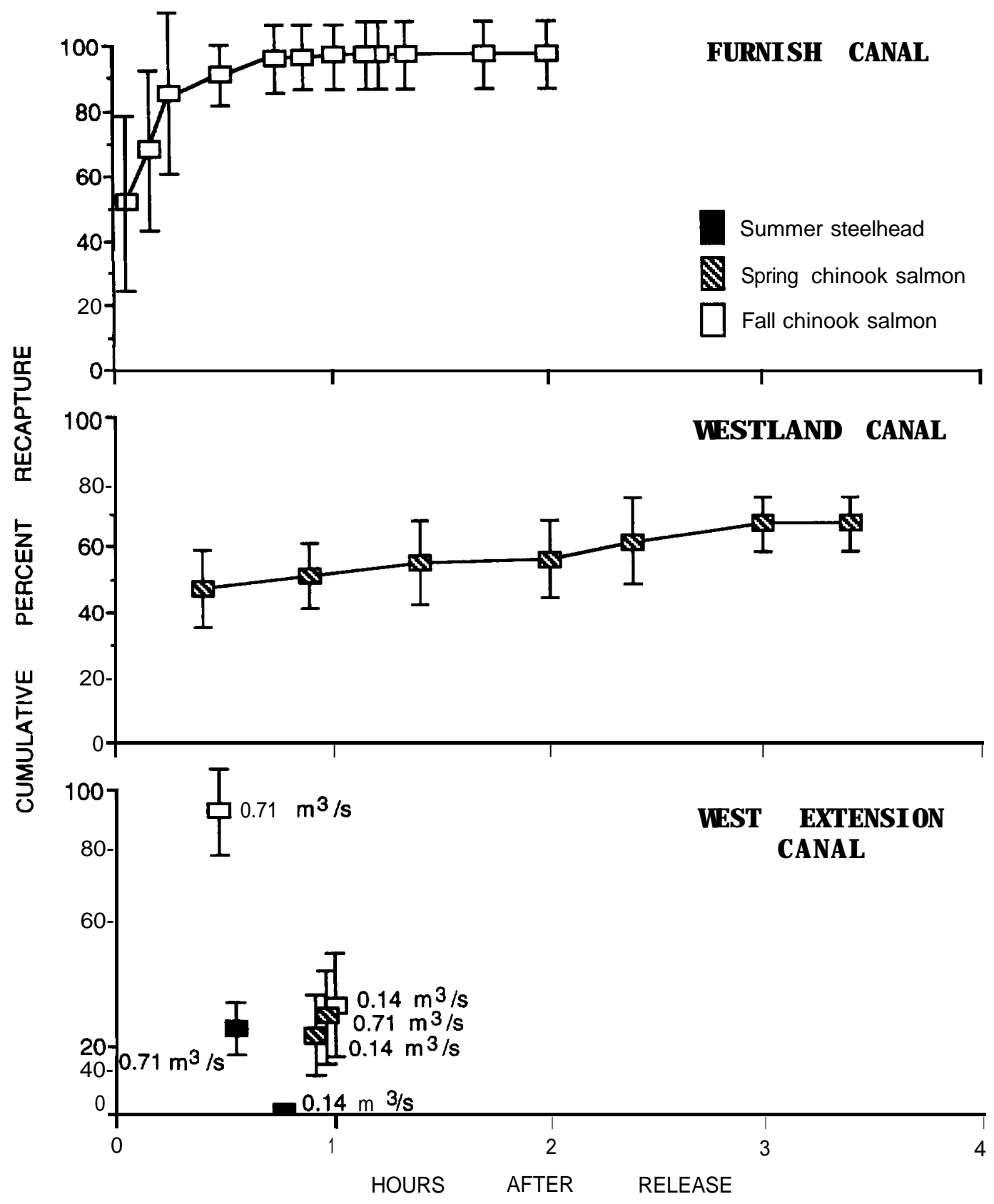

Fi gure 10. Cumul at i ve percent recapt ure (mean and SD) of treat ment fi sh rel eased during i nj ury tests conducted i $n$ the I over porti on of $f i$ sh bypass facilities at Furni sh, Westland, and West Extensi on canal s, Unatilla Ri ver, Oregon. Bypass flow $(\mathrm{m} / \mathrm{s})$ is shown for tests conducted at West Extensi on Canal. 

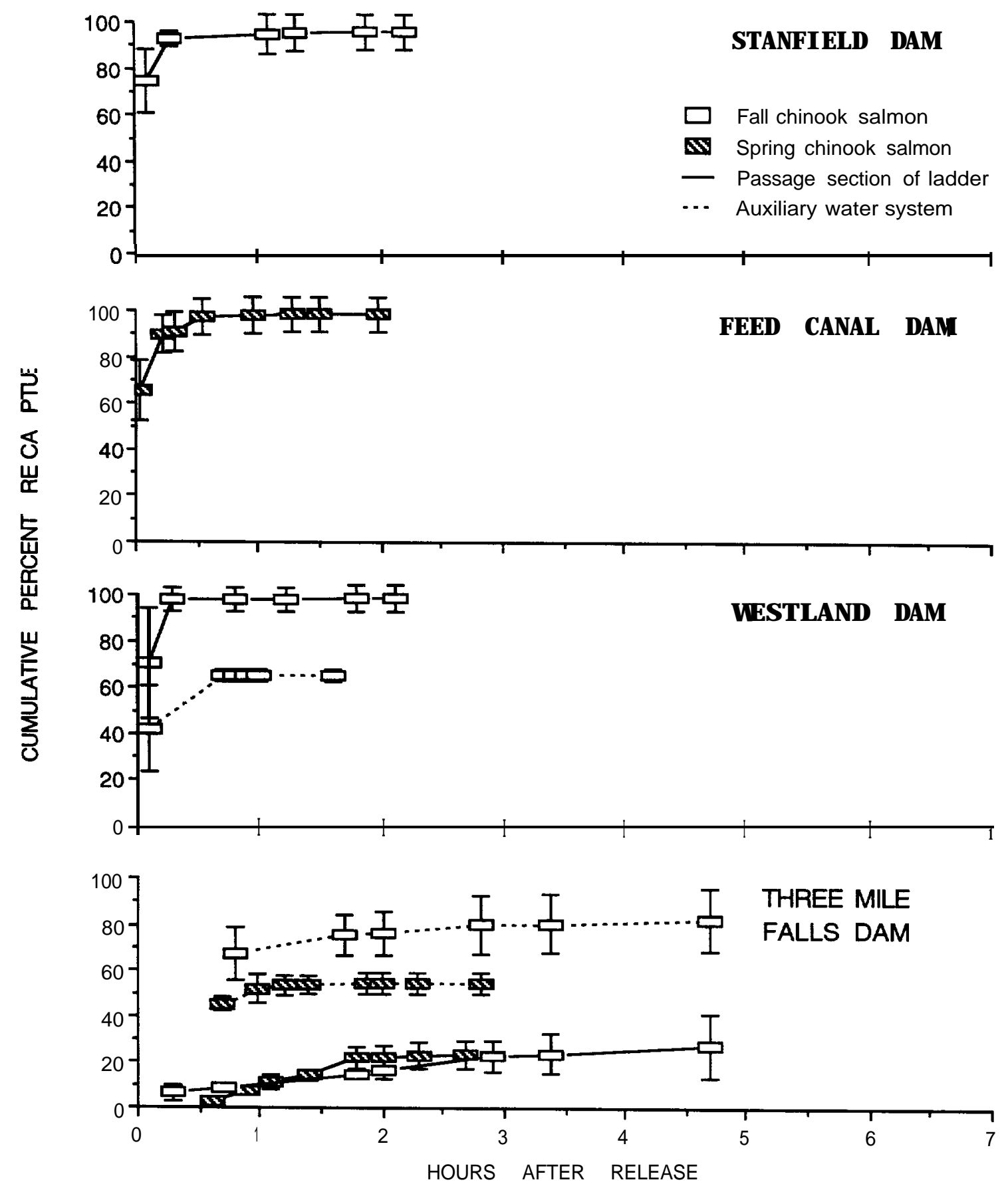

Fi gure 11. Cumul ati ve percent recapt ure (mean and SD) of treatment fi sh rel eased during i nj ury tests conducted in the passage and auxi I i ary water secti ons of $\mathrm{f} i \mathrm{sh}$ I adders at Stanf $\mathrm{i}$ el d, Feed Canal, Westl and, and Three M I e Fal Is dans, Unatilla Ri ver, Oregon. 
Table 5. Test fish rel ease and recapt ure data, fi sh leakage through drum screens, and screeni ng effici ency of drum screens at four i rriqation canal s on the l over Unatill a Ri ver, Oreqon.

\begin{tabular}{|c|c|c|c|c|c|c|c|c|c|c|c|c|}
\hline \multirow[b]{2}{*}{ Canal } & \multirow[b]{2}{*}{$\begin{array}{l}\text { Number } \\
\text { of } \\
\text { screens }\end{array}$} & \multirow[b]{2}{*}{$\begin{array}{l}\text { Percent } \\
\text { maxi mum } \\
\text { canal } \\
\text { fl ow }\end{array}$} & & \multicolumn{2}{|c|}{$\begin{array}{l}\text { Fi sh rel eased } \\
\text { at bypass } \\
\text { channel } \\
\text { entrance } \\
\end{array}$} & \multicolumn{2}{|c|}{$\begin{array}{c}\text { Fi sh } \\
\text { rel eased in } \\
\text { fvke nets }\end{array}$} & \multicolumn{2}{|c|}{$\begin{array}{c}\text { Fi sh I eakage } \\
\text { through screens }\end{array}$} & \multirow[b]{2}{*}{$\begin{array}{c}\text { Mean } \\
\text { screen } \\
\text { ef f i c- } \\
\text { i ency } \\
1 \%\end{array}$} \\
\hline & & & $\begin{array}{l}\text { upstre } \\
\text { Fork } \\
\text { I engt h } \\
(\mathrm{mm})\end{array}$ & $\begin{array}{l}\text { eam of } \\
\text { Num } \\
\text { ber }\end{array}$ & $\begin{array}{c}\text { screens } \\
\text { Recap- } \\
\text { t ur ed } \\
1 \%\end{array}$ & $\begin{array}{c}\text { entr } \\
\begin{array}{c}\text { Num } \\
\text { ber }\end{array}\end{array}$ & $\begin{array}{l}\text { ance } \\
\text { Recap- } \\
\text { t ur ed } \\
1 \%\end{array}$ & $\begin{array}{r}\text { f vk } \\
\begin{array}{c}\text { Num } \\
\text { ber }\end{array}\end{array}$ & $\begin{array}{c}\text { ke nets } \\
\begin{array}{c}\text { Recap- } \\
\text { t ured } \\
1 \%\end{array}\end{array}$ & $\begin{array}{l}\text { Screens } \\
\text { with } \\
\text { l eakage }\end{array}$ & $\begin{array}{l}\text { Mean } \\
\text { fork } \\
\text { length b } \\
(\mathrm{nm})\end{array}$ & \\
\hline $\begin{array}{c}\text { West } \\
\text { Extensi on }\end{array}$ & 4 & $37-42$ & 60.6 & 900 & 68.9 & 900 & 77.0 & 900 & 82.3 & $\begin{array}{ll}1(3), & 2(1) \\
3(1), & 4(1)\end{array}$ & $64.2(5)$ & 99.78 \\
\hline West I and & 10 & $12-16$ & 56.6 & 3,000 & 0 & 0 & 0 & 3,000 & 83.5 & $\begin{array}{c}1(5), 4(1) \\
5(2), 9(1) \\
10(5)\end{array}$ & $53.5(13)$ & 99.95 \\
\hline Feed & 10 & $85-88$ & 64.1 & 3,000 & 88.3 & 1,440 & 98.3 & 3,000 & 84.5 & $\begin{array}{c}1(1), 3(4) \\
4(1), 5(2) \\
7(2), 8(2) \\
9(1)\end{array}$ & $63.0(4)$ & 99.95 \\
\hline Furni sh & 7 & 71- 78 & 67.1 & 2,100 & 49. 9 & 1,028 & 96.8 & 2,100 & 75. 0 & $7(2)$ & $60.0(1)$ & 99.90 \\
\hline
\end{tabular}

aEstimated number of fish that leaked through a screen is given in parentheses next to the screen number wher 7 eakage occurred.

bNumbers of fish in which fork lengths were measured is given in par ent heses. 
$50 \%$ of maxi mum desi gn $\mathrm{fl}$ ow at West Ext ensi on and West I and canal s. A though screeni ng effici ency was hi gh, $50-100 \%$ of the screens at each si te had sone l eakage except at Furni sh Canal where onl y one fi sh was recapt ured behi nd Screen 7. Fi sh I eakage was hi ghest at screens on the upstream and downst ream ends of the screeni ng facilities at Westl and (Screens 1 and lo), West Extensi on (Screen I), and Feed (Screen 3) canal s. Mean fork I engths of fal I chi nook sal mon were smal ler for $f i$ sh that l eaked or rol led over the screens (53. 5-63. $0 \mathrm{~mm})$ compared with fish rel eased upstream of the screens (56.6-67.1 $\mathrm{mm}$. Numbers of $\mathrm{f} i \mathrm{sh}$ capt ured behi nd the screens were too l ow for stati stical anal yses. Capt ure ef $\mathrm{f} i$ ci ency $f$ or i ndi vi dual fyke nets ranged from $48-I 00 \%$ and overal I fyke net ef $\mathrm{f} i \mathrm{ci}$ ency for each si te ranged from $75.0-84.5 \%$

Wh rarel y observed test fi sh i mpi nged on drum screens duri ng drum screen ef $\mathrm{i}$ ci ency tests. Total number of $\mathrm{i}$ mi nged test $\mathrm{fi}$ sh was I ess than $0.01 \%$ of the total number rel eased. I mpi ngenent of test $\mathrm{fi}$ sh was observed at Screen 4 at West Extensi on Canal, Screen 10 at West I and Canal, and Screen 5 at Feed Canal. Onl y one of these i mpi nged test fi sh rol led over the screen (Screen 4 at West Extensi on Canal).

\section{Bel t Screens}

Both bel t screens at Westl and Canal were $100 \%$ ef fi ci ent at preventing test fi sh fromentering the pumpback bay during si mul at ed trapping operat i ons. Most treatment fi sh were recapt ured during testing $(298 \%$ and fyke net effi ci enci es were hi gh ( $\geq 74-99 \%$ ). I mpi ngenent of test $f i$ sh on the screens uas not observed.

The bel $t$ screen at West Extensi on Canal was greater than $99.4 \%$ ef $\mathrm{fici}$ ent at preventing test fish fromentering the pumpback bay when the pumpback bay drai $n$ pi pe was $20 \% \quad 30 \%$ or $40 \%$ open. Screeni ng ef $i$ ci ency was sl i ghtl y I ouer when the drai $n$ pi pe was $20 \%$ open (99.5\% than when the drai $n$ pi pe was $30 \%$ or $40 \%$ open ( $\geq 99.9 \%$. Mbre than $83 \%$ of treat nent fi sh were recapt ured at the end of testing and fyke net effici ency was hi gh ( $\geq 97 \%$.

I mpi ngement of test $\mathrm{fi}$ sh on the bel $\mathrm{t}$ screen at West Extensi on Canal was observed onl y when the drai $n$ pi pe was $40 \%$ open $(0.6 \%$ or when both canal pumps were on $(0.1 \%$. I mpi ngement occurred at the dounstream end of the screen where turbul ence was created by backfl ow of the orifice plate. Two of three fry i mpi nged when the drai $n$ pi pe was $40 \%$ open di ed from bei ng caught bet ween the screen and si de seal. Other i mpi nged fi sh di d not appear i nj ured.

\section{Bypass}

Whter Vel ocity

Accuracy of the drum screen vel oci ty measurements vari ed from $17 \%$ under esti nati on to $42 \%$ over esti nati on based on compari son of canal $f($ ow esti mated from vel ocity neasurements to canal fl ow measured at ONRD gauging stations (Table 6). Mbst approach vel ociti es measured in front of drum screens at the five canal s met screening criteria for protection of smol ts ( 1 $0.24 \mathrm{~m} / \mathrm{s}$ ) at naxi mum canal fl ow expected from March through May (Table 6). Approach vel ocity criteria for protection of fry ( $\leq 0.12 \mathrm{~m} / \mathrm{s})$ was net at 26$79 \%$ of the sampl ing l ocations in front of drum screens at maxi mum canal 
Tabl e 6. Percent of maxi mum canal fl ow expected i n March- May ( max. ), canal fl ow when water vel ocity measurements were collected (ONRD gauge readi ngs), canal fl ow esti nated from vel oci ty measurements, er ror of esti mate, and percent of vel ocity measurements meeting approach vel ocity (AV) and sweep to approach vel ocity (S: AV) criteria at maxi mumcanal fl ow expected in March-My at i rri qation canal s on the I ower Unatill a Ri ver, Oregon.

\begin{tabular}{|c|c|c|c|c|c|c|c|}
\hline \multirow[b]{2}{*}{ Canal } & \multicolumn{3}{|c|}{ Canal f I ow } & \multirow[b]{2}{*}{$\begin{array}{c}\text { Error of } \\
\text { esti - } \\
\text { nate }\end{array}$} & \multicolumn{3}{|c|}{ Percent of measur enents } \\
\hline & $\begin{array}{l}\text { Per - } \\
\text { cent } \\
\text { of } \\
\text { max. }\end{array}$ & $\begin{array}{l}\text { Gauge } \\
\text { read- } \\
\text { ing } \\
\left(\mathrm{m}^{3} / \mathrm{s}\right)\end{array}$ & $\begin{array}{c}\text { Esti - } \\
\text { mąte } \\
\left(\mathrm{m}^{3} / \mathrm{s}\right)\end{array}$ & & $\begin{array}{c}\text { expectec } \\
0.12 \\
\mathrm{~m} / \mathrm{s} \\
\mathrm{AV}\end{array}$ & $\begin{array}{c}\text { to } \text { neet } \\
0.24 \\
\text { mis s } \\
\text { AV }\end{array}$ & $\begin{array}{r}\text { criteri a } \\
2: 1 \\
\text { S: AV }\end{array}$ \\
\hline $\begin{array}{c}\text { West } \\
\text { Ext ensi on }\end{array}$ & 46 & 1.8 & 1.1 & $-42 \%$ & 64 & 100 & 100 \\
\hline Maxuel I & 93 & 1.0 & 0.9 & $-16 \%$ & 52 & 100 & 41 \\
\hline West I and & 85 & 6.0 & 5.0 & $-17 \%$ & 49 & 100 & 100 \\
\hline Feed & 86 & 5.9 & 5.6 & $-5 \%$ & 26 & 96 & 91 \\
\hline Furni sh & 100 & 3.5 & 4.1 & $+17 \%$ & 79 & 100 & 94 \\
\hline
\end{tabular}

fl ow expected from March through My (Table 6). Hi ghest approach vel oci ti es uere regul arly measured at screens cl osest to the bypass channel. Approach vel ocities were cl osest to neeting criteria for fry protection at Furnish Canal and furthest from meeting criteria at Feed Canal.

Rati o of sweep to approach vel ocity was withi $n$ criteria ( $\geq 2$ ) at nore than $90 \%$ of the sampling l ocati ons at al I study si tes except Maxuel I Canal. At this site, onl y $\mathbf{4 1} \%$ of the vel ocity neasurements met sueep to approach criteria ( Table 6). Rati o of sweep to approach vel ocity steadi ly decreased with increasi ng di stance from the bypass channel at Maxuel I Canal (Fi gure 12).

Fl ow patterns in front of drum screens varied with the number of screens at each si te. At si tes with seven or ten screens (Westl and, Feed, and Furni sh canal s), the hi ghest approach vel oci ti es and I ouest sweep to approach vel oci ty ratios were measured at screens at the ends and middle of the screening facility (Fi gures 13-15). Non-I ami nar fl ow i ncreased the variability of measurements in these areas. At West Extensi on Canal, approach vel ociti es uere fai rly uniformanong al I four screens with the exception of a few high readi ngs at $20 \%$ water depth near the middle of the screening facility (Fi gure 12). At Maxuel I Canal, approach vel ociti es were general l y hi ghest at $50 \%$ uater depth and at the ends of the three-screen facility.

Whter vel ocity at bypass channel entrances net NMFS vel ocity criteria and were fai rly uni form anong dept hs and study si tes (Table 7). Vel ocity was hi ghest at the Furni sh Canal bypass (0.79-0.82 $\mathrm{m} / \mathrm{s})$ and ranged from 0. 58- 0.73 $\mathrm{m} / \mathrm{s}$ at al $\mathrm{I}$ other study si tes. 


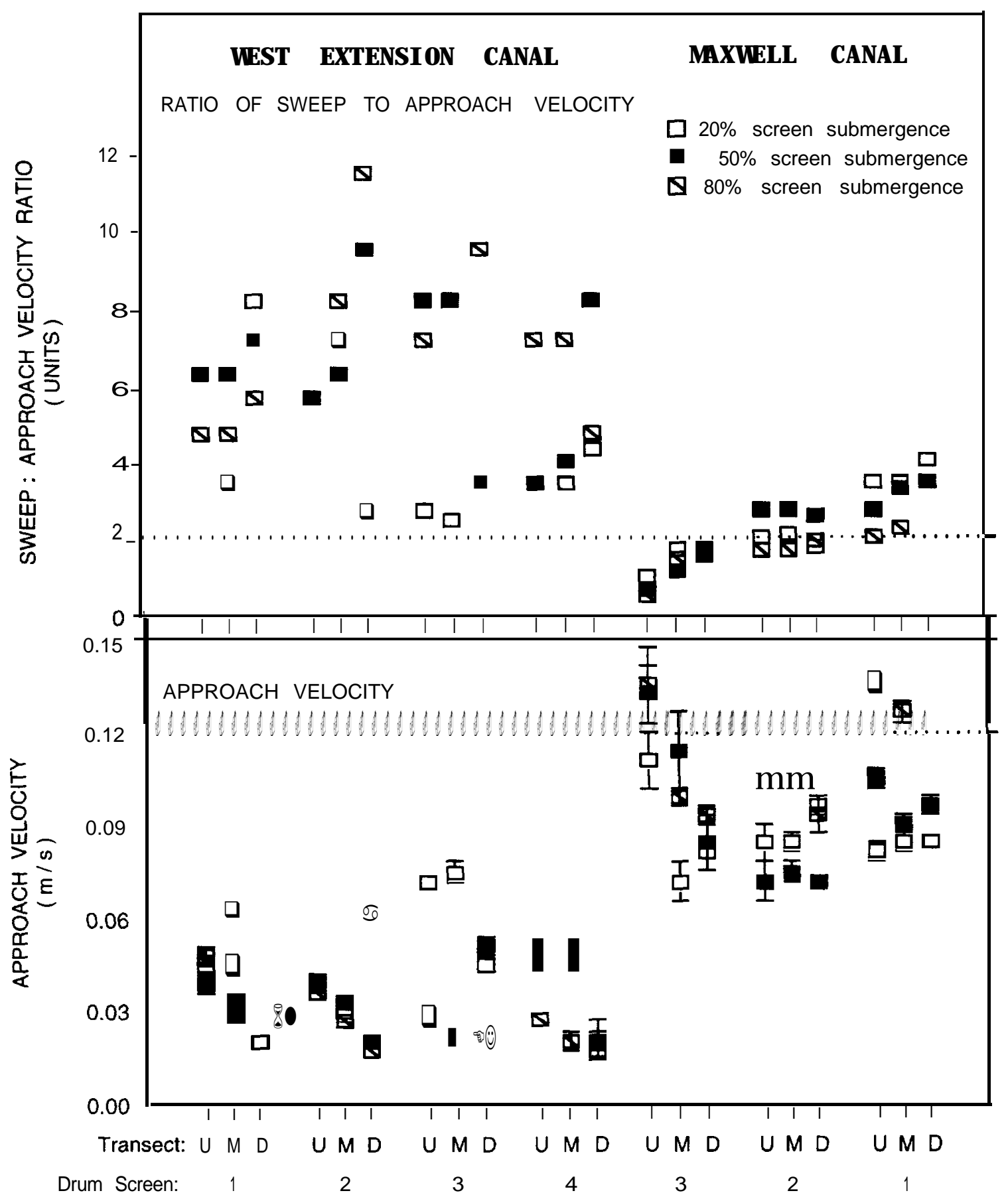

Fi gure 12. Ratio of sweep to approach water vel ocity and approach water vel oci ty measured in front of drum screens at West Extensi on and Mexuel I canal s, Unatilla Ri ver, Oregon. Measurements were col lected al ong upstream (U), midscreen ( $M$, and dounstream (D) verti cal transects ( $N=5$, error bars $=$ SD). Drumscreens are numbered i $n$ ascendi ng order at West Extensi on Canal and descendi ng order at Maxuel I Canal fromthe furthest upstreamscreen to the screen cl osest to the bypass channel. 


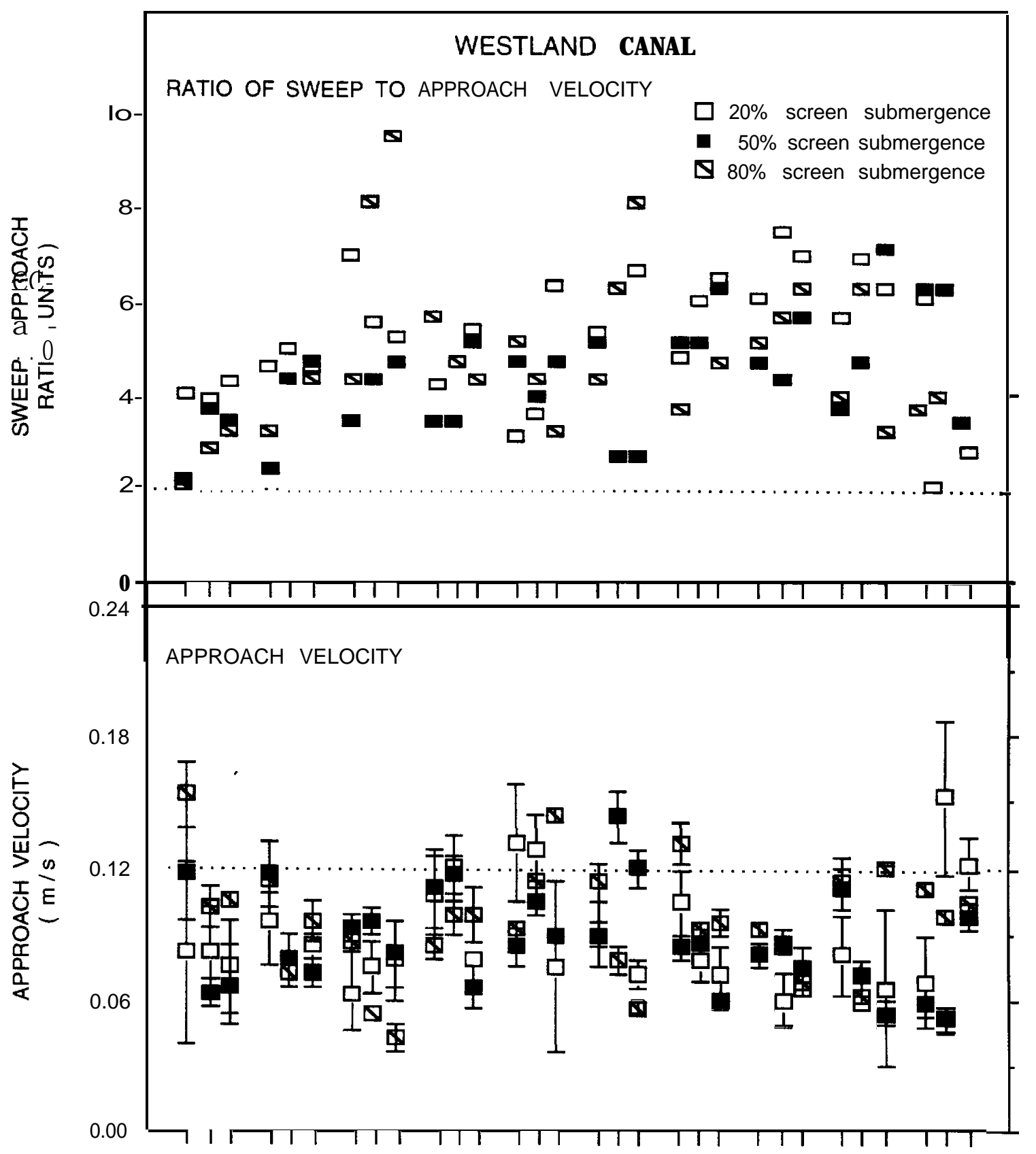

Transect: $U M D$ U $\begin{array}{lllllllllll}\text { Drum Screen: } & 1 & \mathbf{2} & \mathbf{3} & \mathbf{4} & \mathbf{5} & \mathbf{6} & \mathbf{7} & \mathbf{8} & \mathbf{9} & \mathbf{1 0}\end{array}$

Fi gure 13. Rati o of sweep to approach water vel oci ty and approach water vel oci ty measured i $n$ front of drum screens at Westl and canal, Unatilla Ri ver, Oregon. Measurenents were col l ected al ong upstream (U), midscreen ( $M$, and downstream (D) verti cal transects $(N=5$, error bars $=S D)$. Drum screens are number ed i $n$ ascendi ng order from the furthest upst ream screen to the screen cl osest to the bypass channel. 


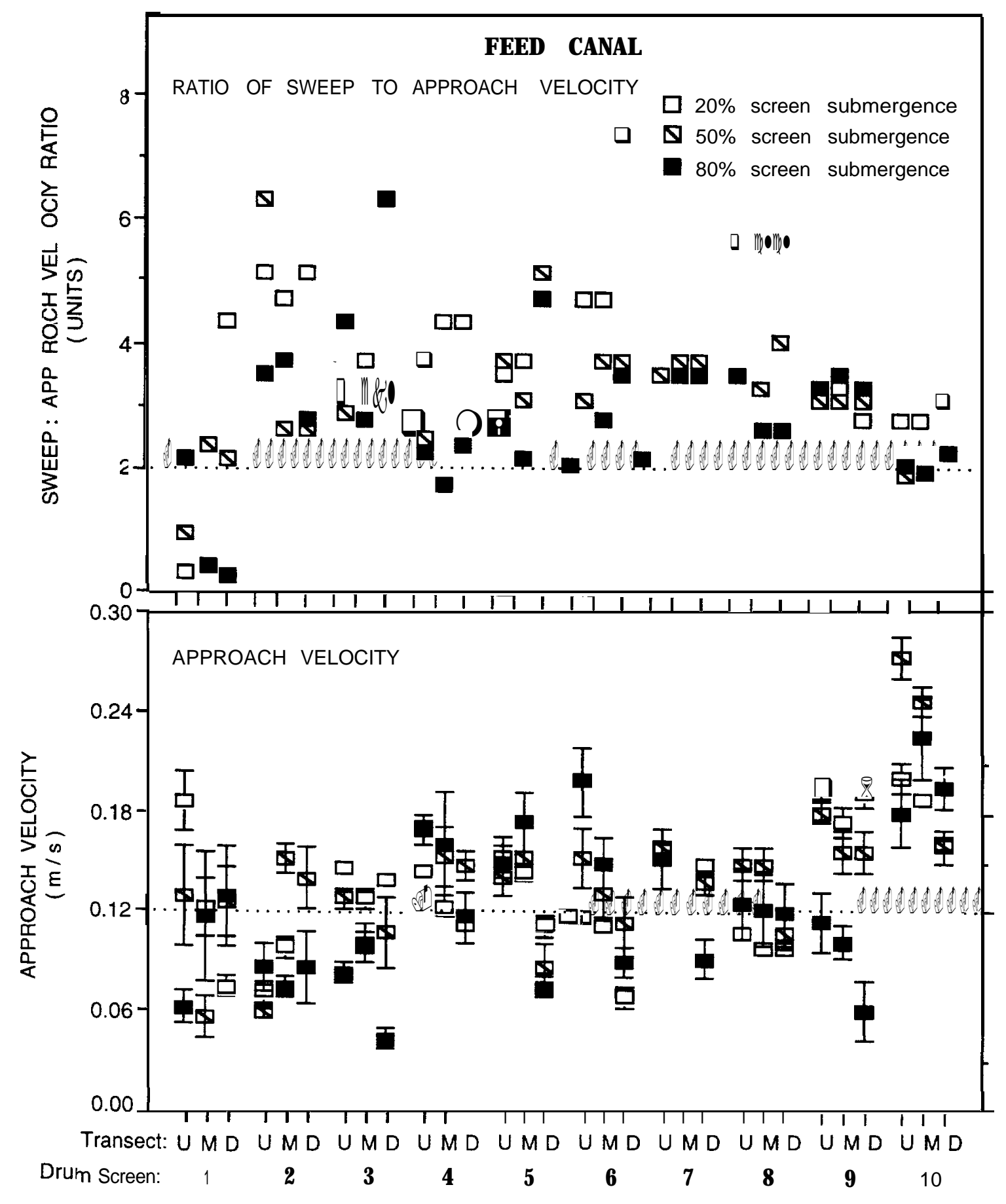

Fi gure 14. Ratio of sweep to approach water vel oci ty and approach water vel ocity measured in front of drum screens at Feed canal, Unatilla Ri ver, Oregon. Measurements were col l ected al ong upstream (U), midscreen ( $M$, and downstream (D) verti cal transects $(N=5$, error bar $s=S D)$. Drum screens are numbered in ascendi ng order from the furthest upstream screen to the screen cl osest to the bypass channel. 


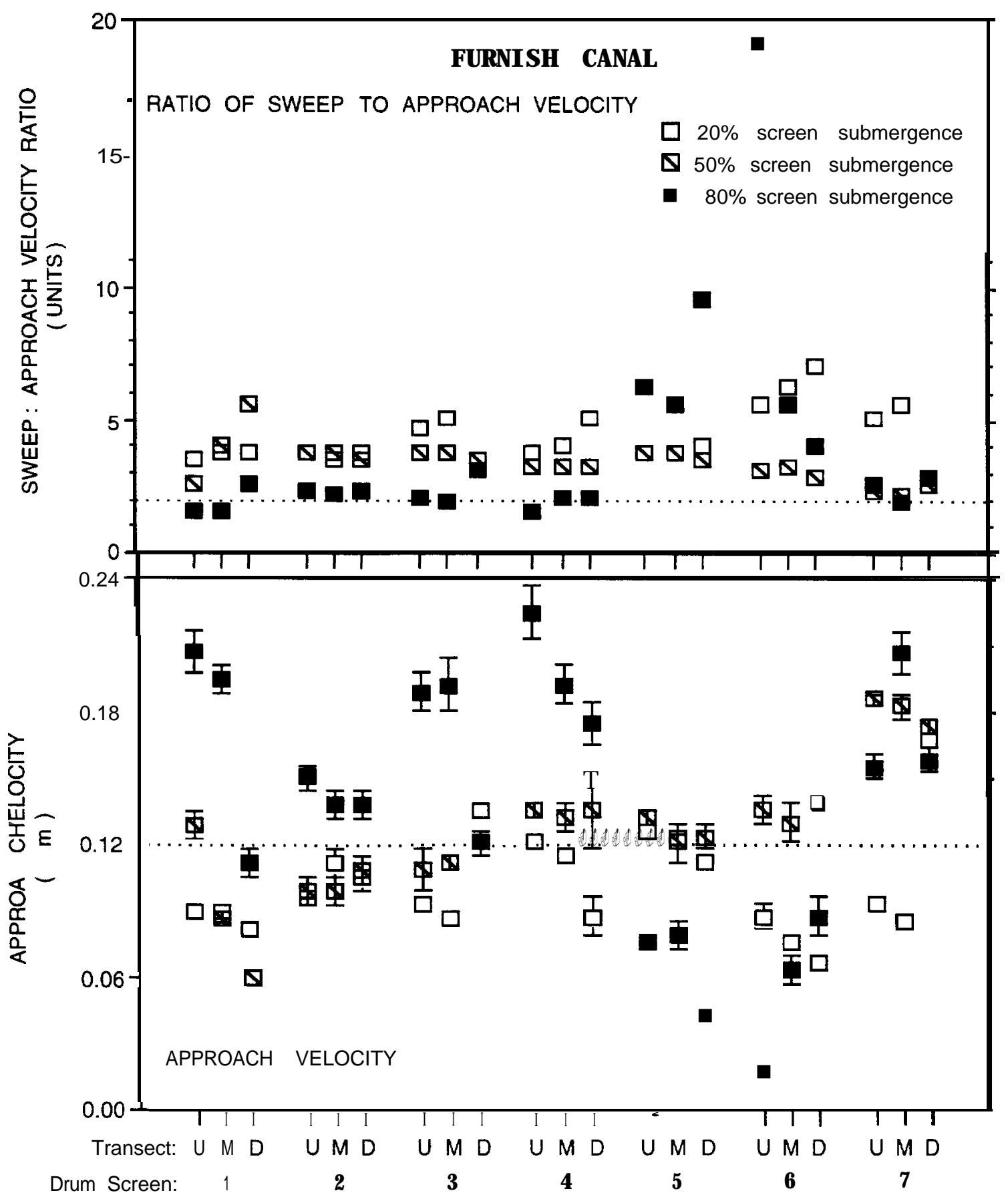

Fi gure 15. Rati o of sweep to approach water vel ocity and approach water vel oci ty measured in front of drumscreens at Furni sh Canal, Unati I la Ri ver, Oregon. Measurenents were col l ected al ong upstream (U), midscreen ( $M$, and downstream (D) verti cal transects $(N=5$, error bars $=S D)$. Drum screens are number ed i $n$ ascendi ng order from the furthest upstream screen to the screen cl osest to the bypass channel. 
Table 7. Wter vel ocity ( $\mathrm{m} / \mathrm{s}$ ) measured at bypass channel entrances duri ng hi gh fl ow bypass operati ons at i rri gati on canal s on the I ower Unatilla Ri ver, Oreqon.

\begin{tabular}{lccccc} 
& & \multicolumn{4}{c}{ Wter vel oci ty } \\
\cline { 2 - 5 } Locati on & Date & $20 \%$ depth & $50 \%$ depth & $80 \%$ depth & Mean \\
\hline $\begin{array}{l}\text { West Ext ensi on } \\
\text { Canal }\end{array}$ & $7 / 27 / 95$ & 0.58 & 0.61 & 0.70 & 0.63 \\
Mexuel I Canal & $5 / 4 / 94$ & 0.70 & 0.73 & 0.64 & 0.69 \\
West I and Canal & $4 / 29 / 94$ & 0.64 & 0.64 & 0.67 & 0.65 \\
Feed Canal & $4 / 14 / 94$ & 0.70 & 0.73 & 0.64 & 0.69 \\
Furni sh Canal & 512194 & 0.79 & 0.79 & 0.82 & 0.80
\end{tabular}

At West Extensi on Canal, sweep vel ociti es in front of the bel $t$ screen met criteria during all six pumpback operations tested (Table 8). Approach vel ocity criteria for fry protection ( $10.12 \mathrm{mis}$ ) was $\mathrm{sl}$ ightly exceeded at a f ew sampl ing I ocati ons duri ng one- or t wo-pump operati ons or when the pumpback bay drai $n$ pi pe uas $20 \%$ open. Approach vel oci ti es exceeded $0.12 \mathrm{mis}$ when the drai $n$ pi pe was $30 \%$ ( 2 I ocati ons) and $40 \%$ ( 6 I ocati ons) open. Excessi ve approach vel oci ti es were pri marily l ocated at ei ther $20 \%$ depth or the upstream transect of the screen. Al operations tested met approach vel oci ty criteria for smol t protection ( $10.24 \mathrm{~m} / \mathrm{s}$ ), except a $40 \%$ open drai $\mathrm{n}$ pi pe. Back-fl ow from the orifice pl ate created turbul ent non-l ami nar current across the downstream one-third of the belt screen, particularly when the drai $n$ pi pe was $40 \%$ open.

A t no-pump operati on and a $20 \%$ open drai $n$ pi pe created si milar fl ous through the bel $t$ screen and mean vel ocities at the bypass channel entrance ( Table 8). Fl ow and vel oci ty steadi I y i ncreased wi th a $30 \%$ and $40 \%$ open drai $n$ pi pe. Vel ocity at the bypass channel entrance produced by the tuo-pump operati on or $20 \%$ open drai $\mathrm{n}$ pi pe approxi mated deşign vel ocity (0.61 $\mathrm{m} / \mathrm{s})$ for facility operations with a bypass fl ow of $0.71 \mathrm{~m} / \mathrm{s}$.

Ladder

At the Three MIe Fal Is Dam east-bank fi sh I adder, fl ow noved across the face of Diffuser 1 toward Transect 1 (Figure 16). Fl ow approached the di ffuser at angl es rangi ng from $24-83^{\circ}$ ( $90^{\circ}=\mathrm{fl}$ ow perpendi cul ar to diffuser). Sueep vel ocity ranged from 0. 06-0.58 $\mathrm{m} / \mathrm{s}$ ( approach vel ocity ranged from 0.13-0.58 $\mathrm{m} / \mathrm{s}$ ( mean $=0.31 \mathrm{~m} / \mathrm{s}$ ). Sueep vel ocity decreased and approach vel ocity increased at Transect 1 where fl ow was di rected nore perpendi cul ar to the diffuser. Approach vel ociti es were generally hi gher near the surface and si des of the diffuser than in the middl e. Water turbul ence associ ated wi th a midchannel I-beam resul ted i n 
Table 8. Whter vel ocity $(\mathrm{m} / \mathrm{s})$ and $\mathrm{flow}\left(\mathrm{m}^{3} / \mathrm{s}\right)$ at the bel $\mathrm{t}$ screen and bypass channel entrance of West Extensi on Canal duri ng pumpback operati ons wi th one or t uo $0.28-\mathrm{m} / \mathrm{s}$ pumps on and when the pumpback bay drai n pi pe was $20 \% 30 \%$ or $40 \%$ open. Measurenents were col l ected at three dept hs al ong an upstream (U). middle (M and downst ream (D) transect on 3 Oct ober 1995.

\begin{tabular}{|c|c|c|c|c|c|c|c|c|c|c|}
\hline \multirow{3}{*}{$\begin{array}{l}\text { Percent } \\
\text { of uater } \\
\text { depth }\end{array}$} & \multirow{3}{*}{$\begin{array}{l}\text { Vel oci ty } \\
\text { component }\end{array}$} & \multicolumn{9}{|c|}{ Whter vel oci ty } \\
\hline & & \multicolumn{3}{|c|}{ Pump 1} & \multicolumn{3}{|c|}{ Pump 2} & \multicolumn{3}{|c|}{$\begin{array}{ll}\text { Pumps } & 1+2\end{array}$} \\
\hline & & $\mathbf{U}$ & $M$ & D & $\mathbf{U}$ & $M$ & D & $\mathbf{U}$ & $M$ & D \\
\hline $\begin{array}{l}20 \\
20\end{array}$ & $\begin{array}{l}\text { appr oach } \\
\text { sweep }\end{array}$ & $\begin{array}{l}0.10 \\
0.26\end{array}$ & $\begin{array}{l}\mathbf{0 . 0 6} \\
0.30\end{array}$ & $\begin{array}{l}0.03 \\
0.21\end{array}$ & $\begin{array}{l}0.16 \\
0.35\end{array}$ & $\begin{array}{l}\mathbf{0 . 0 7} \\
0.32\end{array}$ & $\begin{array}{l}0.05 \\
0.27\end{array}$ & $\begin{array}{l}0.14 \\
0.44\end{array}$ & $\begin{array}{l}\mathbf{0 . 0 7} \\
0.42\end{array}$ & $\begin{array}{l}\mathbf{0 . 1 0} \\
0.40\end{array}$ \\
\hline $\begin{array}{l}50 \\
50\end{array}$ & $\begin{array}{l}\text { appr oach } \\
\text { sweep }\end{array}$ & $\begin{array}{l}\mathbf{0 . 0 5} \\
0.34\end{array}$ & $\begin{array}{l}\mathbf{0 . 0 3} \\
0.30\end{array}$ & $\begin{array}{l}\mathbf{0 . 0 5} \\
0.23\end{array}$ & $\begin{array}{l}0.07 \\
0.35\end{array}$ & $\begin{array}{l}0.06 \\
0.28\end{array}$ & $\begin{array}{l}0.06 \\
0.23\end{array}$ & $\begin{array}{l}0.09 \\
0.50\end{array}$ & $\begin{array}{l}0.11 \\
0.43\end{array}$ & $\begin{array}{l}0.11 \\
0.29\end{array}$ \\
\hline $\begin{array}{l}80 \\
80\end{array}$ & $\begin{array}{l}\text { appr oach } \\
\text { sweep }\end{array}$ & $\begin{array}{l}\mathbf{0 . 0 4} \\
0.38\end{array}$ & $\begin{array}{l}0.03 \\
0.28\end{array}$ & $\begin{array}{l}\mathbf{0 . 0 3} \\
0.24\end{array}$ & $\begin{array}{l}0.19 \\
0.40\end{array}$ & $\begin{array}{l}0.04 \\
0.29\end{array}$ & $\begin{array}{l}\mathbf{0 . 0 5} \\
0.20\end{array}$ & $\begin{array}{l}0.10 \\
0.59\end{array}$ & $\begin{array}{l}0.08 \\
0.41\end{array}$ & $\begin{array}{l}0.06 \\
0.20\end{array}$ \\
\hline
\end{tabular}

Vel oci ty at bypass channel entrance ${ }^{a}$ 


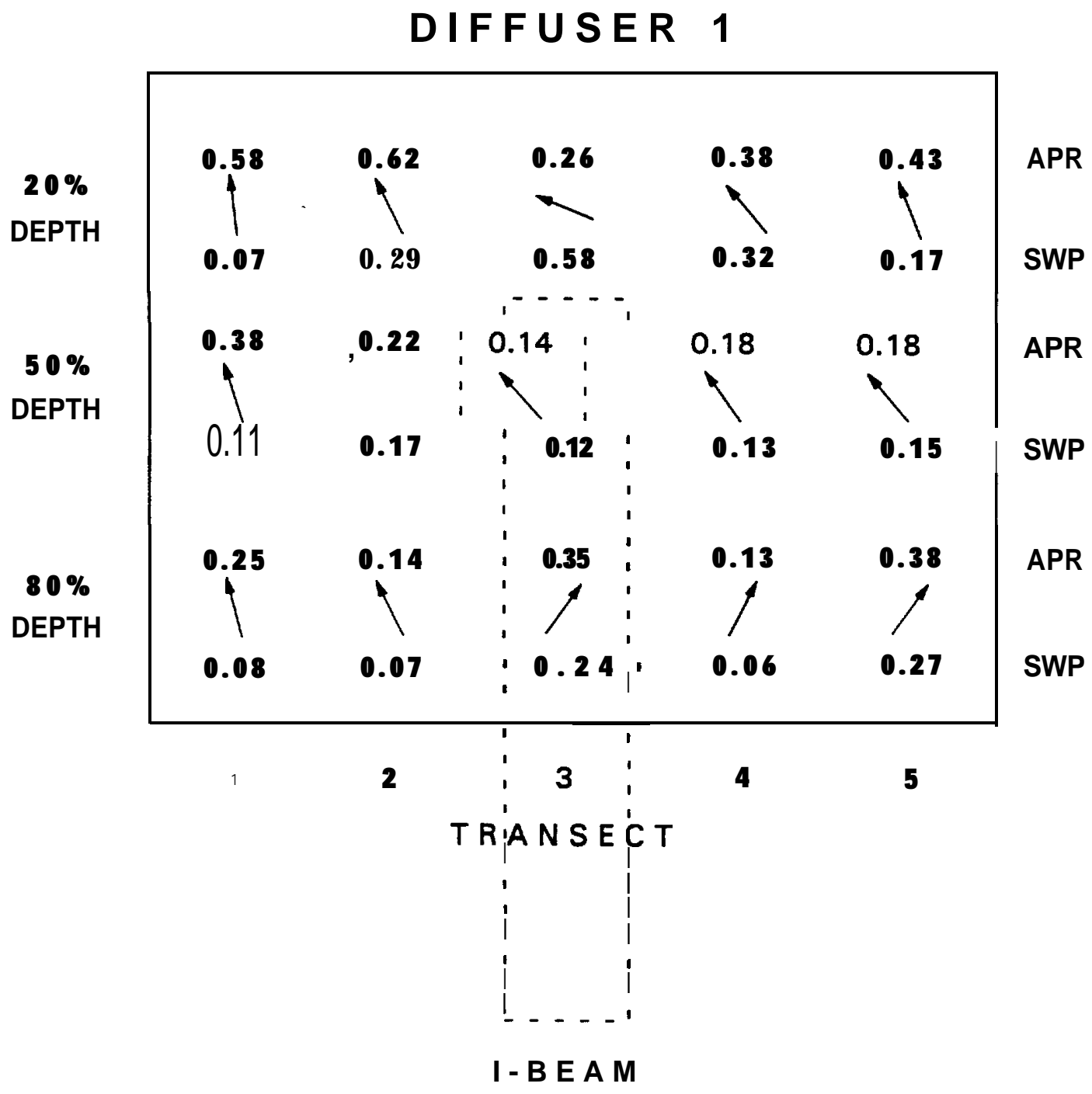

Fi gure 16. Approach (above arrous) and sueep (bel ow arrous) water vel oci ty ( $\mathrm{m} / \mathrm{s}$ ) measured in front of Diffuser 1 l ocated in the passage section of the fi sh I adder at Three MIe Fal Is Dam Unati II a Ri ver, Oregon. Arrous i ndi cate di rection of fl ow Fl ow perpendicular to the diffuser is depicted by arrous poi nting strai ght up. 
vari able approach and sueep vel ociti es at transects 2-4.

A most al I water movenent in front of Diffuser 2 at the auxi I i ary water system fl owed east to west (Fi gure 17). Currents were more of ten di rected across the face of the diffuser on the east panel than the west panel. Angle of $\mathrm{fl}$ ow approaching the diffuser averaged $37^{\circ} \mathrm{f}$ or the east panel and $75^{\circ} \mathrm{f}$ or the west panel. Fl ow was vi rtually parallel to the diffuser at three sampl ing l ocations on the east panel where sueep vel ociti es ranged from 0.32-0.36 $\mathrm{mis}$. In contrast, fl ow was di rected straight at the diffuser at two sampling l ocations in front of the west panel, where approach vel ocity was $0.11 \mathrm{mds}$ and $0.27 \mathrm{~m} / \mathrm{s}$. Mean approach vel ocity was hi gher at the west panel (0.28 $\mathrm{m} / \mathrm{s})$ than the east panel $(0.14 \mathrm{~m} / \mathrm{s})$. Mean sueep vel ocity uas higher at the east panel $(0.23 \mathrm{~m} / \mathrm{s})$ than the west panel $(0.09 \mathrm{~m} / \mathrm{s})$.

DISCUSSION

Injury

Bypass

Overal I, our fi ndi ngs concur with studi es on the Yaki ma Ri ver in that current desi gns of fish bypass facilities using angl ed drumscreens, vertical sl ot bypass channel s, and I arge di aneter bypass pi pes return $\mathrm{j}$ uveni l e sal moni ds to the ri ver wi th negl i gi ble i nj ury ( Nei tzel et al . 1985, 1987, 1988, 1990a, 1990b, 1991; and Hosey and Associ ates 1988a, 1988b, 1989, 1990). Differences in treatment and control inj ury were within confidence Iimits in al I but tuo bypass inj ury tests. In these two tests, si gnificant differences were probably an artifact of sampling error or handling i nj ury.

Si gnificance in the ni ght-ti me screen inj ury test with subyearling fall chi nook sal mon at West Extensi on Canal was a resul $t$ of bi ased pre-test subsampling of control fish. I rrespective of the bi ased esti nate of control inj ury, post-test inj ury to treatment fish was comprised onl y of partial descal ing (8.2\%). St udi es conducted wi th coho sal mon (Oncorhyncus ki sut ch, Bouck and Smith 1979) and chi nook sal mon (Basham et al . 1982) i ndi cated partial descaling did not result in nortality in freshwater systems. Si gni fi cance in the facility inj ury test at Feed Canal was a result of hi gher handl ing inj ury i ncurred by treat ment fish than control fish. Control fi sh rel eased in the trap net were qui ckl y recapt ured with few ot her fi sh; treat nent fi sh recei ved rougher handl ing when they were recapt ured wi th I arge numbers of sal noni $\mathbf{d}$ migrants I ater in the eveni ng. We di d not expect treatment fi sh to temporarily hol d in the screen forebay, based on previ ous test experi ence (Hayes et al. 1992; Cameron and Knapp 1993; Cameron et al. 1994). Large i nf I uxes of migrant fi sh si milarl y bi ased tests conducted at the Whato Canal bypass facility ( Nei tzel et al. 1991).

Poor preci si on i n outfal I and downuel I inj ury tests at West Extensi on Canal was a probable result of vari able inj ury rates associ ated wi th i nconsi stent trap pl acement anong replicates. Even though outfal I and downuel I i nj ury tests were not stat i sti cal l y si gni ficant, test resul ts suggest sone fish are inj ured in the l ower bypass. Inj ury was consi stently higher for treatment fish than control fish in outfal I inj ury tests wi th spring chi nook and subyearling fal I chi nook sal mon. Inj uries to spring chi nook sal non in the 


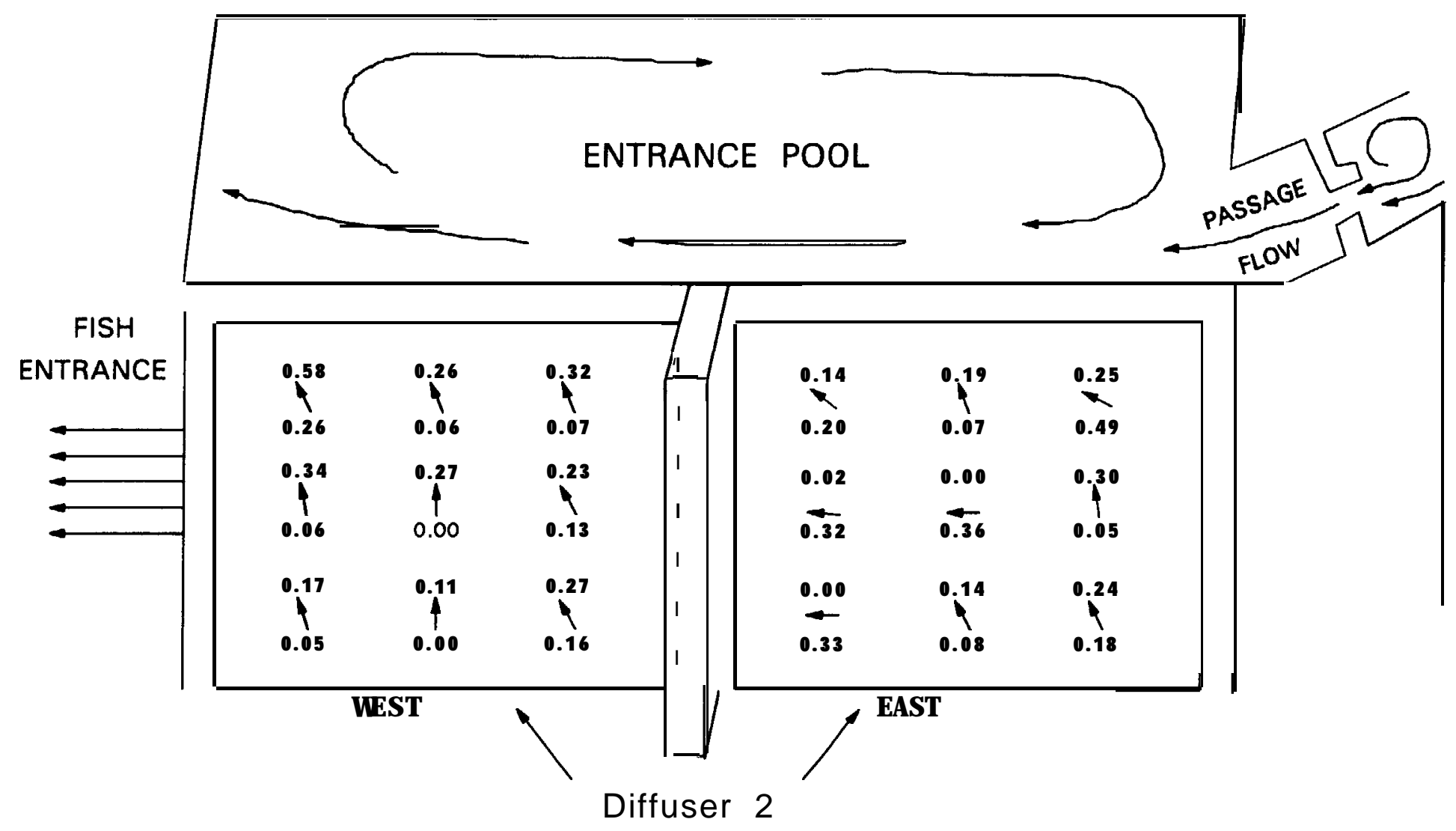

Fi gure 17. Approach (above arrous) and sweep (bel ow arrows) water vel ocity ( $x$ s) measured in front of Diffuser 2 l ocated between the auxili ary uater system and entrance pool of the fi sh I adder at Three MIe Fal Is Dam Unatilla Ri ver, Oregon. Arrous i ndi cate di rection of fl ow Fl ow perpendi cul ar to the di ffuser is depi cted by arrous poi nting strai ght up. 
I ower bypass were not severe (partial descal ing). However, i nj uri es to subyearling fal I chi nook sal mon in the outfall inj ury test (descaling and nortality) were the nost severe of any of the bypass inj ury test results. Weaker swi ming ability of subyearling fal I chi nook sal mon was the most probabl e reason i nj uri es were severe. In addi ti on, fall chi nook sal non were more prone to i nj ury when bypass fl ow was high $(0.71 \mathrm{~m} / \mathrm{s})$. Reducti on of fl ow through the I ower bypass when fal I chi nook sal mon are present (I ate-Myy and $J$ une) shoul d be consi dered to reduce potenti al i nj ury. Non-standard operations with a hi gh downuel I pool depth di d not provi de addi ti onal protection from i nj ury.

\section{Ladder}

M dchannel di ff users were the nost probabl e cause of i nj ury to j uveni I e sal noni ds in fi sh I adders on the I over Unatilla Ri ver. Juvenile sal noni ds noved saf el $y$ through the unobstructed passage secti ons of $f i$ sh I adders at Westl and, Feed, and Stanfi el d dans. In contrast, i nj uri es were nost severe to subyearling fal I chi nook sal mon in the passage secti on of the I adder at Three M I e Fal Is Dam The passage secti on of this I adder has t wo sets of midchannel diffusers. Tuo-thi $r$ ds of the descal ing detected in the passage si de of the I adder was associ ated with di ffusers.

We conducted under water vi deo uork i 1996 that document ed I arge numbers of $f i$ sh i $n$ front of Diffuser 1 (Knapp et al. 1997). Hundreds of $f i$ sh were observed on nunerous occasi ons foll owi ng currents across the upstream si de of Diffuser 1 and frequently i mpacting on it. Subyearling fall chi nook sal non appeared to i mpact the diffuser nore frequentl y than the yearling chi nook sal mon or steel head, apparentl y because of veaker swi ming abil i ty. These observati ons are consi stent wi th I aboratory experi ments i ndi cating normal novenent of $\mathbf{j}$ uveni I e sal non is i nt errupted by vertical bar openi ngs I ess that $76 \mathrm{~mm}$ (Hanson and Li 1983). Current openi ngs are at the maxi mum desi gn criteria $(25 \mathrm{~mm})$ establi shed to prevent gi II ing of i mat ure adul t sal mon. Both yearling and subyearling chi nook sal mon appeared to pass more readi ly through portions of Diffuser 1 where fl ow was di rected at ( $r$ ather than across) the diffuser. Fi sh exit gates were onl y $55 \%$ open when we conducted the inj ury tests. Parti al openi ngs of the gates appear to i ncrease the vel ocity and turbul ence of fl ow through the gates. Fl ow patterns in front of the diffuser might be i mproved by rai sing the fish exit gates to ful I open.

Subyearling chi nook sal mon were al so inj ured in the sl ot-and-pool segnent of the passage secti on of the $f i s h$ I adder at Three Mle Fal Is Dam Fl ow patterns associ ated with a $46^{\circ}$ sl ot jet orientation at the Three Mle Fal Is Damfi sh I adder may be the pri mary cause of i nj ury. J uveni l e sal non were not $i$ nj ured i $n$ the passage section of the fi sh I adders at West $t$ land, Feed, and Stanfi el d dans whi ch i ncorporate a sl ot j et ori ent ation of 36 . A I the fi sh I adders $n$ the Unatilla Ri ver have the same slot and pool di nensi ons and sl ope. Uni que fl ow patterns associ ated with the 46 sl ot j et ori entation onl y caused i nj ury to the weaker swi ming subyearling chi nook sal non and not yearling chi nook sal mon. Under water vi deo could be used in the sl ot and pool secti on of the $f i$ sh I adder to gai $n$ more i nsi ght i nto desi gn factors that may be causing inj ury to subyearling fish. 
J uveni I e sal moni ds were i nj ured i $n$ the auxi I $\mathrm{i}$ ary water system of the fi sh I adder at West I and Dam whi ch i s al so obstructed by a di ff user panel. However, nei ther subyearli ng chi nook or yearl ing chi nook sal mon were i nj ured when they passed through a si mi ar auxi I ary uater system in the fi sh I adder at Three Mle Fal Is Dam Differences in i nj ury at these sites may be rel ated to differences in positi oni ng of baffles that dampen water vel ocity in front of the auxiliary water diffusers. Baffles are positioned parallel to and 0.6 $m$ in front of Diffuser 2 insi de the fish I adder at Three Mle Fal Is Dam At Uestl and Dam baffles are positi oned at a $68^{\circ}$ angl e to the auxi I $i$ ary water diffuser. The baffles range from 0. 6- 6.9 maway fromt he diffuser as a resul $t$ of thei $r$ angled orientation. Positioning baffles parallel to and $0.6 \mathrm{~m} \mathrm{i}$ front of di $f f$ users appears to be a better conf $i$ gurati on $f$ or $j$ uveni l e sal noni $d$ passage through auxi I i ary water systens i n f i sh I adders. However, j uveni I e sal moni d passage through-the auxi l $i$ ary water system at Westl and Dam nay not be a maj or passage concern because al though i nj ury was si gni fi cant, it consi sted of I ow l evel s of descal ing. In addition, the design of the auxili ary uater trashracks ( $38 \mathrm{~mm}$ sl ats spaced $25 \mathrm{~mm}$ apart) and thei $r$ paral lel orientation to ri ver fl ow is expected to gui de nost j uveni l e sal moni ds past the auxi I i ary water i ntake. Bates and Vi nsonhal er (1957) found sl ats wi th $25 \mathrm{~mm}$ openi ng and an ori ent ation to fl ow si milar to the auxiliary uater trashracks at Westl and Dam had gui dance ef $\mathrm{f} i$ ci enci es of $88-100 \%$ for chi nook sal mon ( $73 \mathrm{~mm}$ mean standard I ength) when water vel ocity ranged from 0.4-1.4 $\mathrm{mis}$.

Travel Rate and Recapt ure

Bypass

Rel evant questi ons associ ated with travel rate and recapt ure are whether fi sh bypass desi gns del ay "normal" fi sh movenent and whether canal operations affect the rate of fish passage through the facilities. However, these questions are difficult to answer because travel rate and recapt ure data were ancill ary i nf ormation coll ected during the conduct of i nj ury tests.

Neverthel ess, we observed some general patterns of fish movenent through the fish bypass facilities that are consistent with findings of other studies.

Our onl y I egi ti mate compari sons of travel ti me, travel speed, and recapt ure were based on si mul taneous rel eases of test fish. Comparison of medi an travel speed of subyearling $f$ al $I$ chi nook sal mon rel eased dounstream of the headgates (485 $\mathrm{m} / \mathrm{h}$ ) to those rel eased at the same ti me in the screen for ebay ( $62 \mathrm{~m} / \mathrm{h}$ ) at Furni sh Canal i ndi cated that fi sh movenent was del ayed near the screens. Sl ower travel through screen forebays is al so suggested by data collected at other study si tes. Medi an travel speed of sumer steel head, spring chi nook, and subyearling fal I chi nook sal mon through the screen for ebays at West Extensi on, Westl and, and Feed canal s was rel ati vel y sl ow (5$65 \mathrm{~m} / \mathrm{h}$ ). Medi an travel speed of fal l chi nook sal mon was consi derabl y faster through the I ong headuorks canal at Mexwel I Canal ( $831 \mathrm{~m} / \mathrm{h}$ ). Travel speed is even faster in the river. Based on peak passage ti mes, subyearling chi nook and yearling chi nook sal non rel eased in the upper Unatilla Ri ver ( $\mathbf{r k m} 136$ or 148) travel ed to the I ouer ri ver $(r \mathrm{~km} \mathrm{5.6)}$ at speeds of I, 000 3, $000 \mathrm{~m} / \mathrm{h}$ (Knapp et al. 1996). Peak passage ti me is a cl ose approxi mation for nedi an travel tine. Del ay near screening facilities should be brief because of the short travel di stance through screen forebays. It is unknown whether even a bri ef del ay will affect migration success of $j$ uveni l e sal noni ds because cumil at i ve 
effects of del ays at mul ti ple dans and energetic costs associ ated with the del ays are unknown.

Si mul taneous rel eases of test $\mathrm{fi}$ sh indi cated the headgates at West Extensi on Canal del ayed passage of sumer steel head and subyearling fall chi nook sal non by about 20 hours and prevented sone fish from entering the canal. Headgates that deter fi sh from entering a canal are preferable at si tes where $\mathrm{j}$ uveni l e sal moni ds can pass safel $y$ and qui ckl y over the dam crest or spi II way, or through a fish I adder. However, the fi sh bypass at West Extensi on Canal is the preferred passage route past Three MI e Fal Is Dam The three headgates at West Extensi on Canal open from the bottom and are usual I y set to i denti cal hei ghts $(15 \mathrm{~cm}$ to $1.2 \mathrm{~m})$. Fi sh attracti on to smal I headgate openi ngs is probabl y mi nal, particul arl y when river el evation is hi gh and canal fl ow rel ati vel y l ow Opening the fewest number of headgates when canal withdrawal s are I ow may enhance fi sh passage at West Extensi on Canal.

General patterns of $\mathbf{f}$ ish novenent were si $\mathrm{m} I$ ar $i \mathrm{n}$ the upper portions of bypass faciliti es on the Unatilla and Yaki ma rivers. Data collected at al I study si tes on the Unatilla Ri ver suggest there uas no rel ationshi $p$ bet ueen travel ti me and canal fl ow Fast and sl ow travel ti mes were recorded at both hi gh and I ow canal fl ows. However, there was a tendency for fi sh rel eased on earlier dates to travel sl ower than fish rel eased on I ater dates. We concur with Neitzel et al. (1986, 1988) and Hosey and Associ ates (1990) that these patterns of $f i s h$ movement are attributable to varying degrees of snol ting and migrat ory behavi or exhibited by test fish. Large numbers of fish may hold upstream of the drum screens pri or to thei $r$ devel opment of migrat ory behavi or. Therefore, observati ons of $f i$ sh hol ding i $n$ bypass facil i ti es do not necessarily i mply fi sh are being del ayed. We have observed I arge numbers of yearling sal moni ds hol di ng in the wi de, sl ow vel ocity sections of canal s upstream of the screens at Westl and and Furni sh canal s. Facility desi gners shoul d stri ve to mai ntai $n$ a uniform canal profile upstream of the screens to reduce potential fish hol ding.

Facility operators need to be aware that I arge numbers of fish may be present in the screen forebay when canal s are dewatered. Tens of thousands of fi sh have been present in the screen forebay when Uestl and and Feed canal s were dewatered ( $\mathbf{Z}$ merman et al . 1991, 1992). The forebay drai $\mathbf{n}$ pi pe provi des a neans of ret urning fish to the river if it is unscreened, at I east $100 \mathrm{~mm}$ in di ameter, free of debris and sharp turns, and I ocated at the I ow end of the screen for ebay. Wter l eakage through the headgates typi cally provi des several days of fl ow through the drain pi pe. If the-drai $n$ pi pe is not sited at the I ow end of the screen for ebay, manual removal of $f i$ sh my be requi red.

Diel patterns of fish novenent at bypass facilities nay vary anong river systens and fish stocks. For example, nost species of hatchery fi sh noved wi thi $n$ a few hours of dawn and dusk and i $n$ the midday at $f i$ sh bypasses on the Unati I l a Ri ver (Knapp et al. 1996). I n contrast, peak fi sh novenent can be at ni ght at bypass facilities in river systens with substantial numbers of nat ural Iy produced sal moni ds, parti cul arly age 0 fi sh ( Neitzel et al. 1985; Hosey and Associ ates 1990; Craner et al. 1992). Facility operators should be provi ded i nf or mati on on I ocal patterns of $f i s h$ novenent to prevent conduct of potential Iy harnf ul operations during periods of peak fish novenent (e.g. sl ui ci ng pumpback bays, drai ni ng forebays, al gaci de appl i cati ons). 
The basic I ower bypass design consisting of a downwell, bypass pi pe, and out l et passed subyearling fall chi nook sal mon wi thout del ay. Fi sh were del ayed in the nore compl ex I ower bypass system at Westl and Canal. In our tests, recapt ure of spring chi nook sal mon rel eased i $n$ the I ower bypass was I ow and protracted. Tying the drai $n$ pi pe for the fi sh trap and pumpback bay i nto the bypass pi pe provi des cal $m$ areas for fi sh to hol d. J uvenil $e$ and adul $t$ sal moni ds have suum up the drai $n$ pi pe and entered the fl apgate box and pumpback bay (Zi mernan et al. 1993). The probl em of fi sh accessi ng the drai $n$ pi pe is probabl y exacerbated by the I ow head di fferenti al bet ueen pi pe i ntakes and out l et, whi ch al I ous the I ower bypass system to back up at moderate to hi gh river fl ous. A screen was i nstal led over the drai $n$ pi pe at the flapgate box in 1994 to prevent further movenent of $\mathrm{fi}$ sh into the pond and pumpback bay drai $n$ system Bl ockage of the pond drai $n$ system by debri s accumul ati on on the screen is an operational concern. Design of $f$ ut ure faci lities should consiider 1) addi ng a checkval ve to the drai $n$ pi pe at its $j$ unction with the bypass pipe or 2) separating the bypass and drai $n$ pi pes.

Reduced water vel ocity in the outfal I structure at West Extensi on Canal al so provi des a temporary hol di ng area for juvenile sal noni ds. Onl y subyearling fal l chi nogk sal mon noved qui ckl y through the l ower bypass when bypass fl ow uas $0.71 \mathrm{~m} / \mathrm{s}$. The sl opi ng channel fl oor in the qutfall structure was desi gned to dissjpate water vel ocity at the hi gher $0.71-\mathrm{m}^{3} / \mathrm{s}^{-}$bypass fl ow At the sl ower 0.14- $\mathrm{m}^{3} / \mathrm{s}$ bypass fl ow a cal $\mathrm{m}$ pool is created that provi des an uni ntended sanctuary for fi sh. We have observed yearli ng st eel head and chi nook sal mon preying on subyearling fi sh in the outfal l pool; extent of predati on uas unknown. Outfal I struct ures i ncorporating desi gns for energy di ssi pati on at hi gher fl ous shoul d be desi gned to qui ckl y pass $f$ i sh at I ower fl ous.

The new desi gn of a I arge di aneter pi pe with snooth joi nts and gradual bends has al levi ated nost probl ens with debri s occl usi ons. Debri s accumul at $i$ on at the bypass wei $r$ or pi pe entrance can potential ly del ay fish passage and cause inj ury. Canal trashracks i ntercept nost I arge debris, but j ans i nsi de the pi pe do occasi onal l y occur when debris enters the screeni ng facil ity ( Neitzel et al. 1989b; Knapp and Wtrd 1990). Bypass pi pes shoul d be thor oughl y checked for bl ockage before water up, and af ter temporary shutdowns and fl ood events. Canera systens are avai l able that si mpl ify the i nspecti on process. A regul ar mai nt enance program that i ncl udes i nspecti on and renoval of debris in the bypass system is essential.

Occl usi on of the submerged bypass outl et by bedl oad novement duri ng fl oods can be a chroni c problem that compl etel y precl udes bypass fl ow and fi sh passage, and causes fi sh i nj ury. Thi s has been an ongoi ng probl em at Westl and Canal and si tes on the Yaki ma Ri ver ( Nei tzel et al. 1990a). In addi ti on, erosi on of the shorel i ne by flooding caused the bypass pi pe out l et at hest I and Canal to termi nate i n mi dchannel ( Zi merman and Duke 1993, 1995). Rel ocati on of the out let nearer to shore was necessary to permit gravel removal by heavy equi pment at hi gher river flows. Operating the bypass at maxi mum flow (0.74 $\mathrm{m} / \mathrm{s}$ ) during hi gh river fl ow was at tempted, but not successful in preventing gravel occl usi on. Submerged out l et si ti ng requi res car ef ul eval uati on of ri ver hydraul ics, bank stabi I ity, and potenti al bedl oad novenent duri ng the pre-desi gn stage to prevent or mi mize problens with outl et bl ockage. 
Mai nt ai ni ng proper bypass fl ow is al so i mportant for safe and qui ck fi sh passage through the l ower bypass. This can onl y be achi eved if facility operating criteria is avai lable and adhered to by operators. Stable headworks water el evati on and proper bypass wei $r$ setti ngs are cruci al to mai nt ai ni ng constant spill I evel s over the bypass uei $r$. Aut onated headgates at Furni sh Canal have been very effective for these purposes. However, there is about a hal f-hour ti ne I ag bet ween checkgate adj ust ment and stabilizati on of the headuorks el evati on due to the I ong di stance bet ween headgates and checkgates. Fl uct uati on in bypass fl ow during this I ag peri od is not a maj or concern. However, fish spilling into the overfl ow wasteway at Furni sh Canal during the ri ses in water el evation will probably be i nj ured or stranded. Increasing the hei ght of the wast eway si I l could al l evi ate potenti al fi sh spi I l age.

Aut onat ed checkgates at West I and Canal are l ocated cl oser to the bypass faci I ity and have recent I y been performing wel I. I ni ti al I y, consi derable ef f ort was requi red to debug errors in the instrumentation and operation. Manual headgate adj ust nents are l east ef fecti ve i $n$ mi nt ai ni ng constant headworks el evation and bypass fl ow Fl uctuations in canal el evation are nost di ffi cult to control at the I owernost dam (West Extensi on Canal) due to f requent changes in uater di versi on rates upri ver. Dai l y adj ust ments by operat ors in the morning and eveni ng are adequate when ri ver fl ow is fail $r$ stable, but nore frequent adj ust ments are requi red when ri ver fl ow changes rapi dll y.

Ladder

J uveni I e sal moni ds passed qui ckl y through unobstructed segments of fi sh I adders, but were del ayed in segments of I adders with midchannel diff users. Recapt ure was l owest for test fi sh (spring chi nook and fal I chi nook sal non) rel eased upstream of Diffuser 1 in the passage secti on of the fi sh I adder at Three MIe Fal Is Dam Recapt ure was internedi ate for test fish rel eased in the auxi I i ary water systens of $f$ i sh I adders at Three MIe Fal Is and West I and dans. Del ay of $\mathbf{j}$ uveni l e sal moni ds i $n$ these auxi I $\mathrm{i}$ ary water systens shoul $d$ not be a passage problem because nost fi sh are expected to be gui ded away from the auxiliary water intake by the I ouver-like design of the trashracks. Del ay of j uveni I e sal moni ds is a passage concern at Diffuser 1 . Fish exit gates should be operated full open, vel oci ty measurements retaken, and $f i$ sh behavi or noni tored wi th under water vi deo to assess whether al tered fl ow patterns i $n$ front of Diffuser 1 i mproves $f i$ sh passage. Means of gui ding $f i$ sh around or through the fi sh I adder should al so be consi dered.

Screen Effici ency and I mpi ngement

Drum Screens

Our tests i ndi cated the rotary drum screens were greater than $99 \%$ ef $\mathrm{ficient}$ at excl udi ng chi nook sal mon (>50 m) from the canal s. The hi gh screeni ng ef $\mathrm{f} i \mathrm{ci}$ enci es are I argel y the resul $t$ of i mprovenents in screen technol ogy devel oped through operati onal experi ences in the Yaki na Ri ver and a thorough screen i nspecti on and mai nt enance program

Several i mprovements i n screen technol ogy were i ncorporat ed i $\mathbf{n}$ the design of bypass facilities on the Unatilla River. Sol id-bul b seal s were nore 
effective for sealing the si des of the I arger di aneter screens at West Extensi on Canal. Stai $\mathrm{nl}$ ess steel bands or epoxy was $\mathrm{pl}$ aced over areas of the screen that contact the si de seal to reduce seal wear. Pl astic medges in the frame gui de shift the frame forward to cl ose the gap bet ween the screen frame and guide. Wedges were instal led at Furni sh Canal during constructi on but retrof $i$ tted at other canal sites after we conducted screen effici ency tests. Screen efficiency was highest for the nost recently constructed bypass facility at Furni sh Canal where all new technol ogi es uere used and seal s had the l east wear.

Closing gaps at the bottom of the screens has been nore challenging. Under water vi deo and di ver observati ons suggest many of the $j$ uveni l e sal moni d fry that travel past screens move al ong the canal bottom (Mock and Stei tz 1985; Muel l er et al. 1995) Annual i nspecti on and repl acenent of worn bott om seal s is essential for mai ntai ni ng hi gh screening efficiency. Mai nt enance personnel must be able to recogni ze when seal repl acenent is requi red and be trai ned in seal adj ustment. Adj usting the amount of pressure the seal exerts on the screen is critical. Excessi ve pressure causes rapid seal wear. Not enough pressure all ous gaps to form if the screen is not perfectly round and debri s is nore I i kel y to get caught bet ween the seal and screen. A new desi gn for the bottom seal nount has made fi ne adj ust ments easi er. Proper bott om seal thi ckness and width are al so i mportant to maintai ning a tight fitting seal. Thi cker bott om seal s were retrof itted to the drum screens at West Extensi on Canal after yearling sal mon (>100 m) passed through the screens (Knapp and Ward 1990). Gaps will form at the overlap of the bottom and si de seal $s$ if they are not properly joi ned. Debris uedged bet ween the screen frane and canal bottom al so creates gaps. A hol I ow bul b seal has been added to the bott om of the screen frame to seal this gap.

Even though the rotary drum screens were nore than $99 \%$ effici ent for preventing fi ngerling-si zed chi nook sal mon (57-67 mm mean fork length) from entering the canal, leakage of sal mon fry through the screens is still a concern. Sal mon fry as smal l as $30 \mathrm{~mm}$ have been capt ured at the bypass facilities in March, April, and Myy (Knapp et al. 1996). Our test results may have overesti mated screeni ng effici ency for sal mon fry. At bypass facilities on the Yaki ma Ri ver, screening effici enci es of 75-91\% were docunented for wi Id chi nook sal mon fry $(32-40 \mathrm{~mm})$ when tests wi th larger-si zed rai nbow trout (49$55 \mathrm{~mm}$ mean fork length) i ndi cated screeni ng ef $\mathrm{i}$ ci ency was $96-100 \%$ ( Nei tzel et al . 1990a, 1990b). Peri odi c moni toring for fry l eakage from March through May i s advi sabl e when popul ati ons of wi I d fal I chi nook and coho sal mon becone est abl i shed in the I ower ri ver.

I mpi ngement and rol I-over on rotary drum screens is an i nf requent occurrence during normal canal operations. However, i mpi ngenent and roll-over can resul $t$ in substantial fish losses if canal el evation or fl ow is excessi ve or fish are in a weakened condition. Bypass facilities are operated at a water el evati on of $80 \%$ screen subnergence to bal ance the need to have debris, but not fish, roll over the screens. Fish losses due to roll-over are probabl e if $\mathrm{fl}$ ash fl oods cause headuork el evati ons to approach or exceed $100 \%$ screen subnergence. On one occasi on in 1996, we observed the drum screens at West Ext ensi on Canal cl ose to $\mathbf{1 0 0 \%}$ submerged when ri ver fl ow i ncreased rapi dl y overnight and the headqates were not manual ly adj usted until norning. Uni dentif ied fi sh (appro i matel y 100-300 m) were observed rolling over the screens. I mpi ngement and roll-over caused by excessi ve canal flow can be a 
probl em duri ng trappi ng operati ons at Westl and Canal. Trappi ng operati ons requi re the enti re ri ver to be di verted i nto the canal to prevent strandi ng fish bel ow the damin I ow fl ow Fish entering the canal are restricted to the screen forebay by a screen in the bypass channel to prevent overcrouding in the trap. If river fl ow exceeds design capacity of the canal when trapping operati ons are i nitiated, fi sh restricted to the screen forebay my weaken in swift currents (about 0.6-1.0 mis) and becone i mpi nged on and rol I over the screens (Zi merman and Duke 1993, 1994; Caner on et al. 1994). Duri ng normal canal operations, we have observed onl y mori bund or stressed fi sh i mpi nged on or rolling over drum screens. Subyearling fall chi nook sal mon are particularly susceptible to roll-over because of thei $r$ neak swi ming abilities and stress i nduced by warm uater temperat ures during thei $r$ out $m$ grati on in May, J une, and July. In 1995 and 1996, many of the fal I chi nook sal non col I ected at West Extensi on and Westl and canal s during the I at er porti on of the out migration appeared weak or di seased (Knapp et al. 1996).

\section{Bel t Screens}

Our tests i ndi cat ed I eakage, i mpi ngenent, and rol I-over of chi nook sal mon (> $50 \mathrm{~mm}$ ) associ ated with bel $t$ screens at West Extensi on and Westl and canal s is negl i gi ble $(<1 \%$ when canal s are operated wi thi $n$ criteri a. However, test fish had l ess opportunity to encounter the bel $t$ screens at Westl and Canal than they normal I y woul d because fl ow past the screens was consi derabl y hi gher during si mu atęd trappi ng operati ons $(0.57 \mathrm{~m} / \mathrm{s})$ than normal trapping operati ons $(0.14 \mathrm{~m} / \mathrm{s})$. Leakage and i mpi ngenent rates for fry nay be hi gher at both si tes than our tests i ndi cated because the snal I er si ze of fry (30-40 m) compared to our test fi sh al l ous fry to slip through smal er gaps ( Fi sher 1978; Bel I 1986) and thei $r$ weaker swi mi ng abi I i ty makes them more vul nerable to i mpi ngenent (Easterbrooks 1984). At West Extensi on Canal, sl ui cing si It fromthe pumpback bay with a wi de open drai $n$ pi pe has the greatest potential to i mpinge fish on the bel t screen. I $n$ 1990, subyearling fal I chi nook sal non (approxi matel y $75 \mathrm{~mm}$ mean fork I ength) uere i mpi nged and rolled over the belt screen when facility operators sl uiced silt from the pumpback bay fol lowing a fl ood in My (Hayes et al. 1992). Fi sh have al so been i mpi nged on the bel $t$ screen when the pumpback bay was operat ed with a ful I y open drai $n$ pi pe duri ng fi sh trappi ng operations. In 1991, 107 subyearling fall chi nook sal non (61 mm nean fork length) rel eased in drum screen efficiency tests were $i$ mpinged on the bel $t$ screen when the drai $n$ pi pe was fully open (Hayes et al. 1992). H gh fl ow (>0.85 $\mathrm{m}^{3} / \mathrm{s}$ ) through the pi pe created excessi ve approach vel ocities and turbul ence in front of the bel $t$ screen. Mbst $\mathrm{fish}$ were $\mathrm{i}$ mi nged on the downstream porti on of the bel $t$ screen where turbulence is produced by backfl ow from the orifice plate. Sone of the i mpi nged chi nook sal mon had squeezed bet ween the seal and screen and were crushed by the novenent of the screen. Sl ui cing operations should be avoi ded during the $\mathbf{j}$ uveni I e sal moni d out mi grati on season (March through J une). In addition, high debris loads appear to increase the probability of fish i mpi ngement and roll-over on screens ( Nei tzel 1988; Hayes et al. 1992). Thi s may be the resul $t$ of one or nore fact ors i ncl udi ng i ncreased approach vel oci ty in front of partially cl ogged screens, weakened condi $t i$ on of $f i$ sh during fl oods, and ent angl enent of fi sh i $n$ debris trapped on the screen. At West Extensi on Canal, debris regul arly accumul ates in front of the orifice plate i medi atel y downstream of the bel $t$ screen. Dai l y mai nt enance shoul $d$ i ncl ude renoving debris from this area. 
Bypass

Whter Vel ocity

Whter vel ocity in front of drum screens is expected to exceed approach vel ocity criteria for fry protection ( $\leq 0.12 \mathrm{~m} / \mathrm{s})$ during periods of peak water di versi on i $\mathrm{n}$ Mrch, April, and Myy. Drum screens were not able to meet the current $\leq 0.12 \mathrm{~m} / \mathrm{s}$ criteria because the facilities were desi gned to neet an ol der approach vel ocity criteria of $0.15 \mathrm{~m} / \mathrm{s}$. Mbst canal s operate at peak uater di versi on about one-thi rd of the ti me when sal non fry are nost I i kel y to be present (March, Apri I, and My). I mpi ngenent of sal mon fry on drum screens by hi gh approach vel ociti es is a concern. However, hi gh sweep vel ocity should reduce the potenti al for i mpi ngenent at l ocations where approach vel ocity criteria uas exceeded. We have not observed sal non fry i mpinged on drum screens thus far during normal facility operations, but producti on of fry in the I ower river is currently I ow Approach vel ocity was usual ly hi ghest at the screen cl osest to the bypass channel entrance, particul arly at Feed Canal. Screens cl osest to the bypass channel are where fi sh i mpi ngenent and rol I-over i s nost commonl y observed ( Nei tzel et al. 1988; Cameron et al . 1994). Baffl ing could be i ncreased behi nd Screens 10 at Feed Canal to reduce excessi ve approach vel ocity and potenti al fi sh i mpi ngenent, si milar to changes made at bypasses i n the Yaki ma Ri ver ( Neitzel et al. 1988).

Approach vel ocity anong screens, depths, and transects was not uni form at most sites. This variability was within ranges occurring at $\mathrm{fish}$ bypass faci Iiti es on the Yaki ma Ri ver (Abernethy et al. 1989). An overal I pattern of hi gh approach vel ocity at the end and middl e screens was consi stentl y measured at bypass facilities in the Unatilla Ri ver with I ong and shall ow screen forebays ( Westl and, Feed, Furni sh canal s). The absence of thi s pattern at West Extensi on and Mexuel I canal s suggests fl ow patterns i $n$ front of the screens were affected by forebay l ength. For ebay depth, and fl ow cont rol fI umes upstream of the screens may have been addi ti onal factors i nf I uenci ng fl ow patterns i $n$ front of screens at West Extensi on Canal. High approach vel ocities near the surface of middle screens at West Extensi on Canal nay al so be affected by the si dewal I geonetry of the forebay. Observation of surface water currents suggests that fl ow heading toward the bypass channel bottl enecks near the middle screens and i ncreases fl ow (approach vel ocity) through the screens in this area. Bottl enecking fl ow in the for ebay was probabl y unavoi dable because I imited space at this si te precl uded a bypass desi gn wi th nore screens and a I onger forebay.

Sweep to approach vel ocity criteria was met at al most al I l ocations sampl ed. However, I ow sweep vel ocity at the screen furthest from the bypass channel at Maxuel I Canal (Screen 3) and Feed Canal (Screen 1) i ncreases the potent $i$ al for fi sh hol di ng and i mpi ngement. At Feed Canal, I ow sueep vel oci ti es at Screen 1 were measured al ong the upstream porti on and bott om of the screen. The baffle board behi nd Screen 1 should be enl arged to i ncrease sueep vel ocity in these l ocations. Low sweep vel ocity was measured in al I sampling I ocati ons in front of Screen 3 at Mexuel I Canal, but particul arly al ong the upstream transect. A nore appropri ate method for i ncreasi ng sweep vel ocity i $\mathbf{n}$ front of Screen 3 at Maxuel i Canal might be to add fill to the canal wal I opposite of Screen $3 \mathrm{for}$ a di stance of perhaps $1.2 \mathrm{~m}$ upstream of the screens (personal communi cati on 24 February 97, Steve Rai ney, Nati onal Mari ne Fi sheri es Servi ce, Portl and, Oregon). 
M ni mum water vel oci ty at the bypass channel entrance must equal or exceed the maxi mum uater vel ocity in front of the screens to neet NMS criteria (NMFS 1989). Wter vel ocity at the bypass channel entrances met criteria at al sites. The intent of the criteria is to ensure fish recognize and use the bypass channel as an exit route. Avoi dance behavi or of $\mathrm{fish}$ to excessi ve changes in vel ocity (faster or sl ower) at the bypass channel entrance is a concern (Rai ney 1985). Our travel ti me tests documented a short del ay in fi sh novement in the vicinity of the drumscreens and ue have occasi onal I y observed fi sh pausing at bypass channel entrances (Caneron et al. 1994). However, fi sh readi I y moved through the bypass channel entrance duri ng hours of peak movenent and di $d$ not show si gns of $f$ at $i$ gue when trapped and handl ed ( I ethargy or sensi ti vity to anestheti c).

Del ay of fish associ ated with I ow uater vel ocity at the bypass channel entrance is al so a concern when bypasses are operated i $n$ a I ow fl ow mode. We were not able to col lect vel ocity neasurements when Maxwel I, Feed, and Furni sh canal s operated in I ow bypass fl ow nodes. Feed and Furni sh canal s rarel y operate at I ow bypass fl ow because thei $r$ upri ver I ocati on provi des suffi ci ent ri ver fl ow for canal and bypass needs. However, I ow bypass fl ow operati ons are comon at Maxuel I Canal in I ate spring. Poor fish attraction to the bypass channel during I ow fl ow operations will compound fish passage concerns associ at ed with I ow sueep vel ocity in front of the screens. Therefore, the bypass at Maxuel I Canal shoul d be operated i $\mathbf{n}$ normal bypass fl ow mode ( 0.25 $\mathrm{m}^{3} / \mathrm{s}^{\prime}$ as much as possi bl e.

A I si x pumpback operati ons tested at West Extensi on Canal resul ted i n non- uni form approach vel ocity in front of the bel $t$ screen and varyi ng anounts of turbul ence near the orifice plate. Non- uniform or turbul ent fl ow can be caused by insufficient pool vol une in front of the screen, hydraul ics associ ated with the orifice plate, si de vall geonetry, or pump placenent (Rai ney 1985). At West Extensi on Canal, $t$ urbul ent and non- uni f orm f I ow was pri maril y caused by the orifi ce pl ate bei ng l ocated i medi at el y downst ream of the bel $t$ screen. Li mited construction space necessitated placement of the orifice plate closer to the belt screen than desired. Normally, orifice pl ates are pl aced further away from the screen because turbul ent $f($ ow near the pl ate is expected. Turbul ent-fl ow near the bel $t$ screen is undesi rable because fi sh may attempt to hol d in the back-eddies, weaken, then becone i mpi nged on the screen. In additi on, back fl ow from the orifice pl ate appears to i ncrease fl ow through the upstream porti on of the screen which resul ts in higher approach vel ocities in this agrea. Turbulence caused by the orifice pl ate was $\mathrm{m} \mathrm{ni}$ mal when onl $\mathbf{y}$ one $0.28-\mathrm{m}^{2} / \mathrm{s}$ pump was on and greatest when the drai $\mathbf{n}$ pi pe was $40 \%$ open. A one-pump operation is withi $n$ criteria, but should be avoi ded because fish attracti on to the bypass channel will be compromised by I ow water vel ocity $(<0.4 \mathrm{mis})$. A $40 \%$ open drai $\mathrm{n}$ pi pe produced excessi ve turbul ence and hot spots on the bel $t$ screen.

Pumpack operations with both $0.28-\mathrm{m}^{3} / \mathrm{s}$ pumps on or the drai n pi pe $20 \%$ open produced the best conbi nati on of uater vel ocity at the bel $t$ screen and bypass channel entrance. During these operations, water vel ocity in front of the bel $t$ screen was fai rly uniform met NMS criteria for fry protection in most I ocations, and produced adequate sueep vel ocity. Vter vel ociti es at the bypass channel entrance produced by these operati ons were nearly equal to desi gn vel ocity at a $0.71-\mathrm{m} / \mathrm{s}$ bypass $\mathrm{fl}$ ow Drai $\mathrm{n}$ pi pe operati on has two advantages over pump operations. Openi ng the drai $n$ pi pe does not requi re the 
expense of power for operati on and it provi des addi ti onal fish attraction fl ow through the headgates when canal fl ow i s I ow (Knapp et al. 1996). Hbwever, these advantages must be bal anced with the problem of fal se attraction of adul $t$ fish to the drai $n$ pi pe outl et (Knapp et al. 1996).

Ladder

Design and operation of the $\mathbf{f i s h}$ I adder at Three MIe Fal Is Dam appeared to have a significant inf I uence on fl ow patterns in front of Diffuser 1 . I nf I ow is turned $45^{\circ}$ shortly after entering the passage secti on of the I adder whi ch causes it to approach the diffuser at an acute angle with moderate t urbul ence. Underwater vi deo observati ons in 1996 suggest j uveni l e sal noni ds foll ow currents that gui de thei $r$ movenents parallel to the diffuser until they encounter swifter currents di rected perpendi cul ar to the diffuser near Transect 1. At Transect 1, fi sh tended to swi $m$ upstream away from the diffuser and repeat the swi ming I oop agai $n$. Fi sh were occasi onal ly observed passing through the diffuser near Transect 1 or i mpacting it when surging or turbul ence occurred (Knapp et al. 1997). Fi sh passage through the diffuser appears to be inhibited by turbul ence and fl ow sweeping across the face of the diffuser. Changing the fish exit gate operation from a partial to ful I openi ng may decrease i nfl ow vel ocity and reduce sweep vel ocity and turbul ence at Diffuser 1.

Fl ow from the passage secti on of the I adder sueeping across the backsi de of Diffuser 2 appears to influence the pattern of auxiliary uater fl ow passing through the front si de of the diffuser. Auxiliary water filow was di rected parallel to the diffuser at several l ocations on the east diffuser panel where the i nf I uence of passage fl ow was strongest. Fl ow noving paral I el to the di ff user created a turbul ent back eddy upstream of the east panel when it encountered the wall di vi di ng the east and west panel s. Fl ow patterns in front of the east panel of Diffuser 2 are not conduci ve to juveni I e fi sh passage based on vi deo observations and water vel ocity neasurenents at Diffuser 1 . Juvenile sal noni ds should pass through the west panel easi er than the east panel because there is less of a sweeping component to the fl ow approaching the uest panel. The I ong length of Diffuser 2 is probably key for provi ding some passage areas for juvenile sal nonids while ensuring auxiliary water fl ow is diffused enough to prevent fal se attraction of adul $t$ fish. 


\section{RECOMMENDATI ONS}

\section{Facility Mdi fi cations}

1. Test operate the fish exit gates full open at the Three MIe Fal Is Dam ( east-bank) fi sh I adder to i mprove hydraul i c and fi sh passage condi ti ons at Diffuser 1 . Document changes in fl ow patterns with vel oci ty measurenents and changes in fi sh behavi or wi th underuater vi deo.

2. Met hods f or gui di ng $\mathbf{j}$ uveni l e $\mathbf{f} \mathrm{i}$ sh past or through the east-bank $\mathbf{f} \mathrm{i}$ sh I adder at Three MI e Fal Is Dam shoul d be consi dered to $\mathrm{mi} \mathrm{ni}$ ze fi sh i nj ury and del ay. Potenti al nodi fi cati ons i ncl ude a curtai $n$ or I ouver gui dance system coupl ed wi th an Obermyer wei $r$ on the east end of the dam or a l ouver gui dance system coupl ed with a bypass system in front of Diff user 1 .

3. Renove non-f uncti onal I-beam i $\mathrm{n}$ front of Di ff user $\mathbf{l}$ i $\mathrm{n}$ the east-bank fi sh I adder at Three MIe Fal Is Dam

4. Aut onated headgates are the most ef fecti ve means of mi nt ai ni ng proper headuorks el evation and bypass fl ow Where feasible, bypass facilities shoul d be designed or retrofitted with aut onated headgates.

5. I ncrease wal I hei ght of wast eway overf I ow at Furni sh Canal by addi ng a $102 \mathrm{mmsill}$ to prevent fish fromspilling into the wast eway when headworks el evati on temporari I y ri ses in response to headgate adj ust nents.

6. Baffle boards behi nd Screen 1 at Feed Canal shoul d be modi fi ed to decrease approach vel oci ty and i ncrease sweep vel oci ty in front of the screen. At Maxuel I Canal, adding fill to the canal wall across and upstream of Screen 3 shoul d be consi dered to i ncrease sweep vel oci ty i n front of Screen 3.

\section{Facil ity Operati ons}

1. Facility operating criteria must be available and adhered to by bypass operat ors and anended by National Mari ne Fi sheri es Servi ce when necessary.

2. Fi shery managers should regul arly provide facility operators with i nf or mati on on I ocal patterns of fi sh novenent to avoi d conduct of potent $i$ al I y harnf ul canal or bypass operations during peri ods of peak fi sh novenent ( pumpback bay sl ui ci ng, drai ni ng forebays, al gaci de appl i cati ons, etc. ).

3. Dai I y mai nt enance shoul d i ncl ude i nspecti on and removal of debri s at the canal trashracks and headgates, drum and bel t screens, orifice plate, bypass channel and wei $r$, downuel $I$, bypass pi pe, and outfall/outl et. Debri s renoval is parti cul arl y i mport ant duri ng fl oodi ng, uat er up, and when canal s are restarted after temporary shut downs. Checking bypass 
pi pes for debris bl ockage before water up and after flood events is critical.

4. Manual adj ust ment of the canal headworks el evati on is usual I y requi red on a twi ce-a-day basis to ensure proper bypass fl ow and headworks el evation. Mre frequent adj ust ment is requi red if ri ver el evati on is changi ng rapi dl y.

5. Mai nt ai $n$ screen submergence at $80 \%$ to reduce potent $i$ al rol I-over of snall-si zed fi sh, especi al ly weakened subyearling fall chi nook sal mon.

6. I nspecti on and mai ntenance of screen seal s should be conducted annual I y by know edgeabl e nai nt enance personnel.

7. Peri odi c noni tori ng for I eakage of sal mon fry through the drum screens at canal s on the I ower Unati I I a Ri ver is recomended bet ween March and May when natural popul ati ons of $f$ al I chi nook or coho sal non i ncrease i $n$ the fut ure. A si mpl e moni tori ng program mi ght i nvol ve overni ght depl oyment of a small, easily retri evabl e fyke net at the canal checkgates at l east one day a week.

8. When total headgate openi ngs are I ess than $1 \mathrm{~m}$ at West Extensi on Canal, open the fewest number of headgates as wi de as possi bl e to i mprove fi sh attraction and passage. Initial testing should begi $n$ with opening the West Headgate first fol I owed by the M ddl e and East headgat es.

9. Pref er red pumpback operati ons at West Extensi on Canal are t wo $0.28-\mathrm{m}^{3} / \mathrm{s}$ pumps on or the drai $\mathrm{n}$ pi pe $\mathbf{2 0 \%}$ open.

10. Operate Maxuel I Canal i n normal bypass fl ow node $\left(0.25 \mathrm{~m}^{3} / \mathrm{s}\right)$ as much as possible to hel $p$ maintai $n$ sweep vel ocities in front of the drum screens.

\section{Desi gn Consi derati ons}

1. Fut ure bypass facility desi gns should maintai $n$ a uniform canal and forebay profile to mi mize potenti al hol di ng areas for sal monids and predat ors.

2. Submerged outl et conf $i$ guration and si ting is critical during the facility desi gn phase to prevent or mi mize occl usi on probl ens resul ti ng from bedl oad movenent. Ri ver hydrauli cs and bank stability should be taken i nt o consi derati on.

3. Facility desi gns should avoid tying a secondary pi pe into the bypass pi pe to el i mate potenti al fi sh hol di ng areas and del ay.

4. Devel opment of out $f$ al I designs that do not rel $y$ on a pool for energy di ssi pati on shoul d be consi dered to $\mathrm{mini}$ me fi sh hol di ng areas and del ay i $n$ bypass outfalls.

5. Drum screen desi gns shoul d i ncl ude rubber seal s of proper wi dth and thi ckness that seal gaps al ong the si des and bottom of the screen, and 
bet ween the screen frame and canal bott om Wedges shoul d al so be installed in the rear of the frame guide sl ots to force the screen frame agai nst the gui de sl ots and cl ose gaps.

\section{ACKNOVZEDGMENTS}

We woul d I i ke to thank the numerous i ndi vi dual s from vari ous agenci es that assi sted in the pl anning and i mplenentation of thi s project and those that revi eued this report. We thank our former program and proj ect I eaders Ray Beamesderfer, Tony $\mathbf{N}$ gro, and Dave Uhrd, Research I mpl enent ati on Comm tt ee Chai $r$ Barry MtPherson, our seasonal staff Troy Baker, Becky Banghart, Steve Banghart, J i II Berry, Bi I I Bl ount, Ki rk Bradf ord, Tracey Bruce, Dotti e Chan, Gary Chri stopherson, Dave Guard, M ke Hayes, Todd HII son, Ti a J ensen, Chri s Kern, M ke Lambert, Robert Mrgan, Robert Muel l er, Doug Nei sz, Bri an Ri ggers, Boyd Schrank, Randy Stephens, Chri s Stevens, Kathy Terrel I, and Eri c Veach, and I ocal hi gh school students Ri kki Cul ley and Deni se Henderson. We thank Jack Hurst, Randy Winters, and staff of the Unatilla Hatchery and Ray HII, Whde Bergeson, and staff of I rrigon Hatchery for providing test fi sh. We thank Ti m Bai I ey, Bob Becker, Ki rk Bei ni ngen, Mary Buckman, Bi I I Duke, J an Ehnke, J on Gernond, Dave Harconbe, Whyne Kowal ka, Bryce Lundqui st, J i m Phel ps, Bruce Schmi dt, J oann Smith, Mari o Sol azzi, Enery Whgner, and Karl a Yeager of the Oregon Department Fi sh \& Vild ife for thei $r$ I ogi sti cal and technical assi st ance.

We appreci ated the advi ce and assi stance of Scott Abernethy, Bi II Lusty, and Duane Neitzel' of Battelle, Paci fi c Northuest Laboratori es; Gary James, Paul Ki ssner, K eth Kutchi ns, Gerry Rowan, J ed Vol kman, and Bri an Zi mmerman of the Conf ederated Tri bes of the Unati II a Indi an Reservati on; A Sol onsky of Hosey and Associ ates; Harry Senn of Fi sh Managenent Consul tants; Larry Basham of the Fi sh Passage Center; Steve Achord, Ed Meyer, and Steve Rai ney of the Nati onal Mari ne Fi sheri es Servi ce; Spencer Day, Larry Dei rdorf, J ohn Dyson, Tom G over, Gary Grey, Denni s Hudson, Ri ch Heyne, J i m J ohnson, Tom Leonard, Dave Payne, and Dal e VII cox of the U.S. Bur eau of Recl angti on; and Joel Hubbl e of the Yaki ma I ndi an Nation. We thank staff of the Hermiston, StanfieldWestl and, and West Extensi on i rrigati on di stricts, Oregon Whter Resources Department, U. S. Fi sh and VII dl i fe Servi ce, and U.S. Geol ogi cal Survey for thei $r$ efforts and assi stance.

We especi al I y thank Jerry Bauer and Jay Marcotte of the Bonnevi I l e Power Admi ni stration for thei $r$ assi stance with project coordi nation, oversight, and f undi ing. 


\section{REFERENCES}

Abernethy, S. C. D. A Nei tzel, and E. W Lusty. 1989a. Vel oci ty neasurenents at si $x$ fi sh screeni ng facilities in the Yaki ma Ri ver basi $n$, Whshi ngton. Bonnevi I l e Power Admi ni strati on, Report DOE/ BP- 1830- 4.

Abernethy, S. C., D. A Neitzel, and E. W Lusty. 1989b. Vel ocity measurenents at three fish screening facilities in the Yaki ma River basi $n$, Whshi ngt on. Bonnevi I l e Power Admi ni strati on, Report DOE/ BP- 1830- 10.

Basham L. R. MR. Del arm and S. W Pettit. 1982. Fi sh transportation oversi ght team annual report. FY 1981: Transport operati ons on the Snake and Col unbi a Ri vers. Nati onal Oceani $c$ and At nospheri c Admi ni stration, Nati onal Meri ne Fi sheri es Servi ce, Techni cal Menorandum NMS F/ MR-2, Portl and, Oregon.

Bates, D. W and R. Vi nsonhal er. 1957. Use of I ouvers for gui di ng fi sh. Transacti ons of the Aneri can Fi sheri es Soci ety 86: 38-57.

Bates, K 1988. Screen criteri a for j uveni l e sal mon. Whshi ngt on Depart ment of Fi sheri es, $\mathbf{d}$ ympi a, Whshi ngt on.

Bel I, M C. 1986. Fi sheri es handbook of engi neeri ng requi renents and bi ol ogi cal criteria, 2nd edition. U.S. Army Corps. of Engi neers, Portl and, Oregon.

Bouck, G. R. and S. D. Smith. 1979. Mrtal ity of experi mentally descal ed snol ts of coho sal mon (Oncorhyncus ki sutch) in fresh and sal t water. Transacti ons of the Ameri can Fi sheri es Soci ety 108: 67-69.

Boyce, R. R. 1986. A comprehensi ve pl an for rehabi l it ati on of anadronous fi sh stocks in the Unatilla River basin. Bonneville Power Administration, Report DOE/ BP- 18008- 1.

Cameron, WA and S. M Knapp. 1993. Pages I-48 in S. M Knapp, edi tor. Eval uation of $j$ uvenil $e$ fish bypass and adul $t$ fish passage facilities at water di versi ons in the Unatilla Ri ver. Bonneville Power

Admi ni strati on, Report DOE/ BP- 01385- 3.

Caneron, WA, S. M Knapp, and B. P. Schrank. 1994. Pages I-76 in S. M Knapp, edit or. Eval uati on of $\mathrm{j}$ uveni $\mathrm{l} e \mathrm{f} \mathrm{i}$ sh bypass and adul $t \mathrm{f} i \mathrm{sh}$ passage facilities at water di versi ons in the Unatilla Ri ver. Bonneville Power Admi ni strati on, Report DOE/ BP- 01385- 4.

Caneron, WA, S. M Knapp, and B. P. Schrank. 1995. Pages I-98 in S. M Knapp, editor. Eval uation of $j$ uveni $l e$ $f i$ sh bypass and adul $t$ fi sh passage facilities at water di versi ons on the Untilla Ri ver. Bonneville Power Admi ni strati on, Report DOE/ BP- 01385- 5.

Q ay, C. H 1961. Desi gn of fi shways and other fi sh faci lities. Canadian Department of Fi sheri es, Ot awa, Ontario.

d ay, C. H 1995. Desi gn of fi shupys and other fi sh facilities, 2nd edition. Lewi s Publ i shers, Ann Arbor, M chi gan. 
Craner, S. P. , D. Denco, C. Fl emi ng, T. Loera, and D. Neel ey. 1992. J uveni I e chi nook passage i nvesti gations at G enn-Col usa I rri gati on Di stri ct Di versi on. Report of S.P. Craner and Associ at es to G enn-Col usa I rrigati on Di stri ct, Vill ous, Cal i f orni a.

Easterbrooks, J.A 1984. Juveni l e fi sh screen desi gn criteri a: a revi ew of the objectives and sci entific data base. State of Whshi ngt on Department of Fi sheri es, Yaki na, Whshi ngt on.

Gunsol us, R. T. and G. J. Ei ther. 1970. Eval uati on of fi sh-passage faci I $i$ ti es at the North Fork Project on the Clackanas Ri ver in Oregon. Fi sh Commissi on of Oregon and Portl and General El ectri c, Portl and, Oregon.

Hanson, C. H and H W Li . 1983. Behavi oral response of j uveni l e chi nook sal mon, Oncorhyncus tshawytscha, to trash rack bar spacing. Cal if orni a Depart ment of Fi sh \& Gane 69(I): 18- 22.

Hart, P.J.B. and T. J. Pi tcher. 1969. Fi eld tri al s of fi sh marking usi ng a j et i nocul at or. J ournal of Fi sh Bi ol ogy 1: 383-385.

Hayes, MC. S. M Knapp, and A A N gro. 1992. Pages 53-103 in S. M Knapp, editor. Eval uati on of $j$ uvenile $f i s h$ bypass and adul $t$ f $i$ sh passage facilities at water di versi ons in the Unatilla Ri ver. Bonneville Power Admi ni st rati on, Report DOE/ BP- 01385- 2.

Hosey and Associ ates. 1988a. Eval uation of the effectiveness of $\mathrm{fish}$ protection facilities, Chandl er facility eval uation. Report of Hosey and Associ at es Engi neeri ng Company and Fi sh Managenent Consul tants to U. S. Bur eau of Recl anati on, Yaki na, Whshi ngt on.

Hosey and Associ ates. 1988b. Eval uati on of the effecti veness of $\mathrm{fish}$ protection facilities, Col unbi a facility eval uation. Report of Hosey and Associ ates Engi neering Company and Fi sh Management Consul tants to U. S. Bur eau of Recl amati on, Yaki ma, Whshi ngt on.

Hosey and Associ ates. 1989. Eval uation of the ef fecti veness of $\mathrm{f} i \mathrm{sh}$ protection facilities, Roza facility eval uation. Report of Hosey and Associ ates Engi neering Company and Fi sh Managenent Consul tants to U.S. Bur eau of Recl amati on, Yaki ma, Whishi ngt on.

Hosey and Associ ates. 1990. Eval uati on of ef fecti veness of Chandl er, Col umbi a, Roza and East on screeni ng faciliti es. Report of Hosey and Associ ates Engi neering Company and Fi sh Managenent Consul tants to U.S. Bur eau of Recl amati on, Yaki ma, Whshi ngt on.

Knapp, S. M and D. L. Utrd. 1990. Pages 1- 32 i n A. A N gro, edi tor. Eval uat $i$ on of $j$ uveni l e fish bypass and adul $t$ fi sh passage facil $i$ ti es at Three MIe Fal Is Dam Unati Il a Ri ver. Bonnevill e Power Admi ni stration, Report DOE/ BP- 01385-I .

Knapp, S. M 1992. Pages 1-52 i n S. M Knapp, edi tor. Eval uati on of j uveni I e fi sh bypass and adul $t$ fish passage facilities at water di versi ons in the Unati I l a Ri ver. Bonnevi I l e Power Admi ni stration, Report DOE/ BP- 01385- 2. 
Knapp, S. M, J.C. Kern, WA Caner on, S. L. Shapl ei gh, and R. W Carmi chael 1996. Eval uati on of $j$ uveni l e sal moni $d$ out migrat $i$ on and survi val i $n$-the I ower Unatilla Ri ver basi $n$. Report of Oregon Department Fi sh \& Vil dl ife to Bonnevi I l e Power Admi ni strati on, DOE/ BP 01385- 6.

Knapp, S. M, J.C. Kern, WA Cameron, S. M Snedaker, and R. W Carmichael 1997. Eval uat $i$ on of $\mathbf{j}$ uveni I e sal moni $\mathbf{d}$ out mi grati on and survi val i $\mathbf{n}$ the I ower Unatilla Ri ver basi $n$. Report of Oregon Departnent Fi sh \& Vil dl ife to Bonnevi I l e Power Admi ni strati on, DOE/ BP 01385- 8.

Mook, S. W and C. E. Stei tz. 1985. South Cow Creek fi sh I adder and screen eval uati on studi es. Paci fi c Gas and El ectri c Company, San Ranon, Cal i f orni a.

Muel I er, R. P., C. S. Abernethy, and D. A Nei tzel . 1995. A fi sheri es eval uati on of the Dryden fish screeni ng facility. Bonneville Power Admi ni strati on, Report DOE/ BP- 00029- 2.

Nei tzel, D. A, C. S. Abernethy, E. W Lusty, and L. A Prohamer. 1985. A $f i$ sheries eval uation of the Sunnysi de Canal $f i$ sh screening facility. Bonnevi I l e Power Admi ni strati on, Report DOE/ BP- 1830- 1.

Nei tzel , D. A, C. S. Abernet hy, and E. W Lusty. 1987. A fi sheri es eval uat i on of the Ri chl and and Toppeni sh/ Sat us Canal fi sh screeni ng faci li ti es. Bonnevi I l e Power Admi ni strati on, Report DOE/ BP- 1830- 2.

Nei tzel, D. A , C. S. Abernethy, E. W Lusty, and S.J. Wmpl er. 1988. A fi sheri es eval uati on of the Ri chl and and Whato Canal fi sh screeni ng faciliti es. Bonneville Power Administration, Report DOE/ BP- 1830- 3.

Nei tzel, D. A , C. S. Aber nethy, and E. W Lusty. 1990a. A fi sheri es eval uati on of the Whato, Sunnysi de, and Toppeni sh Creek Canal fi sh screening faciliti es. Bonnevil l e Power Admi ni strati on, Report DOE/ BP- 1830-6.

Nei tzel, D. A. C. S. Abernethy, and G A Martenson. 1990b. A fi sheri es eval uati on of the Westsi de Ditch and Town Canal fi sh screeni ng facilities. Bonneville Power Admi ni stration, Report DOE/ BP- 01830-9.

Nei tzel, D. A , C. S. Abernethy, and E. W Lusty. 1991. Eval uat i on of rot at i ng drum screen facilities in the Yaki ma Ri ver Basi $n$, south-central Whshi ngt on State. Aneri can Fi sheri es Soci ety Symposi um 10: 325- 334.

NMF ( Nati onal Mari ne Fi sheri es Servi ce). 1989. Fi sh screeni ng cri teria. Nati onal Mari ne Fi sheri es Servi ce, Portl and, Oregon.

NMFS ( Nati onal Mari ne Fi sheries Servi ce). 1990. Fi sh passage faci I iti es functi onal desi gn gui del i nes and suppl ement al cri teri a. Nati onal Mri ne Fi sheri es Servi ce, Portl and, Oregon.

NPPC ( Northwest Power PI anni ng Counci I). 1987. Col unbi a Ri ver basi $\mathbf{n}$ fi sh and wi I dl ife program (as anended). Northuest Power Pl anni ng Counci I, Portl and, Oregon. 
ODFW (Oregon Department of Fi sh and Vil dl i fe) and CTU R (Conf eder at ed Tri bes of the Unmti Ila Indi an Reservation). 1989. Col unbi a Basi n system pl anni ng, Unati I l a Subbasi $n$ PI an. Report of ODFW and CTU R to Northwest Power Pl anni ng Counci I, Portl and, Oregon.

ODFW ( Oregon Department of Fi sh and Vil dl i fe) and CTU R (Conf eder at ed Tri bes of the Unatilla Indi an Reservation). 1990. Unati I l a hatchery master pl an. Report of CDFW and CTU R to Northwest Power PI anni ng Council, Portl and, Oregon.

Orsborn, J.F. 1985. New concepts i n fi sh I adder desi gn. Bonnevi I l e Power Admi ni strati on' , Report DOE/ BP- 299.

Pearce, R. Q and R. T. Lee. 1991. Some desi gn consi derati on for approach vel ociti es at j uveni le sal noni d screeni ng facilities. Aneri can Fi sheri es Soci ety Symposi um 10: 237- 248.

Rai ney, WS. 1985. Consi derati ons in the desi gn of $\mathrm{j}$ uveni l e bypass systens. Symposi um on smal I hydropower and fi sheri es. May 1-3, 1985. Aur ora, Col orado. Li brary of Congress 85-72260, pp. 261-268.

Rai ney, WS. 1991. Recent adul t fi sh passage projects on tributari es of the Col unbi a Ri ver. $\quad$ Aneri can Fi sheri es Soci et y Symposi um 10: 278- 288.

Taf $t$, E. P. 1986. Assessment of dounst ream mi grant $\mathbf{f} i$ sh protect $i$ on technol ogi es for hydroel ectric appl i cati on. Report of Stone \& Webster Engi neering Corporation to El ectric Power Research Institute, Pal o A to, Cal i f or ni a.

Thedi nga, J.F. and S.' W J ohnson. 1995. Retenti on of j et-i nj ected marks on j uveni l e coho and sockeye sal non. Transacti ons of the American Fi sheri es Soci ety 124(5): 782- 785.

Zi merman, B. C. B. Duke, G. A J anes, and K V'tty. 1991. Trappi ng and transport of adul $t$ and $\mathbf{j}$ uveni I e sal mon i $n$ the I ower Unati l l a Ri ver i $n$ northeast ern Oregon, 1990-1991. Report of Conf ederated Tri bes of the Unmti I l a I ndi an Reservati on and Oregon Department Fi sh \& Vildl i fe to Bonnevi I l e Power Admi ni strati on, Portl and, Oregon.

Zi merman, B. C. , B. Duke, G A J anes, and K V'tty. 1992. Trappi ng and transport of adul $t$ and $j$ uveni $I$ e sal non i $n$ the $I$ over Unati I l a Ri ver i $n$ northeastern Oregon, 1991-1992. Report of Conf ederated Tribes of the Unati I I a I ndi an Reservati on and Oregon Department Fi sh $\&$ Vild i fe to Bonnevi I l e Power Admi ni strati on, Portl and, Oregon.

Zi mer man, B. C. and B. B. Duke. 1993. Unati Il a Ri ver basi n trap \& haul report. Bonneville Power Admi ni strati on, Report DOE/ BP- 98636- I.

Zi merman, B. C. and B. B. Duke. 1995. Unati II a Ri ver basi n trap \& haul report. Bonnevi Il e Power Admi ni strati on, Report DOE/ BP- 98636- 2. 